\title{
"Apa salahku?"
}

Interrogating social policy problem representations of domestic violence within Singapore's Malay/Muslim population

By

Nabilah Husna Binte Abdul Rahman

A thesis submitted to the Victoria University of Wellington in fulfilment of the requirements for the degree of Master of Arts in Social Policy

Victoria University of Wellington

2021 


\section{ABSTRACT}

What's the problem of domestic violence (DV) represented to be in Singapore's social policy? This thesis interrogates the social policy responses to DV by looking at its discursive effects on Singapore's Indigenous Malay/Muslim population. Undergirding the study is a theoretical understanding of structural intersectionality, which allows for a recognition of the unique identity of the Malay/Muslim population in Singapore. Such an approach contextualises Malay/Muslim women's experiences of DV against the backdrop of Singapore's colonial history and its current Anglo-Chinese political hegemony, which adopts a neoliberal, patriarchal and authoritarian form of governance.

Through qualitative interviews with seven professional advocates working in the social sector and public service, and in-depth analysis of policy documents and first-hand accounts, I examined the ways in which the problem of DV has been imagined and, thus, remedied. Using thematic analysis and taking some inspiration from Carol Bacchi's post-structuralist "What's the problem represented to be?" analytical tool, I identified the representations of DV that are found in the interviews and first-hand accounts by survivors and uncover the implicit problematisations within the discourses. These representations show that DV within the Malay/Muslim population is seen as experiences of patriarchal and religious authoritarianism, housing and income insecurity, inadequacies with informal strategies of resistance, and limitations of formal forms of resistance. Then, using the WPR mode of questioning more conventionally, I analysed policy documents and solutions, such as counselling, public education and criminal justice solutions, to reflect on the parameters and limits of how DV has been problematised and where policies fall short in addressing Malay/Muslim women's experiences according to discourse.

The study concludes that social policy solutions define DV within the Malay/Muslim population largely as cultural problems, divorced from the historical and structural context it operates within. Problem representations also mute the overarching ideological position of Singapore's governance. 
The findings urge advocates and policy-makers to commit to a structural intersectional framework that actively dismantles the neoliberal capitalist systems and patriarchal ideologies legitimised by the State, which underpin and intensify experiences of DV among Malay/Muslim women and other marginalised groups. 


\section{KIA ORA \& TERIMA KASIH}

\section{"Violence has its own whakapapa"." \\ Cavino, 2016}

This work would not have been possible without generations of Indigenous advocates on this whenua ${ }^{2}$ and my own tanah air $^{3}$, who worked through genealogical lines of grief in spite of-and because of-their trauma.

To Carol for your guidance, insights and validation. I lucked out with you as a supervisor!

Ad, for your support, your immense wisdom and sessions at the Kopitiam.

Rachel, for helping me untangle knots and teaching me how to "be a friend" to myself.

To my research participants, thank you for generously offering your great insights to this thesis. Your dedication to your work is inspiring and painfully necessary!

Terima kasih to my family and whānau4:

Johnny, for your politics, compassion, support, love and unwavering belief in my abilities.

Abah, for helping me see the importance of intergenerational healing and transformative justice. Love you.

Kak Pai, for teaching me the power and dynamics of resistance.

$\mathrm{Ha}$ and Abang, for all your daringness, strength and resilience, and for ending cycles.

And to Mama, for all the times that you said everything 40,000 words, decades of "research" and tens of thousands of "experts" could never begin to articulate. You lived so beautifully. Sayang Mama.

\footnotetext{
${ }^{1}$ Genealogy in the Māori language

${ }^{2}$ Land in Māori

${ }^{3}$ Land, soil or homeland in the Malay language

${ }^{4}$ Often translated as family in Māori, but also includes physical, emotional and spiritual dimensions and is based on whakapapa
} 


\section{CONTENTS}

Abstract i-ii

Acknowledgments iii

CHAPTER 1. A STATEMENT ON PROBLEMS 1

CHAPTER 2. THE SINGAPORE STORY

2.1. Singapore's Malays and Muslims

2.1.1. Race and Indigeneity

2.1.2. Religion 11

$\begin{array}{ll}2.1 .3 \text { Socioeconomic status } & 12\end{array}$

2.2. Patriarchy, authoritarianism and neoliberalism 13

CHAPTER 3. THEORETICAL FRAMEWORK \& LITERATURE REVIEW 19

3.1. Intersectionality 19

3.2. Representations of Muslim women's DV experiences 20

3.3. The ways to end DV 23

3.3.1. Legal protections and the criminal justice system 25

3.3.2. Religious leadership $\quad 27$

3.3.3. Cultural competence $\quad 29$

3.3.4. Public education 32

3.4. Analytical tool: Why study problematisations? 33

CHAPTER 4. METHODOLOGY 37

4.1. Selection of 'texts' 37

4.2. Sampling method \& interview format 39

4.3. A social constructivist approach $\quad 42$

4.4. Thematic analysis \& WPR 43

4.5. Researcher's positionality $\quad 44$

$\begin{array}{ll}4.6 \text { Research ethics } & 45\end{array}$

4.7. Limitations $\quad 46$

CHAPTER 5. WHAT'S THE PROBLEM? First-person accounts of DV and interviews with participants $\quad 47$

5.1. Patriarchal violence, religious authoritarianism and the State 47

5.2. Housing and income in a patriarchal and capitalist economy 52

5.3. Inadequacies with informal strategies of resistance 59

5.3.1. Personal strategies of resistance $\quad 59$

$\begin{array}{ll}\text { 5.3.1.1. Friends and family } & 61\end{array}$ 
5.3.2. Informal strategies of resistance

5.3.2.1. Asatizah and religious leadership

5.4. Limitations of formal strategies of resistance

5.4.1. Police, PPOs and criminal justice system

5.4.2. Social services

5.4.2.1. Shelters

5.4.2.2. Social service organisations

5.5. Conclusion

CHAPTER 6: WHAT'S THE PROBLEM REPRESENTED TO BE? Policy texts, State solutions and participants' problematisations

6.1. Family and individual counselling

6.2. Women's empowerment

6.3. Working with men who use DV

6.4. Public education and attitudinal change

"Raising awareness"

"Equipping bystanders"

6.5. Religious and cultural counter-education

6.6. Legal and criminal justice remedies

6.7. Conclusion

CHAPTER 7. CONCLUSION

Appendix 


\section{CHAPTER 1. A STATEMENT ON PROBLEMS}

Almost a decade ago, I sat in the living room of my family flat, handing my mother brochures for a campaign I was getting involved in. It was an anti-gender violence campaign and a glimpse into my new job at a feminist organisation. I was proud. Back then, the kaupapa ${ }^{5}$ of the work offered me a large lexicon to name problems I had been long ensnared in. I told my mother, "Mama, tengok (look), these are the workshops l've been helping to run. Nak ikut (Want to join in)?". She glanced at the brochure. Perhaps the word 'empowering individuals' was on the brochure, perhaps it was how I sold the message. Either way, her response was, "Kenapa? Apa salah ngan Mama? (Why? What's the problem with me?)".

I remember being struck by this, but its gravity did not hit me fully until much later. As I was knee-deep in this study, I also started counselling. There, I explored how despite greater knowledge and understanding, I still struggle envisioning alternative responses to my own experiences of oppression or violence. I still returned to the same formula: self-blame, guilt and a dose of shame. I had limited my imagination to rely on the same responses. As a result, everything else was out of reach, becoming a situation of 'you don't know what you don't know'. Then, my mother's reaction all those years ago made sense on a visceral level. The solution she was continually offered became the limits of how she could imagine the problem. If she was told she needed to be empowered to end domestic violence (DV), the problem was that she was too disempowered. The problem became her.

A recognition of the way social policy has this effect-of defining problemsundergirds this thesis. In conventional policy studies, policies are accepted as neutral, rational solutions to social problems that exist outside of the policy-making arena (Bacchi, 2012a). But one could argue that policies are, indeed, productive. Formal and informal policy texts (like laws and public campaigns) have power to influence and shape definitions, frameworks and representations of DV. How did the solution of empowerment above help my mother name the problem of DV? Where did it limit her?

${ }^{5}$ Principle or policy in Māori 
How does the parameter of DV policies become the parameter of DV as a problem itself? These questions became the guiding force of my study.

This thesis was written entirely in Aotearoa New Zealand, beginning just as the country went into lockdown from the COVID-19 health crisis. As I worked on it, COVID-19 was consistently revealing the major social, economic and political fault lines that ripple through all our societies, including back in my home country of Singapore. Back home, as people went into lockdown, calls to social services and the police for DV spiked. Given the reality of socioeconomic inequality, many from my own Malay community would have more complex considerations when seeking safety from an abusive situation. Writing this thesis in this moment in time allowed me to bear witness to how racial, religious and class oppressions may have rendered many experiences of DV invisible.

Throughout this thesis, I consciously use the term 'domestic violence' instead of similar alternatives like 'family violence' or 'intimate partner violence'. DV in this thesis refers to violent, coercive, controlling, threatening or aggressive behaviour within the home or by household members. This definition acknowledges that women, girls and gender minorities, particularly ethnic minorities and Indigenous populations, are disproportionately victimised in situations of DV (as I will further establish in Chapters Two and Three). I work from an understanding that DV includes physical, sexual, financial, religious, cultural and/or psychological violence, among other forms of violence. This manifests in battering, sexual abuse, dowry-related violence, marital rape, female genital mutilation and other practices (Declaration on the Elimination of Violence against Women, 1993).

It is important to also note that I use 'domestic violence' particularly as a response to the more common term, 'family violence', used in Singapore. 'Family violence', in its legal definition, excludes non-married (heterosexual and same-sex) partners. I also chose to use 'domestic violence' rather than 'intimate partner violence' to examine the effects and experiences of any abuse within the household, which may include child abuse, elder abuse or violence done by siblings or other relatives. 
I chose to work from the margins by focusing on the Indigenous Malay (largely Muslim) population in Singapore. I followed in the footsteps of intersectional theorists by questioning the cultural and structural ways the Malay/Muslim ${ }^{6}$ population may be affected by social policies. My analysis subverts the dominant narratives which typically present patriarchal DV as cultural problems specific to certain groups. I move attention away from discourses that centre assumed intrinsic differences between races, religions or cultures, by spotlighting the structural positionalities of Malay/Muslims in Singapore's governance and colonial history. I acknowledge how, besides individuals, families or communities, players such as policy-makers and social service workers actively decide how 'culture' is defined, understood and spread, how 'religion' is practiced dominantly, how DV is problematised and tolerated, and how policy 'fixes' the problems represented. Thus, advocates working with Malay/Muslim women who have undergone DV must have deep self-reflexivity, strong knowledge of the group's socio-structural positionalities, and the political will to create transformative, justice-driven change.

This piece of research sets out to answer the question of how Singapore's social policy has represented the problem of DV. It does so by interrogating the discourses that comprise social policy solutions that are either meant to protect people from DV or are represented as approaches to end DV in the long-term. To do this, I use Carol Bacchi's "What's the problem represented to be?" (WPR) tool. The tool is used by viewing policy solutions as levers to analyse how social problems are defined, framed and represented. WPR is an expansion of Michel Foucault's post-structuralist suggestion that texts seen to be "practical" or "prescriptive" solutions to a problem rely on a particular representation of the problem, rather than the problem itself (Bacchi \& Goodwin, 2016). In broadening Foucault's idea, Bacchi coined the term "problem representation", which decides how a particular social issue is "problematised", and recognised policies as one form of such 'text'. The intention of the tool is not to determine a single objective truth of the problem - in this case, of DV_-but to deeply analyse social policy solutions until we can find the limitations and exclusions in these

\footnotetext{
6 I choose to use "Malay/Muslim" as the majority of Malays in Singapore are legally recognised as Muslims. At the same time, I acknowledge that many Malays do not personally identify as Muslims, and many Muslim families are not recognised by the State as 'Malays' but culturally affiliate themselves with Malay identity. I use this term instead of the oft-used "Malay-Muslim" or "Malay Muslim" which conflates racial and religious identity. My chosen terminology is not perfect but allows me to work with the intended demographic while factoring in variations in identity.
} 
taken-for-granted policy 'texts'. It then helps us understand "the politics...that have gone into their making" (Bacchi, 2012b, p. 5).

By interrogating the problematisations of DV—not simply within 'formal' policy texts such as laws, but also in interview materials, first-person accounts, media narratives, political speeches, educational campaigns, social service policies and public information - I argue that advocates should broaden their imagination of the remedies to DV beyond the limits of these discourses. Besides the obvious potential this has in transforming policy-makers' work, the findings can have a substantive impact on the social service industry, which finds itself subject to the whims of a neoliberal government.

The next chapter gives an overview of Malay/Muslim identity and positionalities, examining it within Singapore's governance style. Knowing the historical and structural realities of the population helps to contextualise how women who have experienced DV may live, and allows for deeper comprehension of the systemic barriers they face.

Based on these insights, I move into a review of domestic violence literature and the theoretical framework of 'intersectionality' that underpins this study. In Chapter Three, I describe some international and Singapore-specific research which is contextually relevant to my study and explains the significance of intersectional studies in relation to ethnic minority women experiencing DV. I also study literature on common social policy approaches adopted to prevent or intervene in cases of DV, and demonstrate the value of studying the 'problem representations' within Singapore's DV social policy, which have power to shape discourse about DV within the Malay/Muslim population. Here, I explain further the WPR tool which is my chosen methodology for this thesis.

From the knowledge gleaned in Chapter Three, Chapter Four explains the selection of 'texts' and justify my decision to interview social service and policy professionals for this thesis. I describe the social constructivist research paradigm that this study is predicated on and explain my research methods, analytical tool and ethical considerations further. 
In Chapter Five, I present the first half of my findings, which analyses the problematisation of DV experiences within interviews, first-person accounts and policy documents available online or in publications. Chapter Five focuses on answering and analysing the question, 'what are some of the problem representations of the experiences of Malay/Muslim women going through DV?'. I explain how discourses have described DV within the Malay/Muslim population as issues of patriarchal violence and religious authoritarianism, housing and financial insecurity, and inadequate informal and formal strategies of resistance.

The analysis from these findings leads into the next chapter, where problem representations of experiences are mapped against the problem representations of DV within policy solutions themselves. In Chapter Six I analyse social services websites, policies and laws, media texts and government speeches, among others, to determine how DV is problematised as an issue to be solved with family and individual counselling, women's empowerment, working with men who perpetrate DV, religious and cultural counter education, public education to change attitudes, and legal and criminal justice remedies. The analysis from this chapter looks into where these 'solutions' fall short of the problem representations articulated in Chapter Five, and the literature that contextualised structural realities faced by Malay/Muslim as a result of Singapore's governance.

My findings illustrate how dominant problematisations of DV mute the State's ideological adherence to patriarchal authoritarianism, the neoliberal conditions that are punitive to individuals that stray from patriarchal households, and the racial and religious marginalisation of the Malay/Muslim population which is rooted in both Singapore's colonial history and contemporary policies. The implications of this allows me to discuss and conclude, in Chapter Seven, potential preventative ways forward to dismantle the structures that allow DV to happen, and transformative interventions so that Malay/Muslim women, and everyone else who experiences DV, receive the support and justice they need.

Overall, this thesis is an examination of domestic violence policy problem representations, but these policies cannot be interrogated without a thorough consideration of the positionalities of Malay/Muslim women in Singapore. The next 
chapter attempts to summarise the historical and contemporary structural forces that have shaped these experiences, which will ultimately support the analysis of my findings later in the thesis. 


\section{CHAPTER 2. THE SINGAPORE STORY}

This chapter will shed light on the more significant identities and positions that the Malay/Muslim population in Singapore has occupied historically. This includes their status as ethnic minorities, Indigenous peoples, religious minorities and as a population that is disproportionately represented in lower-income categories. Following these articulations is a section on the Singapore State's style of governance, which has been described by scholars as patriarchal, authoritarian and neoliberal, facets of which affect the Malay/Muslim population in ways that would trickle down to their experiences of DV.

Singapore is a small, wealthy city-state in Southeast Asia that sits on the southern tip of the Malaysian peninsula, with a history that goes back millennia (Kwa, 2018). Indigenous Malays migrated to the Nusantara (Malay archipelago) between 2000 and 5000 BC. The Malay population is far from homogeneous, with genetic, linguistic and cultural diversity forming part of the Nusantara identity (Rahim, 1998).

A former British colony, Singapore achieved independence in 1965 led by the People's Action Party (PAP), which until today has political hegemony over the country. The PAP has been widely credited for Singapore's GDP ${ }^{7}$ growth, home ownership rates and high standard of living. Contemporary Singapore has been described as being among the most open economies in the world (Charlton, 2019), as an illiberal democracy (Mutalib, 2004), and as an authoritarian capitalist nation (Lingle,1996).

\subsection{Singapore's Malays and Muslims}

\subsubsection{Race and Indigeneity}

A deeply racialised country, Singapore has a racial classification system that allocates every resident's identity in accordance with four main categories: Chinese, Malay, Indian, or 'Other' (Clammer, 1997). The Malays are an ethnic minority group (13.4\% of the population) ("What are the racial proportions", 2019) and constitutionally

\footnotetext{
${ }^{7}$ Gross domestic product
} 
recognised as Indigenous ("Minorities and special position of Malays", 2020), while the majority Chinese make up $74.4 \%$. Most (99\%) of Singapore's Malays are recognised in census statistics as Muslims ("Census of Population", 2010a).

I highlight Malay indigeneity in this study because international literature has demonstrated the impact of colonisation on Indigenous populations' experiences of DV. Scholars argue that marginalisation from colonisation is correlated to Indigenous peoples' intergenerational trauma from racism, alienation from land, and erosion of social structures within their communities (Al-Yaman et al., 2006; Gauthier et al., 2018; Dhunna et al., 2018). This manifests in poor health outcomes, addiction, poverty and higher rates of DV (Bryers-Brown, 2015). In Singapore, the political power and resources of the Malay population have been systemically weakened over the years through policies that maintain their minority status, and that splinter and reduce their electoral force e.g. through the Ethnic Integration Programme (EIP) (Rahim, 1998). Indigenous researchers argue how by weakening communities, Indigenous peoples' relationships with their land, neighbours, and families change, resulting in loss of autonomy and the disintegration of the systems of accountability necessary to end DV (Cavino, 2016). I quote Māori researcher Cavino (2016), who wrote about intergenerational sexual violence and whānau, below:

Settler colonialism led to rapid and intensifying shifts in our ability to be both autonomous and accountable to one another.....when we lost geographic proximity to each other because of the theft of land we lost our ability to be intimate....namely, our ability to know and be accountable to one another and ourselves. (Cavino, 2016, p.11)

Similar to tangata whenua ${ }^{8}$ in Aotearoa, Malay marginalisation can be dated back to the British colonial occupation period. One example is in the colonial spatial town plan which ensured a racial hierarchy that geographically privileged Europeans, followed by the migrant Chinese population. Malays were largely excluded from the colonial narrative of economic growth and "relegated to the jungles" $(\mathrm{Ng}, 2019)$, as they were unwilling "to become a tool in the production system of colonial capitalism" (Alatas, 1977, p.72). Racial stigma of Malays being "lazy" and "unintelligent", while the Chinese are hardworking, persist in modern Singapore's cultural memory, tracing its genealogy to a colonial depiction of the Malay race as inferior (Alatas, 1977). This sentiment was

${ }^{8}$ Māori or 'people of the land' 
repeated over time, including by founding Prime Minister (PM) Lee Kuan Yew, who served as PM from 1959 to 1990, and remained in Cabinet until 2011 before his death in 2015 (Tamney, 1996; Joraimi, 2019).

Scholars have identified Sinocentric policies, such as tight cultural and business links with the People's Republic of China, and racial quotas for ethnic minorities ("Ethnic Integration Policy", n.d) in the government's public housing system-Housing Development Board (HDB)-resulting in systemic discrimination against Malays (Clammer, 1997). The Othering of the Malay/Muslim population is normalised through continual positioning of Singapore as a Chinese State surrounded by what the State perceives to be 'hostile' Malay/Muslim nations of Malaysia and Indonesia ( $\mathrm{Ng}, 2019$ ). One policy manifestation of this is the limitation of Malay men's participation in some roles within the Armed Forces, rooted in the fear of the Chinese-majority State being betrayed by Malay Singaporeans' 'intrinsic' loyalty to their racially-kin neighbours $(\mathrm{Ng}$, 2019; Rahim, 2012).

In the labour market, Malays are under-represented in senior positions in the public sector and the judiciary (Rahim, 2012). Many Muslim women face a specific type of marginalisation: women who wear the tudung (Islamic headscarf) are discriminated against, with employers justifying their actions with uniform requirements (C. Lim, 2019; Beh, 2020). Policies that prohibit the tudung in nursing and some front-line government jobs have been defended by some Ministers, who instead of pushing for counter-policies that protect Muslim women from such forms of employment discrimination, espouse beliefs that society would evolve "gradually" and "informally" to be more inclusive. Specifically, Prime Minister Lee Hsien Loong once stated that any change on what has colloquially been called the "tudung issue" would first require that "people get used to new norms" rather than "being pushed for in terms of rights and entitlements and to the detriment of the overall progress of harmony between the communities" ("Allowing hijab problematic", 2013; J. Tan, 2014). These ideas tie Muslim women's rights over their own dress choices and bodies directly with the disruption of social harmony.

Such beliefs also push for minority assimilation into a dominant culture, as issues faced by the Malay/Muslim population have been framed as "cultural" or "community" 
problems. In the "tudung issue", former Nominated Member of Parliament (NMP) Zulkifli Baharudin blamed it on Muslims who do not make an effort to "compromise and integrate themselves", expecting "others to accommodate them" (J. Tan, 2014). This comment reproduces the colonial image of the non-compliant Malay/Muslim who refuses assimilation into Anglo-Chinese culture.

Health campaigns target the population similarly, relying on cultural explanations for the high rates of diseases like diabetes by blaming Malay 'lifestyles' and cuisines, rather than recognising their socioeconomic realities or ease of access to healthcare (Khalik, 2014; Chua, 2017; Wong \& Toh, 2017). Malays are also overrepresented in crime and drug statistics (Toh, 2017), but public education campaigns-such as 'Dadah Itu Haram' ('drugs are Islamically forbidden')-target the Malay/Muslim population by attributing drug addiction to wayward cultures, ignoring the intersecting factors that can contribute to drug use among low income, ethnic minority groups (Windsor, 2009; Aljaru, 2020). Carceral policies offer "financial literacy" and "parenting courses" (A. Lim, 2018) for Malay/Muslims inmates, pointing to individual and cultural failures, rather than structural and economic deficiencies which cause poverty and drug addiction.

Rahim (1998) defines this phenomenon as the 'cultural deficit thesis': Malay/Muslim problems are represented as a result of inherent deficiencies, instead of systemic oppression. This spills over to DV when police officers respond to DV cases with stereotypes and assumptions about drug use if Malay families are involved (Ganapathy, 2008). State narratives on violence and extremism strengthen this view of the violent, backward Malay/Muslim Other, when political leaders continually emphasise the threat of radicalisation and conservatism among Muslims (Ab Razak, 2019).

Despite this, the domineering myth of meritocracy within a multiracial Singapore mutes allusions to structural inequality, and creates a utopian vision of the Singapore system that allows Malays, "just like anybody else", to succeed (Toh, 2017; Baharudin, 2017). What results is the overall flattening of the power structures that course through institutions, society, and families. 


\subsubsection{Religion}

Malay ethnicity and the Islamic faith are conflated in Singapore, unlike other faith and ethnic communities. Rahim (2012) pointed to the Singapore State's tendency to indulge in ethno-nationalist discourse which rationalises the ideologies and actions of the majority Chinese country in marginalising the constructed "Malay/Muslim" population. An example of this is how, in his book, founding Prime Minister Lee Kuan Yew once considered Muslims "distinct and separate" (Rahim, 2012).

The distinction again dates back to the British colonial era where in order to 'respect' the adat (laws and customs) of the Malays, Islamic personal law was enacted (Abdul Rahman, 2012). Today, personal law continues to operate for all Muslims as part of constitutional recognition of Malay indigeneity in Singapore. Unless one formally renounces the religion, personal law affects Muslims in the areas of marriage, divorce and inheritance. For instance, in the area of divorce, it is permissible for a man to use talaq ('to release') as a form of unilateral divorce. A woman has to prove khuluk (divorce by redemption or compensation), taklik (divorce by breach of marriage condition) or fasakh (annulment of marriage including on grounds of cruelty by the husband) (Administration of Muslim Law Act, 2020).

Although presented as a way to retain Indigenous autonomy, governance of Islam in the multicultural society can also be seen as a chance to further the State agenda. The statutory board MUIS (Islamic Religious Council) relies on predominantly male leadership within the Malay/Muslim population to determine Islamic matters (Jamil, 2016). Recognition of the group's autonomy is granted to male and conservative leadership, conflating the most 'authentic' version of the population with patriarchal conservatism (Sahgal \& Yuval-Davis, 1992). This follows the strategy of relegating a particular site of power to uphold minority rights in multicultural societies, though scholars have argued that power held by the minority communities is largely symbolic (Stasiulis \& Yuval-Davis,1995).

MUIS's roles include issuing religious guidance to the Muslim population, like providing the text of Friday prayers' khutbah (sermons) to male worshippers (Rahim, 2012). Moreover, the border between MUIS and the influences of PAP politicians is extremely 
porous as many Muslim organisations rely on State funding and the dominant presence of PAP politicians in their organisations (Rahim, 2012). MUIS thus closely echoes the conservative, patriarchal and paternalistic ideologies of the Singapore government.

\subsubsection{Socioeconomic status}

Malays have the lowest average and median incomes in Singapore, when compared to the other major ethnic groups, the Chinese and Indians ("Census of Population", 2010b) and are marginalised in political and educational spheres (Rahim, 1998). Class, like race, is an important factor in studies on DV, as economic inequalities exacerbate the impact of DV on abused women (Josephson, 2005). Women seeking protection in DV shelters are often unemployed, underemployed or poor: a structural overlap in marginalities which shelter- and service-providers cannot ignore (Crenshaw, 1991). Kimberlé Crenshaw proposes the idea of "structural intersectionality" as a way of comprehending this, wherein poverty and social class intersect with gender and race, making ethnic minorities' experiences of DV qualitatively different than that of the dominant group. (The theoretical concept of intersectionality will be further explained in Chapter Three). Higher incidence of poverty among minority women, the lack of available jobs (as a result of structural racial discrimination) and the lower likelihood of minority women having networks for financial support, hinder women's efforts to leave abusive relationships (Crenshaw, 1991). Given that experiencing DV also has been linked to poor health outcomes, like an increased risk of cardiovascular diseases (Chandan, 2020), women's socioeconomic class plays a particularly large role in the work of ending DV.

In her study on the Malay working poor, Manap (2010) identified how lack of a structural intersectionality lens results in the double victimisation of those living in poverty as they attempt to access support services. Culturally essentialist biases and subconscious analyses that social service workers harbour have reduced Malay clients' behaviours to a product of their 'culture' (often assumed to be static and monolithic). Malay social workers' portrayals of fellow Malay clients represented them as "lacking foresight" and devoted to God, such that religious factors ("backward Islamic orientation") are perceived as reasonings for economic underdevelopment. 
Interpreting Manap's findings within the context of this study can go several ways but a relevant takeaway is in observing the slipshod convergence of several facets of the Malay/Muslim identity that 'experts' such as social workers fall prey to.

In all, navigating the intricacies of indigeneity, socioeconomic class, race and religion is a challenging endeavour, but one that nevertheless must be taken in order to end the enactment of structural violence against minoritised populations. In the next section, I will look at the ideologies that underpin Singapore's style of governance, to get a picture of the ways they sit alongside Malay/Muslim positionalities.

\subsection{Patriarchy, authoritarianism and neoliberalism}

The Singapore brand of governance has been described as a competitive authoritarian regime, which lacks robust democratic practices thus severely disadvantaging political opponents of the PAP (Levitsky \& Way, 2009; Zhang, 2012). The refrain of pragmatism, meritocracy, and traditional 'Asian values' has been used to defend patriarchal authoritarian governance (Ortmann, 2011; E. Tan, 2008; Clammer, 1997). Singapore is also known as a neoliberal society, where there is emphasis on "individual initiative, enterprise and responsibility" with minimal state intervention (Ishkanian, 2014, p.334). Neoliberalism in Singapore manifests in how individuals are encouraged to be self-sufficient, while social services function to catch those who have slipped through the cracks, and effective political discussions among the people are restricted, resulting in fewer achievable "egalitarian and socially progressive goals" (K. Tan, 2017, p.16).

Deference to political authority-reiterated through East Asian values that the Chinese-majority government upholds-results in elitist and hierarchical social structures that are rarely seen as problematic (Rahim, 1998). This has effects on patriarchal structures within families, too. Patriarchy has been broadly defined as "social arrangements that privilege males", male domination over women "both structurally and ideologically", resulting in "hierarchical arrangements that manifest in varieties across history and social space" (Hunnicutt, 2009). For instance, patriarchal structures are represented-whether directly or indirectly-in the ideologies underpinning Singapore's 'head of household' is a policy concept, used in various 
arenas including the State's census processes. The 'head of household' is "normally the oldest member, the main income earner, the owner/occupier of the house or the person who manages the affairs of the household" ("Singapore's Demographic: Heads of Household", n.d.). The government attempted to justify this recognition as genderneutral by claiming that tax relief for working women recognises them as breadwinners ("Report on CEDAW", 2017). However, social realities remain, and men more often than not assume the position of heads of households.

More than that, the 'head of household' concept normalises authoritarian structures, which is used more broadly to regulate the population. Draconian legislation like the Maintenance of Religious Harmony Act has been viewed through this lens (Rahim, 2012). Such legislation has been used to silence and restrict political discussions among people. During the 2020 General Elections, opposition party candidate Raeesah Khan - who had years before spoken about 'Chinese privilege', in the justicesystem on her personal Twitter account-was investigated by the police under the offence of promoting enmity between different groups on grounds of religion or race (S298A of the Penal Code) ("Police investigating WP candidate", 2020). A year prior, a similar fate had befallen the Nair siblings, a comedy duo, who made a parody video calling out Chinese privilege, 'brownface' and racism in government-approved media advertisements (Jaipragas, 2019).

Even without the use of a legislative muzzle, authoritarian governance in Singapore discourages, to say the least, any criticism of the State. In 2020, Member of Parliament Tan Wu Meng once blogged on the official PAP website about how Malay Singaporean playwright Alfian Sa'at has a "preference for Malaysia over Singapore" (W.M. Tan, 2020). Sa'at had, over the years, written social media posts criticising Singapore's nationalist propaganda, Chinese hegemony, and former Prime Minister Lee Kuan Yew. He has also written affectionally about the cultural environment in Malaysia, in contrast to Singapore (W.M. Tan, 2020). The MP's blog post indiscriminately pulled screenshots from Sa'at's Facebook account between 2012 to 2018, accusing Sa'at of being disloyal to Singapore. This blog was also written specifically as a way of furthering the PAP's General Election 2020 campaign against an opposition party whose leader, Pritam Singh, once supportively called Sa'at a "loving critic" of Singapore. This is just one example of how political dissent, and even personal 
opinions on social media, are authoritatively disparaged by the state. More specifically, as contextualised previously, critiques of the State are framed according to the mould of nationalism (or lack thereof), resulting in the building of an adversarial character in opposition to the State. In this case, it is of the disloyal Malay/Muslim citizen whose allegiance supposedly lies with the neighbouring Malay/Muslim-majority States, an accusation that stokes the decades-old boogeyman of the untrustworthy, potentially dangerous Malay/Muslim Singaporean. Thus, the concept of "racial and religious harmony" is used as a double-edged political tool to silence critics who attempt to shatter the myth of Singapore's multicultural meritocracy.

One of the more conspicuous examples of patriarchal authoritarianism is compulsory military service for male citizens, which institutionally bolsters the view of men as natural "protectors" of the nation and land, and normalises men's participation in military defence and State-sanctioned violence. But patriarchal ideology is upheld through other policies that both directly and indirectly limit women's participation in public life and is particularly punitive towards low-income, low-educated, ethnic minority women. These policies have included the implementation of a quota which limited the admission of female medical students into universities (lifted in 2003) ( $E$. Tan, 2008); the Graduate Mothers' Priority Scheme, where children of graduate mothers received priority registration in Primary Schools ("Reproductive Rights", 2015) (this was rescinded in 1985 after public outcry); and the Small Family Incentive Scheme which coerced less educated, low-income parents into undergoing sterilisation to limit their family sizes with a $\$ 10,000$ Central Provident Fund deposit. The sterilisation requirement was removed, but the scheme, in its essence, remains in the current HOPE Scheme which serves the same purpose ("Reproductive Rights", 2015). These eugenicist policies were intended to "promote higher birth rates among educated Chinese women and to curtail prevailing rates among Malays and Indians" (Doran \& Jose, 2002), reinforcing the gender, racial and class hierarchy in the country.

Although the Women's Charter (1961) is often touted as a fool proof protection of women's legal rights, the legislative act largely covers the domains of family and marriage law, which tightens the conflation of women's issues with the domestic sphere (Kong \& Chan, 2000). Traditional gender roles are anchored in parental leave policies (16 weeks for women, two for men). Married heterosexual couples are 
privileged in areas of housing, Baby Bonus Cash Gifts and tax reliefs, while divorced and unmarried mothers face unapologetic discrimination in these areas ("Legal and policy distinction", 2016). Legal and policy distinctions between "legitimate" and "illegitimate" children have material effects on citizenship and inheritance, which socially engineers the government's vision of the desirable nuclear, heteronormative, patriarchal family: the basic unit of society (Kong \& Chan, 2000; E. Tan, 2008).

This privileging of patriarchal values is attached to the desire for capitalist development. Marxist feminist theories argue that capitalists are invested in women's role in the domestic sphere, as it continues the "reproduction of the labour force" (Kong \& Chan, 2000). Even as the modern State changed its tune to encourage women to enter the labour force, their role within the familial arena remains. This "second shift" of domestic work on top of paid work is a well-documented strain on women's lives (Hochschild \& Machung, 2012). Women contend with the expectation of being a 'supermom' -a working mother who can juggle paid employment and unpaid domestic work (Suratman, 2011). "Women's work" such as professional caregiving, cleaning and domestic work, are notorious for their low salaries (Hingorani, 2018; Ho, 2020). Thus, patriarchy and capitalism work hand-in-hand to capitalise on women's labour both in the domestic sphere and within the labour force.

Still, the State consistently aligns its values with that of a pragmatic capitalist society, repeatedly distancing itself from the "welfare state". Its neoliberal policies focus on GDP growth while compromising on social policies (Beng-Huat, 1985; Kim \& Bhaskaran, 2015). The Singapore story of successful social policies centres selfreliant individuals with their families "as the first line of support" (Mehta, 2006; Jagdish, 2018a). State intervention only comes in as a last resort (E. Tan, 2008). Yet, the State's social services are a major intervention platform for people going through DV. In Singapore, individuals are presented with the option of reaching out to social service offices (SSOs), Family Service Centres (FSCs) or Family Violence Specialist Centres (FVSC) under the Ministry of Social and Family Development (MSF), faith-based organisations, or independent non-profits such as AWARE and LGBTQ advocacy groups like Oogachaga, Brave Spaces and The T Project offering counselling and/or hotlines. At the same time, the representation of the social sector and 'welfare aid' has clear effects on how accessing them is viewed by individuals. People have expressed 
feeling shame and indignity when engaging with processes of receiving welfare aid (Teo, 2015). Social service practitioners reproduce cultural stereotypes and unconscious but damaging evaluations of 'deservedness' (Manap, 2010), which can also be observed in State discourse (Jagdish, 2018b; Wong, 2019).

Overall, scholars have argued how the State poses its form of pragmatism in contrast with the liberal democracy of the "West". "Asian" values reign in these defences of the PAP's patriarchal and authoritarian governance (E. Tan, 2008; K. Tan, 2017). Founding PM Lee is famous for his use of authoritative and violent metaphors, usually in response to public criticism on governance from civil society. Dissent and criticism from Singaporeans was viewed by the State as an 'attack' that the government would have to reciprocate. Such counterattacks against critics have included public statements by Lee such as: "take a sharp knife, metaphorically, and I'll take a sharp knife of similar size; let's meet." (quote in Wrage, 1995) and "if you take me on, I will put on knuckle-dusters and catch you in a cul de sac." (Han et al., 1998); and by former PM Goh Chok Tong, such as: "If you land a blow on our jaw, you must expect a counter-blow on your solar plexus" (quoted in 'Those with agenda', 1995).

These bold, candid proclamations simply put a human face to the use of threats, violence and punishment by the Singapore State. But physical violence is also entrenched in law, through the permissible use of corporal punishment against children for the purposes of "discipline" both in homes and in schools, corporal punishment in prisons, and the use and defence of the death penalty for drug-related and sexual violence crimes (Tham, 2020; Lum, 2020). The legal definition of 'family violence' in the Women's Charter omits non-family members in its protection, including people who are not recognised as married to their partners (both heterosexual and same sex couples), and some children who are subject to punitive forms of discipline (Women's Charter, 2020). In essence, the Singapore definition of 'family violence' bases itself off what the State counts as 'family' and what it considers as unacceptable forms of 'violence'. The overall effect is a State that has normalised the use of 'some' patriarchal and authoritarian violence (such as State violence and punitive discipline), which would affect minorities disproportionately. 
Despite these hard-hitting realities, not all studies have chosen to frame patriarchal leadership as an inherent problem, some describing it as "benevolent" and nondiscriminatory (Kong \& Chan, 2000; Chew, 2004). Chew's study framed patriarchal leadership as such: as long as the social contract that decides the roles of citizens according to their gender is fulfilled, "all will prosper" (Chew, 2004, p.7).

But such a perspective must also overlook patriarchy's roots in power imbalance, and how the effects of this imbalance seep into political, social and economic arenas of individual lives. It overlooks the question of who, ultimately, benefits from the "social contract", and whose rights and protections are curtailed. It also silences the role of patriarchal ideologies that buttress gender violence, presenting a mythical, defanged vision of patriarchy where any gender inequality is justified by a country's overall economic wealth, and where patriarchal violence-if it is acknowledged as such-is entirely detached from a patriarchal State. 


\section{CHAPTER 3. THEORETICAL FRAMEWORK \& LITERATURE REVIEW}

The previous chapter establishes where the Malay/Muslim population sits within Singapore society, and how their marginal identities in race, religion, and socioeconomic status shape the resources they can access and the power relations they contend with. Their social standing is consequently reinforced by Singapore's authoritarian, patriarchal and neoliberal governance, which leans on concepts of selfreliance, meritocracy and benevolent authoritarianism and patriarchy.

But how exactly would these factors shape problem representations of DV in discourse and social policy? In this chapter, I propose that an intersectional approach to DV will bridge this gap. I will do this by offering an introduction to intersectionality as a framework, before examining how it can and has been applied to both local and international literature on DV within Muslim populations. I will dive into an examination of the literature available about the common social policy approaches to end DV, and where they fall short. Finally, I will examine the value of studying problematisations to make the case for my study's methodology.

\subsection{Intersectionality}

Intersectionality is a rich and elaborate theoretical framework which prompts a critical study of the multiply-marginalised identities of, among others, ethnic minority women (Crenshaw, 1991). Analysing the "intersections of oppressions"-wherein race, gender, sexual orientation, social class, religion and other identities are socially constructed (McHugh, 2014), intersectionality demands that converging identities of individuals should be seen not merely as the sum of its parts, but as a unique whole (Milani et al., 2018). Living on the intersection of oppressions does not simply "add to" oppressive experiences; it changes them.

DV is a problem where intersectionalities distort the meanings and the nature of women's experiences - "how it is experienced by self and responded to by others, how personal and social consequences are represented, and how and whether 
escape and safety can be obtained" (Bograd, 1999). Intersectionality allows us to pick apart the social, cultural, religious and structural pressures and systems that Malay/Muslim women navigate, and where it situates them in a Singapore society.

Using this theoretical framework for Malay/Muslim women's perceived experiences is not merely about viewing DV through the lenses of religion, culture and gender separately, but about how these elements interact with one another. Thus, I will also examine the positionality of Malay/Muslims in the social, economic, political and structural paradigms of Singapore, which was contextualised in the previous chapter.

Critical analysis of wider systems of oppressions-particularly on account of race, ethnicity, poverty and religion-in the lives of people experiencing DV is not as commonly found in many pioneering academic texts and theories of DV. However, early works by Crenshaw (1991) and other feminists of colour paved the way for an 'intersectional' approach to understanding DV. Nuanced studies into multiplyburdened populations, including ethnic, racial and religious minorities who experience DV, have slowly but surely emerged (Sokoloff \& Pratt, 2005). Although my study is situated within the intersectional model of analysing DV, recognising how different scholars, researchers and practitioners have seen 'solutions' to end DV provides a basis of understanding for how this study's participants can conceptualise the issue, and how intersectional Singapore's own policy responses are. In the next section, I will illustrate why a structurally intersectional approach is critical in this particular study.

\subsection{Representations of Muslim women's DV experiences}

Within the body of international research on Muslim women's experiences of DV, scholars have attempted to debunk the myth of Muslim societies and 'culture' as fixed, unchanging and particularly patriarchal-a myth which, as previously established, Singapore arguably falls prey to as well. It is therefore important to look at how patriarchal violence is mediated through "structural forms of oppression, such as racism, colonialism, economic exploitation, heterosexism" (Sokoloff \& Dupont, 2005, p. 45). 
Studies on Muslim women have shown how those enacting DV wield patriarchal interpretations of religion as one way to coercively control (Hassouneh-Phillips, 2001b; Niu and Laidler, 2015). Scholars identified how such coercion makes those experiencing DV subordinate, dependent, isolated, exploited or deprived of resistance and escape (Stark, 2008). For Muslim women this has taken the form of regulating or attempting to dominate their faith and practice of religion, restricting their ability to leave their homes without permission of their husbands or a man claiming that a woman has to obey him because it is a Muslim woman's duty to submit to her husband (Hassouneh-Phillips, 2001b; Niu and Laidler, 2015; Tabrani, 2018). However, these manifestations of DV have been seen in other religious groups besides the Muslim community (Sharp, 2014; Nason-Clark, 2004). Hassouneh-Phillips, Niu and Laidler and Tabrani's studies all focus on the textured, complex accounts of those experiencing DV and living in the intersection of class, gender and religious oppressions.

There are also attempts to look at the dilemma of minority Muslims experiencing DV as they grapple with reconciliation of two "different" cultures-their own authoritarian and collectivist culture, and the dominant egalitarian and individualist culture (Milani, et al. 2018). However, in my study, I hope to avoid the danger of conflating a minority "culture" with inherent patriarchal beliefs by considering how the dominant AngloChinese culture of the State has, indeed, strengthened authoritarian, patriarchal cultural practices.

The studies above also exemplified how religious texts (Quran and hadith) have been used to exert power and control over women. But Islamic feminist theorists have challenged the androcentric realm of Quranic interpretation, offering alternative readings-for instance, using concepts of Tawhid ('oneness') and arguing that male supremacy contradicts "the undivided supremacy of God)" (Rasool \& Suleman, 2016). This shows how there is room within religion itself to grow beyond the dominant patriarchal narrative. For these narratives to prevail, open and progressive discourse about religion is needed, something which is muzzled in Singapore due to the Maintenance of Religious Harmony Act (K. Tan, 2017; Han, 2020). Fighting for the normalisation of concepts like Islamic feminism, where religion and feminism are reconciled rather than at odds, is a fight against the grains of the status quo, where 
both the religious arena and the multiracial "secular" nation-State operate under patriarchal hegemony (Chew, 2004; Straughan, 2009).

There are also economic consequences that must be considered. Studies on DV experiences have shown that women report fear from the threat or enactment of talaq both in jurisdictions where Islamic law is in effect, like Singapore (Tabrani, 2018), and those where it is not, like China and Canada (Niu and Laidler, 2015). Where interviews were conducted with 14 Hui Muslim women in west China, practices of unilateral divorce remain within the community, rather than recognised in the nation's law. One of the earliest studies on spousal abuse in the Muslim community was conducted in the U.S. Through phenomenological studies of Muslim women, scholars demonstrated how the religious sanctity of marriage played a key role in women staying in abusive relationships (Hassouneh-Phillips, 2001b). These findings indicate strong relationships to cultural and religious practices that may affect some women's experiences with abuse, but also reveals how lack of extended family networks and Muslim legal recourse in the U.S. leave women more vulnerable.

Other international studies reveal that divorce and economic security are areas where women experience psychological, cultural and structural pressures and lack of agency in their lives (Dasgupta, 1998; Tonsing, 2016). Some of the challenges that surface when women attempt or consider divorce include the belief that it is primarily the right of the husband (Rasool and Suleman, 2016), the idea that disclosing the abuse and leaving the marriage is a $\sin (T a b r a n i, 2018)$, the unsupportive cultural pressures that stigmatise divorce, especially female-initiated ones (Fortune et al., 2010; Tonsing, 2016; Milani et al., 2018), and economic and structural barriers they face when seeking support, especially within the immigrant context where visa sponsorship is tied to the husband (Tonsing, 2016). These are ways in which women's experiences of abuse are silenced, reinforcing the belief that DV is a 'private' or 'family' problem (Stark, 2008; Barwick, 2020).

Some scholars attribute this 'silence' to cultural or religious reasonings, representing the incredible importance placed on the idea of honour in 'intact' families (Niu and Laidler, 2015; Ghafournia, 2017), and the debilitating shame that comes from being a divorcee (Fortune et al., 2010) that keep women in abusive relationships. But cultural 
values interact with structural realities, too: studies on migrant Muslim populations found that abused women face impediments such as language barriers and exacerbated social isolation, and lack of knowledge about available social services (Tonsing, 2016; Milani et al. 2018). In Singapore, Tabrani's (2018) honours thesis study is the only known study conducted on Muslim women's experiences of intimate partner violence in Singapore. She found that patriarchal perceptions of spousal relations, patriarchal dominance through religion, the stigma surrounding divorce, women's economic dependency on the men in their family and law enforcement agencies that uphold the patriarchal family unit, for example, are reasons why women stay in abusive relationships. Although small-scale, her findings contribute to filling the large void in literature on the DV experiences of Malay/Muslim women. She identifies the need for discursive transformation that would not allow patriarchal ideology to take root, in order to end DV.

Another aspect that many studies explore is how religion can both help and hinder women's safety and recovery. A Singapore study done on the motivations of those experiencing DV to leave their relationships (which interviewed one Indian Muslim and five Malay Muslim women) found that religious faith facilitated their decision to leave, and helped them find empowerment in recognising divorce as their right (Khng \& Ow, 2009). Studies on South Asian women's experiences of DV point to how Quranic recitations and prayer may also provide resources for emotional coping (HassounehPhillips; 2003; Thiara and Gill, 2009). I am interested in seeing how religion and religious teachings are presented in discourses, whether as methods of coping and empowerment or, conversely, as obstacles and impediments.

\subsection{The ways to end DV}

As discussed above, there are many studies on the manifestations of DV in Muslim women's lives. Theories on the causes of DV similarly vary, and this has shaped, for better or worse, the solutions that have been proposed and enacted to end DV. For example, some studies have described DV as a result of unregulated anger of those perpetrating violence (Holtzworth-Munroe, 2000). This is a common conception of the problem, which can explain why treatment programmes for men who perpetrate 
violence sometimes feature anger management sessions (including in Singapore's mandatory counselling programme) ("Family Protection \& Welfare Services" (n.d.).

However, many feminist scholars counter this representation of DV, adopting instead a feminist lens to root DV within patriarchal power and control (Connell, 1987; Straka \& Montminy, 2008). This lens understands gender-based domestic violence as strategically motivated by male power and control over women, which stands in contrast with the aforementioned theories of violence as purely a result of anger or a loss of control. It has resulted in one of the more widely known proposed models to tackle DV, the Duluth Model, which holds men who use violence to account and keeps women and girls safe by changing societal conditions that support men's use of power and control over women (Pence, 1993). The Duluth model helps practitioners to understand the gendered nature of DV, how it implicates women and girls' lives and is fed by patriarchal beliefs and attitudes, and thus, how to dismantle such ideologies and end DV.

Again, some scholars have critically reflected on the limitations of the Duluth model, or understandings that pin DV solely on male power and control over women. For instance, a common point of contention lies in the narrow scope of the theory, which does not entirely consider women who use violence, non-heterosexual men who perpetrate violence, nor diverse variables in race and ethnicity (Bohall et al., 2016). Ideologically oppressive forces, structural violence and cultural milieu that can shroud and maintain patriarchal power can also end up being lost in the original representation of the model. In the original Duluth model, Malay/Muslim experiences-that is, a population's history with colonialism, economic marginalisation, racism and Islamaphobia-may easily be muffled in favour of the effects of patriarchal power on their lives. Still, it lays bare the central element in domestic violence-power and control. This concept has been transformed by some scholars to be more structurally intersectional. For instance, The Misuse and Abuse of Power toward People of Colour wheel below (Almeida et al., 1992) that identifies how racism, colonisation and imperialism can affect experiences of DV. Thus, inequality and power and control remain, at least within many feminist understandings of DV, a largely undisputed foundation to oppressions of many kinds. 


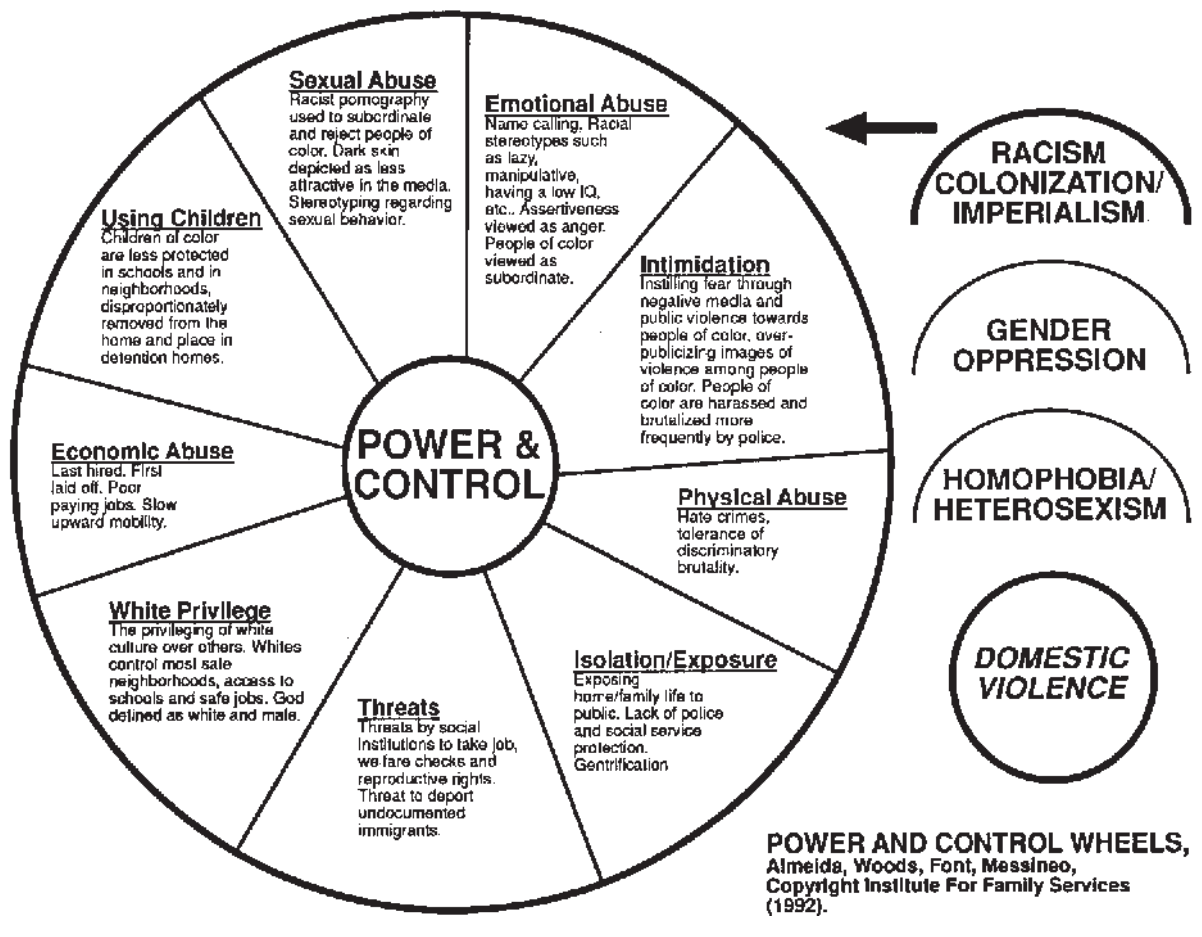

Overall, there have been many approaches to understanding the nature of DV, and the ideological components that uphold it, including through an intersectional lens. These theoretical perspectives have allowed for the emergence of social policies aimed at tackling the issue. The Singapore strategy to manage DV has been summarised as centering four elements: legislative framework; a "many helping hands" approach that collectivises government and non-government agencies, communities, and families; competency of service providers; and public education (Goh, 2009). In the next sections, I will examine research, both local and international, that has been done on these different intervention approaches to tackle DV.

\subsubsection{Legal protections and the criminal justice system}

Legal protections and criminalisation of DV are major parts of the discourse on ending DV, with many advocates seeing State recognition of DV as a marker of the issue being pushed out of the 'private' sphere and into the 'public' sphere (Amirthalingam, 2003). Scholars have investigated criminal justice policies and how they affect how individuals experiencing DV consider their options for safety. One major DV study in Singapore focuses on policing practices (Ganapathy, 2008). It offers a wealth of 
knowledge in understanding the barriers of seeking justice for DV through the criminal justice system. For example, a large majority of women who experience DV never called the police, and among those who do, many feared separation from their partners, and felt trapped between wanting to leave and the social isolation that would come with life after a divorce. Ganapathy concluded that women stay in these relationships as a result of 'rationally chosen' decisions based on their own socialstructural circumstances, calling for a cultural and structural framework to policing family violence. (Ganapathy, 2008).

However, the push for criminalising perpetrators of DV_relying on a carceral system of police, prosecutors, courts and punishments-has been defined by some scholars as "carceral feminism" (Kim, 2019; Sweet, 2016). Some argue that such a model leans on the assumption that violence of such nature is a problem of individuals' behaviour, and that the problem to fix is within those individuals, even as the State doles out violent punishments through criminal justice. Anti-carceral feminists criticise social work systems that treat women as 'clients' who "need services" (Sweet, 2016) instead of advocacy leaders, thus feeding into the narrative of disempowered women. In Singapore, women who report intimate violence are also subject to polygraph tests by police and gruelling and long court processes (Jalote, 2014). Moreover, the disproportionate impact of the criminal justice system on ethnically minoritised groups demand a more complex undertaking of the problem. The "tough on crime" approach done in the name of protecting women has the effect of expanding the punitive grip that State systems already have over racially and economically marginalised populations (Terwiel, 2019).

In Singapore, critical reflection on such practices is precisely needed because of its already patriarchal and authoritarian government. Reliance on the criminal justice system thus means reliance on policing practices that reproduce social stratification of class, race, gender and sexuality (Ganapathy, 2008). Regular calls for harsher punishments and stiffer penalties by the State against those who perpetrate genderbased violence ("Conversations Women Development", 2020) have ignored the disproportionate incarceration of ethnic minorities like Malays and Indians (Ganapathy \& Lian, 2016), the impact on poorer, minoritised populations as a result, and the ways 
the State has operationalised patriarchal and authoritarian concepts to end symptoms of patriarchal violence.

In place of criminal justice solutions, there is a growing call for transformative justice solutions by intersectional, anti-carceral abolitionists and advocates, who argue for responses to gender violence that build resistance and community solidarity through the "leadership and interests of marginalized communities" (Kim, 2019). These calls reject the hegemonic criminal justice system for its violence and oppression of minority groups.

Finally, a dated study on the profiles of those experiencing DV in Singapore concluded that the proportion of individuals with "an awareness of community and legal help services" doubled between 1992 to 2002 (Foo \& Seow, 2005). However, the study also showed that despite greater knowledge of these resources, "the profile of the female domestic violence has remained largely unchanged" and that DV continues to be largely underreported. Reflecting this underreporting, the most recent (though still dated) Singapore study on prevalence, conducted using the International Violence Against Women Survey, found that $58.8 \%$ of those who report experiencing violence were repeatedly victimised though $71 \%$ of those who experienced intimate partner victimisation did not make a police report. The survey also found that Malays were overrepresented among those who report experiencing violence in the last year (Chan, 2012). This shows that social policies may have a disproportionate impact on Malay/Muslim women going through DV, and that despite knowledge of their existence, remain inadequate solutions to women's DV experiences.

\subsubsection{Religious leadership}

There is a common Western discourse that focuses on misogynistic violence within Muslim communities and teachings which assumes that all Muslim women are oppressed as a result of their religion (Hilsdon \& Rozario, 2006). This has continually placed Muslims as the violent and extreme 'Other' across different societies. Studies in Singapore (Jumblatt, 2017; Ng, 2019) have attempted to show this in relation to how Singapore views Islam as, quoting Lee Kuan Yew himself, distinct and separate. Religious leadership in Singapore is tied to social policy approaches based on how 
Ministries work with religious institutions to address DV (MUIS, 2020). The way the government has trained asatizah (religious teachers) to respond to DV also gives an indication that there is a tendency to see the community as particularly responsible for espousing messages that perpetuate DV.

It is true that international studies have identified the role of religious leaders in shaping the views that women have of their experiences of violence, and their decision-making and help-seeking behaviour (Hassouneh-Phillips, 2001a; Niu and Laidler, 2015). In Singapore, a study on religious leadership and education found how domains of religious education are active spaces where women make sense of religious doctrines, discuss texts, and organise seminars (Jamil, 2016). Although patriarchal interpretations and male supremacy are regularly negotiated and contested by Muslim women, these sites "often upheld the sanctity of subordination to God's will and male authority" (Jamil, 2016).

Another currently unpublished study on Malay/Muslim women's experiences in Singapore looks instead at preventative social policies. It studies a State-approved resource for families: pre-marriage courses for Muslim couples (PMCs). The researchers conducted interviews with 22 Muslim women, revealing that PMC trainers "condoned physical and sexual violence, through the use of religious and cultural ideology". Trainers justified husbands "whipping" their wives to discipline them and taking silence as consent for sex (Beyond The Hijab, Crit Talk, Penawar and WALI, 2021). The study shows the horrific levels of discursive violence within PMCs, and recommends ways forward to improve the PMCs' curriculum and content, suggesting comprehensive discussions on DV, consent, and conflict resolution, and legal rights of parties in a marriage, to cite a few examples. Thus, the researchers proposed that the way forward to end DV requires improvements - even a transformation—of PMCs as a specific social policy.

International studies that reported on interventions through religious leaders found that women asking for help and advice were told to be "patient"; that to stay in the marriage would be either rewarded by Allah or would lead them on their way to jannah (heaven) (Hassouneh-Phillips, 2001a; Ghafournia, 2017). These studies expose the continued weakness in the safety net of support that religious leaders provide, when religious 
leaders spout messages of coping with abuse which are incompatible with women's immediate and long-term needs. While literature has shown that that religious leadership and education are areas of transformation explored in DV policies for Malay/Muslim families, how does the governance of a religious minority, through its patriarchal conservative leadership, produce particular problem representations of DV?

\subsubsection{Cultural competence}

There is little research specific to cultural competence within Singapore's social services for experiences of DV, but some studies can offer relevant clues. A large study encompassing data from Singapore Association against Family Violence (SAFV) from 1997 to 2007, mentioned how cultural stereotypes prevail in social service practices. The paper cites an unpublished study which found that whenever a call on family violence is received by social services, many would assume that the caller is Malay, indicating that there may be a tendency to see Malay men as 'particularly' violent. SAFV's paper determined that cultural competence is necessary to remedy such stereotypes that seep into practice ("Singapore's response of family violence", 2008). Similarly, Tonsing \& Tonsing's (2019) study on South Asian Muslims in Hong Kong suggests that lack of cultural competence (e.g. language differences) within social service mechanisms have contributed to low utilisation of services among the group. This exposes the need for social services to be well-resourced and extremely effective in meeting the emotional and material needs of those experiencing abuse.

At least one attempt has been taken by researchers to measure and broaden the effectiveness of social services for Malay/Muslim women in Singapore. In a study on social work practice in Singapore, Ow \& Saparin (2014) sought to understand helpseeking attitudes of Muslim clients, and did this through a largely Islamic worldview framework. However, the study makes some leaps by implying that clients' understanding and articulation of cultural and religious forces can be taken as a measure of the extent to which Islam impacts their personal lives and decision-making. For instance, the Islamic concepts of qada' and qadar' (destiny and divine foreordainment) were mapped against examples where Malay/Muslim clients who are 
financially struggling "lack...self-motivation and ability to think forward". The authors deduced that this implicates social work in that practitioners have to keep the Islamic worldview in mind, through cultural competence training, when Malay/Muslim clients express similar sentiments.

Social services may thus oppress those experiencing DV further, whether by ignoring the role of culture and religion in their experiences, assuming stereotypes of their racial, ethnic or cultural identity, or reducing their experiences of violence to mere "cultural practices" or religious worldviews. There are other well-documented and tangible structural barriers outside of an ethnic 'culture' or 'religion' that many lowincome families face which may contribute to continued, intergenerational disempowerment, though they may be articulated through more familiar cultural or religious reasonings by the individuals themselves. It is not so easy to dismantle cultural belief systems from generations of structural oppression, colonialism and discrimination faced by Malays living in poverty. The latter might equally have power over feelings of disempowerment or distrust of nation-State systems that many lowincome families have, but might not be verbalised as often. Using 'culture' or religion as a catch-all for the struggles that Malay/Muslims face risks being a reductive, marginalising way of analysing social problems, essentialising or misrepresenting culture as having a particular 'influential explanatory power' (Sokoloff \& Dupont, 2005; Thiara \& Gill, 2009).

To counter this, solutions like "cultural competence" and "cultural sensitivity" have been explored by many scholars and advocates as a solution to supporting ethnic minority women, but the concept of cultural competence is far from universal. In fact, the aforementioned study by Ow and Saparin (2014) found that an understanding of the Islamic worldview by social workers is a form of cultural competence. Cultural competence has been described also as "not a one-time event", the use of a common language, adapting to customs and preferences and focusing on individual needs and concerns (Purnell et al., 2012). Other studies have examined how DV within Indigenous populations has been responded to with "retraditionalisation"-granting self-determination to the Indigenous population so they can respond to DV according to their own values and response systems (Valencia-Weber \& Zuni, 1995); others have argued that this approach assumes the existence of a single authentic Indigenous 
community, ignoring the interplay of social values and structural realities within the population itself (Larsen \& Peterson, 2001). In Singapore, this was after all the idea behind the constitutional recognition of Malays as the Indigenous population, which gave way to a more heavy-handed approach to governing the community, under the guise of providing it "autonomy".

Thiara \& Gill (2009) argue for an approach that reinforces the power of gender equality and egalitarianism within cultural and religious groups, where feminist values of choice, agency and human rights are not in opposition to culture or religion, but reconciled with community norms. It can be assumed that policy interventions following this strategy would not fall into the trap of cultural essentialism, which assumes that culture is inherent and unchanging across every member within a cultural group. Another model that was created to challenge authoritarian and patriarchal DV, and the intersections with race, class, religion and other identities is the Cultural Context Model (CCM), which utilises the role of cultural consultants within a particular cultural group to counter harmful teachings and customs of domination, and change cultural systems of values beyond an individual family unit (Almeida \& Lockard, 2005). According to CCM, where dominant remedies fail is in how it locates DV "within the interior of family and individual psyche". CCM counters this by creating opportunities for women to be connected to a coalition of other women to empower her and male allies to challenge male privilege themselves. Other scholars still challenge surface-level 'cultural competence' frameworks, claiming that supporting minorities is "not simply an issue of providing multicultural services to survivors of violence" as these can easily ignore the role of colonialism, racism and economic oppression in addressing DV (Smith, 2005)

Considering the historical and socioeconomic position of the Malay/Muslim population in Singapore that have defined their lives deeply, these approaches promise a radical and imaginative dismantling of current social policies, systems of oppression and and practices. However it is imagined though, an intersectional approach to 'cultural competence' would need to also come with thorough knowledge of structural realities. 


\subsubsection{Public education}

Researchers have previously pointed to the significant role of educational awareness campaigns in DV prevention (Wolfe and Jaffe, 1999; Keller et al., 2010). For instance, the public health model considers awareness campaigns as part of "primary prevention"9 which aim to introduce new values that are incompatible with violent behaviour (Wolfe and Jaffe, 1999). Awareness campaigns and other primary prevention efforts can also occur simultaneously with secondary prevention (crisis responses after violence has occurred) and tertiary prevention (longer-term response after violence has occurred) in order to make systemic transformations (Ministry of Women's Affairs NZ, 2013).

The consequence of not being sufficiently sensitised to ethnic minorities' social and material barriers in the implementation of education campaigns is that their problems are not publicly seen and problematised (Point Research Ltd, 2010; Keller et al., 2010). Awareness campaigns therefore contribute to how widely a social problem such as DV is publicly condemned. This may be referred to as the "naming" of DV, which identifies what is made visible-and, inversely, invisible -in policy and practice, including "whose experience is named and whose is not" (Murray \& Powell, 2009).

Educational campaigns also allow women themselves to name their experiences of DV. A report examining Singapore's response to DV found that awareness campaigns following changes to the Women's Charter resulted in callers to social services having stronger ability to articulate their problems with DV ("Singapore's response of family violence", 2008). Though the study extensively recommended strong social policy responses to DV, the intersectionality of ethnic minority women's experiences was missing in its analysis. Intersectionality must be as much a part of public education discourse.

I also note that the work Singapore has done on public education is restricted to "awareness" of violence, and at best, "early intervention" efforts. This can be observed

\footnotetext{
${ }^{9}$ Wolfe \& Jaffe (1999) describe primary prevention as strategies that "can introduce...new values, thinking processes, and relationship skills that are incompatible with violence and that promote healthy, nonviolent relationships" (p.136).
} 
in campaigns like MSF's Break the Silence, docudramas for the Malay population, educational comic books for primary school children and social sector-led education campaigns. These efforts revolve around educating individuals about forms of violence, services and help-seeking options (Teoh, 2020). They ultimately look at DV as a crisis that is already happening, albeit at an "early" stage, working to nip it in the bud without little commitment to identifying its roots (Goh, 2009).

Another study in Singapore identified that solutions lie in education through interagency networking, greater police training and responses, offender programmes and training DV workers (Briggs et al., 2001). Once again, the idea of prevention is limited to early intervention, and points to "fine tuning" State solutions such as Protection Orders and expanding police capacity by building specialist units. The State itself has over the years continued to work along similar lines of "prevention", recently through interagency task forces and a national DV hotline (Cara Wong, 2020). Questioning the limits of these approaches challenges advocates to think beyond State public education, social services and criminal justice solutions that have curbed our ability to think of strategies of resistance and prevention that would create lasting social change beyond these realms.

\subsection{Analytical tool: Why study problematisations?}

The literature reviewed so far has provided a wealth of perspectives. The theoretical framework of intersectionality is a convincingly robust method of studying the effects of DV social policy on a multiply-marginalised population. It allows for a consideration of historical factors such as colonial oppression, structural factors such as racism and economic marginalisation, and the racial, cultural, and religious identities that those experiencing DV occupy. The examination of international and Singapore-based research then establishes the need for an intersectional approach, given how Muslim women's experiences of DV are intricately woven with societal pressures, racial and religious marginality and material inadequacies. Finally, the study of the common social policy approaches undertaken or attempted internationally and by Singapore allowed an understanding of how previous scholars have identified policy inadequacies. 
The review begs several questions that led to defining my own research question. If social policies which are presented as solutions to end DV actually work, why do many women still experience it? Why, if awareness of social services and resources have increased or improved in Singapore, is the problem still largely underreported? Why, if criminal justice systems are presented as solutions to the problem and the Women's Charter adequately protect families from DV, do women face challenges with the system? Too little research has been done on questioning the taken-for-granted policies that Singapore upholds in DV prevention and intervention. The policy analysis tool, "What is the problem represented to be?" (WPR) (Bacchi \& Goodwin, 2016) is an opportunity to analyse 'texts' to dissect the problem that is represented as DV in social policy, how these representations have impacted discourses, and how those have in turn shaped policy solutions.

Scholars have studied problematisations of domestic violence using Bacchi's WPR tool and gleaned significant insights on where social policies have fallen short. An Australian study looking at the problematisations of domestic/family violence gave an example of how public education on DV plays a role in framing the problem (Murray \& Powell 2009). It cited a campaign that aimed to educate youth about respectful relationships against its replacement campaign, which highlighted only criminal physical and sexual violence, thus muting representations of emotional abuse. The authors concluded that the contested representations of DV have influenced policy approaches, determining who receives funded services, what prevention of DV looks like, and who is 'protected' from DV and from whom. Another example of how the study of problem representations can be valuable in this field is found in a Canadian DV policy paper, which used the lens of women's resistance to analyse anti-violence against women policies (Paterson, 2009). The study found that resistance against DV is not uniform, yet policy-makers have created a 'one size fits all' system that dangerously alienates many women.

WPR is a post-structuralist perspective of policy analysis and demands that we challenge a simple conventional assumption: that policies are reactive, created to solve problems that are waiting to be discovered outside of the policy realm. Instead, we need to be able to interrogate how policies are productive: producing problem 
representations. From there the tool challenges us to see policy itself as a cultural and social construction, rooted in history, creating effects and consequences accordingly.

The tool argues that policies and policy-makers are not charged with objectivity and rationality, and encourages us to probe at the assumptions policy-makers and policy researchers make about social relations, which underpin the policies they develop. The tool acts as a lever to work backwards, to critically interrogate policy and problem representations, based on a list of seven questions and steps. These questions allow the scrutinisation of policies that uphold these problem representations, and how they produce particular kinds of 'governable' subjects (e.g. perpetrators, victims, bystanders). In other words, "What we propose to do about something reveals what we think needs to change and hence what we think the 'problem' is" (Bacchi \& Goodwin, 2016).

To clarify, the study of these policy representations is not, according to Bacchi, about the impression policy-makers have of a problem, nor is it deliberate or malicious distortion of a problem. Rather, the focus is upon the presuppositions and assumptions evident in their representations of the problem. A WPR approach treats interviews with policy professionals and service providers as texts that represent a policy problem. Such an analysis does not claim to uncover the subjective reality or experience of the interviewees, nor the meaning of the policy in the heads of interviewees. WPR will guide an examination of the unexamined and what is largely assumed to be 'true' within this context, that means dissecting how DV is framed in policy texts; identifying the 'silences' in DV policy; diving into the effects of the problem representation; and as a step towards self-reflexivity, facilitating the interrogation of this study's initial assumptions of the problem.

All the studies I have reviewed, together with Bacchi's argument for analysis of problem representations within policy, offer a persuasive ground for my study to examine how Singapore's own policy texts have problematised DV. My focus when identifying some of these problematisations will be on how it has resulted in discourses that limit or frame the solutions available to Malay/Muslim women going through DV. Thus, overall, my overarching research question inquires into what other scholars 
working on DV in Singapore have not fully asked: what exactly, according to Singapore's social policies, is the problem of DV within the Malay/Muslim population? 


\section{CHAPTER 4. METHODOLOGY}

In the previous chapter, I presented the value of approaching a study on DV policy through the study of problem representations, and argued for the elemental framework of structural intersectionality to be used to do justice to Malay/Muslim women's experiences. Here, I describe the social constructivist research paradigm I have chosen, and go into further detail on how my study was conducted over the course of a year between March 2020 to April 2021.

\subsection{Selection of 'texts'}

The aim of this study is to understand the discourses on DV resulting from Singaporean State social policies, and a major sector that contributes to such discourse is the social and public sector. For this study, I chose to conduct interviews with professionals who have interacted and worked with families going through DV. These include social service workers/counsellors, victim advocates, lawyers who have provided aid to women going through DV, and researchers working on DV policy. These professionals are well-positioned to contribute to this study as, due to their line of work, the discourses they produce and reproduce have a direct effect on the problematisation of DV. They straddle the position of having both an ear to the ground and a direct line of contact with State mechanisms to bear witness to and share interpretations about. The problematisations they shared come from their work with women who, for the most part, have sought support through social service agencies (including non-government service organisations) or government institutions.

Given that experiences of DV is an incredibly sensitive topic, the choice to not interview women who have gone through DV was a significant ethical consideration and was done deliberately to avoid potential re-traumatisation. There has been plenty written on the DV experiences of Malay/Muslim women that could be studied as text and that fulfils the needs of this study, without needing women to revisit their traumatic pasts in order to understand their shape of their experiences. It was also a more realistic and ethical endeavour considering the duration and scope of this study. This choice means that voices of women who have gone through DV were not captured through 
interviews, but rather relayed through professionals' representations of their experiences. This is however, consistent with my study of how professionals interacting with those experiencing DV have constructed and understood the problem of DV.

This also means that problematisations by women who have not sought support through social services or similarly formal avenues are missing. I attempted to rectify this gap by also looking into first-hand accounts by Malay/Muslim women that are publicly available, and inquiring through my participants' interviews about other avenues for support that women reported going through, and the information they have relayed.

The interviews, alongside the first-hand accounts, are viewed using the WPR method as 'texts' to be analysed for their problem representations. The tool, after all, allows for a broad definition of 'texts' which offer solutions to policy problems, and is not just limited to formal policy documents or laws. Overall, the texts I analysed are summarised

below:

- interviews with participants

- accounts shared on Beyond the Hijab (BTH), an online platform for Muslim women in Singapore to share their stories of religion and gender

- accounts in publications such as Penawar, a feminist zine for Muslim women, and Growing Up Perempuan, a collection of stories by Muslim women

- accounts shared on End Domestic Violence, a public education campaign on DV

- accounts from Violence \& Discrimination against LBTQ Women in Singapore published by Sayoni, an advocacy group for queer women

- publicly available information on DV and sources of support and justice e.g. government and social service websites, Ministers' quotes and speeches

- religious education materials e.g. Friday prayer khutbah transcripts by MUIS

- public education campaigns e.g. run by MSF, family violence specialists and NGOs

- media articles

- laws and policies 
I originally planned to fly to Singapore to conduct research interviews over two months. However, the initiation of my programme coincided with implementation of travel restrictions due to the COVID-19 pandemic. Interviews were held over Zoom and email follow-ups instead. Over the COVID lockdown, the social sector in Singapore was overstretched with increased demand for support. More DV cases were reported (lau, 2020). Some organisations publicised their reasonable prioritisation of workload and were not accepting student interviews during this period. As a result, response rates to participate in my study may have been affected. About 50 organisations and individuals were contacted, and the final study conducted, through semi-structured qualitative interviews, data from seven participants who have directly and professionally worked with Malay/Muslim women who have gone through DV.

I chose to conduct qualitative research due to the complexities involved in the analysis of policy texts and problem representations. A qualitative research method lends itself well to observe the "changing and shifting phenomena" of DV, and allows me to continually maintain a consideration for the intersecting political, social, economic, cultural and historical contexts that the research topic exists within (Richards \& Morse, 2007 , p. 30). Given that my analysis includes an unpacking of how the problem of DV has been understood, including by examining how participants' process "the meanings they put" (Richards \& Morse, 2007, p. 30) on the problem of DV, a qualitative method is more suitable than a quantitative one.

Although the sample size is small, each interview extensively and deeply covered participants' experiences and personal perspectives on the research question. Interviews ran between one and one and a half hours. Participants were professionally diverse, having worked with women and families at different stages of help-seeking, and advocating for protection against DV in different ways.

\subsection{Sampling method \& interview format}

A combination of purposive sampling and snowball sampling methods was used to identify participants, based on my knowledge and contacts within social service and advocacy organisations in Singapore. Purposive sampling was chosen as it allows for 
in-depth studies where statistical representativeness is not claimed. This sampling technique uses "special knowledge to intentionally "hand pick" elements for a sample" (Ruane, 2016, p. 248). Although such a sampling method comes with its own risks, it is cost- and time-effective, given the tight boundaries of this study. To a smaller extent, a snowball sampling method was also adopted throughout the fieldwork, which allowed me to seek research participants through referrals and social networks (Ruane, 2016, p. 247).

As part of the recruitment process, I put together a list of NGOs, social service organisations, shelters and domestic violence-related groups and public leaders, relying on online research and my own knowledge of those who work with women experiencing DV, social services and NGOs in Singapore. Potential participants were all contacted via email, with an information sheet that gave an overall picture of the intended study. Though details on the study have changed and been refined since the interviews were conducted, the information sheet and summary given at interviews spoke of the general direction of this thesis, which is on domestic violence social policy and its impact on the Malay/Muslim population.

Interviewees were also informed that I was formerly employed at the feminist advocacy group, AWARE, and that the research was not related to AWARE in any capacity. They were aware of my identity as a Malay/Muslim Singaporean. In a few cases, I had former professional and friendly relationships with participants through work in the sector. This became unavoidable due to the nature of the industry and the length of time I was in it. Throughout these interviews, I made sure to clarify that as they went through the interview process to regard my positionality as primarily a researcher, rather than a former colleague. However, given the social constructivist approach I was adopting, being an 'objective' researcher was not the goal for this study nor was it to approach the interviews through a 'clean slate' of knowledge. Rather as a researcher, I considered it central to this study how my own social constructions of the topic have been mediated heavily by my positionality, as someone who is Malay/Muslim, who has worked in the sector, who is a former colleague to some research participants, and who is now a researcher. These realities are not muted in my approach to data-making and analysis. My chosen social constructivist approach and positionality will be unpacked later in this chapter. 
Interviews were held over Zoom; this 'fieldwork' took place over four months between May and August 2020. Interview participants were selected based on having professional experiences with enough Malay/Muslim women who have experienced DV to draw reasonable patterns based on their own conceptualisation of the problem. Interviews were conducted largely in English, with the occasional use of Malay or Singlish (colloquial Singaporean English), which I have translated wherever quotes are used in this thesis. Interviewees who participated in the study were given consent forms to fill out and sign and/or gave verbal consent through a recorded video. Their anonymity and the confidential nature of the study was assured throughout, and they were not made aware of any other participants' involvement. In return for their time and contributions, research participants were offered koha ${ }^{10}$ in the form of a voucher, though most declined them. Some general information on interviewees (pseudonyms are used) can be found below.

\begin{tabular}{|l|l|l|}
\hline Respondent & Profession & Affiliated organisation or sector \\
\hline Yati & Counsellor & Social service organisation \\
\hline Irfan & Counsellor & Social service organisation \\
\hline Maya & Case worker & Social service organisation (NGO) \\
\hline Bel & Case worker & Social service organisation (NGO) \\
\hline Farah & Legal professional & Legal industry \\
\hline Sofia & Researcher & Public service \\
\hline Alia & Case worker & Social service organisation (NGO) \\
\hline
\end{tabular}

In my interviews, I asked participants about the challenges and experiences of Malay/Muslim women who go through DV, the practices and policies their organisations abide by, their perspectives on training and "cultural competence", and recommendations for social policy. In return, they generously shared their perspectives, personal and professional understandings, patterns they have seen, and cited examples of cases they have seen.

10 Token of appreciation 
Given that the study was conducted over the COVID-19 lockdown period, I had initially been concerned about conducting Zoom instead of face-to-face interviews, which have contributed to strong qualitative studies. With Zoom, interviews risked being pixelated, fuzzy and distant. However, although the candid manners and non-verbal nuances of face-to-face conversations might have been lost, the interviews themselves were rich enough in detail and perspectives to substantively aid the analysis of this study.

\subsection{A social constructivist approach}

I approached this study with a social constructivist approach for various reasons. A constructivist approach in social science research such as this one makes room for the study of subjectivity and relativism in participants' experiences (Lincoln \& Guba, 2013). Emerging from this are multiple perceptions (or constructions) of social problems, and solutions to them. This approach stands in contrast with more positivist approaches, which are ontologically driven by a search for a single 'truth'.

Thus, my research is not an ethnographic study that claims to reveal the realities of Malay/Muslim women's 'true experiences', but a study of how multiple discourses of DV, and the constructions that prop them up, govern people's lives. In my analysis and interpretation of the selected texts, I subvert the dominating problem representations found in State discourses. In doing so, I analyse how people who work in the field of DV - and have regular interactions and influential force over Malay/Muslim womenarticulate the problems and solutions surrounding DV. While I do make use of some first-person accounts alongside interview material, these are narratives told by people from a reflective state (i.e. they are verbalising their perceptions and understanding of their experiences), and subject to the social construction of their experiences as well, mediated by the dominant discourses that have had a hand in shaping the articulation of 'experiences'. Thus, my thesis uncovers the multiple discourses-and the silences within them-surrounding DV and their effects on Malay/Muslim women's lives.

With this research paradigm, it is understood that ideas such as 'domestic violence', and 'culture' are matters of definition and convention (Lincoln \& Guba, 2013). These 
concepts will have varying interpretations across the spectrum, according to who is answering the question. Still, they determine how reality is shaped and the power they have over people's lived experiences is all-encompassing. Social policy is not neutral as a result, and these constructions form the basis of the texts I study. It is also crucial to view policies not as more 'rational' constructions of the problem, but simply dominant ones with institutional backing. As a researcher, social constructs are also filters through which I interpret how Malay/Muslim women report experiencing DV. A constructivist inquiry shifts according to who knows, and what they know. The discourse that social service workers or researchers produce is mediated by their positionality - their experience, their privileges, the institution they work for, the training they have been provided, the professional values they espouse and the personal experiences that influence their perspectives.

\subsection{Thematic analysis \& WPR}

I chose to use a thematic analysis approach in this thesis. Such an approach allowed me to abstract from the data the major themes that emerged from my findings, by "identifying and describing both implicit and explicit ideas within the data" and allowed me to capture the "complexities of meaning that emerge from the study " (Guest et al., 2012). Moreover, the WPR concept of 'problematisations' and the framework of intersectionality allowed me theoretical tools to support the analytical process, where themes from the data sources were further categorised into what I interpreted as "problematisations". For example, in Chapter Five, I look at how DV experiences are represented by interviewees and in first-hand accounts using a thematic analysis method. Although I do not apply Bacchi's tool here exactly as it was intended (that is, using policy solutions as levers to understand a problem representation), I look for more implicit solutions and problematisations in the discourses of the interviews. In Chapter Six, I use WPR explicitly and as conventionally intended, studying policy solutions and working backwards to uncover the common representations of DV; the results of this analysis are organised according to the different 'solutions'.

The major themes found in Chapters Five and Six were determined both deductively, based on the literature review I conducted, and inductively, where new themes throughout the research writing process materialised from interviews and policy 
documents. Using a qualitative software programme, MAXQDA, I categorised coding sets according to the following broad categories: problematisations of DV experiences, social service experiences and perspectives, problematisations of causes of DV, and problematisations of remedies of DV. Each coded set had subsequent subsets, such as "gender roles in the household", "abuse of religious values", "unmet economic needs (housing/income)", "criminal justice remedies" and "reports of social service experiences". I observed the same themes in data from my interviews, first-person accounts and policy documents that were relevant to the study, and built my analysis and conclusions from there. Due to the limitations of the thesis, my themes focused on answering three main questions that the WPR tool prompts researchers to ask: "What's the problem of DV represented to be in a specific policy or policies?", "what deep-seated presuppositions or assumptions underlie this representation of the problem representation?" and "what is left unproblematic in this problem representation? Where are the silences?".

\subsection{Researcher's positionality}

I come into this work with a multidisciplinary background. I have worked as an antiviolence campaign coordinator, and led communications for policy advocacy at Singapore's oldest feminist advocacy group, AWARE. I have educational training in culture and communications, and my professional work was centred around advocating to support women, including DV survivors, through community education, marketing and media work, events organisation, and campaigning. I also built my network within the non-governmental organisation (NGO) and social services sphere, which I relied on during the data making phase of my research.

Throughout the research process, I was cognisant of my own personal identity and lived experiences. I am biracial and ethnically Malay, grew up Muslim, and DV has been a confronting reality in my family background. Studying the perceived Malay/Muslim experience of DV became an act of learning and unlearning about my personal and my community's experiences, the discourses I was immersed in, and my own assumptions and biases. Moreover, it allowed me to view the connections between public and private violence which prop up DV and delay recovery. 
I found comfort, inspiration and insights from the Indigenous research approaches and thinking articulated in Decolonizing Methodologies (Smith, 1999). The 'Othering' of Indigenous populations happens when society positions scholars, social workers, NGOs, activists or field 'experts' as more knowledgeable of a marginalised group's lived experiences and needs than the group members themselves. Working from the position of being Malay and Muslim means that I am not studying these realities from an outsider's perspective. As a Singaporean Malay-Muslim woman, who would also have to grapple with the effects of any social policy interventions on DV, I am what Smith (1999) describes as an 'insider' Indigenous researcher, immersed in the group's 'issue' as much as tasked with the role of unravelling it. Even as I undertook this study, I found myself having to test and apply my learnings into my personal life. Although my research method does not explicitly work within relevant Indigenous research frameworks, recognising where it is situated has helped me make sense of the significance_and limitations_of my thesis.

Throughout my study, I learned to consistently exercise self-reflexivity, accessibility and decentralisation of knowledge, and 'unlearn' some of the ideas that I have blindly absorbed about research, advocacy, social work and policy-making. Many ideas I had picked up and taken for granted throughout my career in anti-violence advocacy were re-examined and dissected. I found this process harmonised with my research methodology and helped to do some justice to the complex problem of DV and structural violence against my community in Singapore.

\subsection{Research ethics}

I battled with the conundrum of seeking time from a sector already over-stretched as a result of increased demand for social support during the COVID-19 lockdown. Still, participants enthusiastically volunteered their time for the study as they felt strongly about the problem and wanted to see change. I am grateful for their dedication and honesty. The timing of it is also an opportunity to be seized, as COVID-19 has laid bare the inequalities and failures of policy that, like all nations, Singapore, has to reckon with. 
All participants' identities are kept confidential and no information on women or 'clients' were divulged. I will share the findings from this study with both participants and those working in the sector, and invite further conversations with social sector and policy professionals. This study was approved by the Human Ethics Committee at the Victoria University of Wellington, New Zealand, under the application number 0000028464 (see Appendix).

\subsection{Limitations}

Because of the small sample size, the findings in this study cannot be generalised across the entire population. However, it gives us a starting point into imagining more transformative solutions that rely less on the formulaic interventions that have been envisioned by the State. Although this study focuses on a population with marginalised identities, it is still limited in that it explores largely intimate partner relationships between cisgender, mostly heterosexual men and women, within the broad Malay/Muslim population. While attempts were made during the research process to conduct interviews with advocacy groups working with the LGBTQ population, and to find out about reports related to Malay/Muslim LGBTQ experiences of DV, not enough data was gleaned from this segment of the population. A similar theoretical framework can be applied to gender and sexual minorities within the Malay/Muslim or other ethnic minority populations, but this focus was unfortunately excluded from this thesis' analysis. The scope of this study is also regrettably unable to make reasonable deductions about the needs and perspectives of disabled survivors of violence. 


\section{CHAPTER 5. WHAT'S THE PROBLEM? \\ First-person accounts of DV and interviews with participants}

Although this chapter takes some inspiration from the WPR tool in its exploration of the concept of 'problem representations', it does so less strictly than intended by Bacchi, and does not use explicit policy 'solutions' as levers. Rather, I have chosen to first reveal what experiences of DV are represented as, according to participants and first-person accounts of DV. Within these representations, I make some analysis of the implicit solutions to DV that emerge in the discourses, which gives insight in the 'silences' in DV representations.

This chapter summarises participants' and survivors' discourses and representations of DV into four main themes: patriarchal violence and religious authoritarianism; housing and income in a patriarchal household; inadequacies with informal strategies of resistance; and limitations of formal strategies of resistance. Within each section, I analyse and discuss the problematisations according to the knowledge I have gleaned from my literature review using the theoretical framework of intersectionality. The findings from this method of analysis allowed me to deduce policy solutions that I eventually chose to focus on in Chapter Six, where the WPR tool is more conventionally used.

\subsection{Patriarchal violence, religious authoritarianism and the State}

All participants named how gender roles undergird women's experiences of DV. Although not always described as "patriarchal", DV was discussed in terms of expectations of women's subservience, a male head of household, and as a gendered phenomenon.

Two participants explicitly discussed DV as the result of patriarchal structures in families and society, while others spoke about patriarchal misinterpretations of religious text. The latter was described as the use of scripture or Hadiths by men perpetrating DV to dominate, as they believe that their role as disciplinarians and the "head" of households justifies the education and control of women (and children) 
through direct violence. Below is one excerpt that showcases this problem representation:

[Men who use violence are] saying that the victim has actually stepped over the boundary of how a child or a woman should behave...that it's not appropriate. And the most usual way of shutting it down is aggressive behaviour [by the abuser]. Like it seems that they are in the position to actually enforce this rule to...educate or to make sure that the child or spouse behaves in a socially accepted way. .... The most common thing is that they will say that Jannah [heaven] lies at the feet of the husband. (Irfan, counsellor)

Patriarchal violence was sometimes spoken about through religious or cultural beliefs, such as the belief cited above heaven lying at the feet of the husband. Literature has also suggested that the stereotype of ethnic minority men being particularly abusive has emerged in practices and attitudes among social workers in Singapore ("Singapore's response of family violence", 2008). How has this affected the way patriarchal violence in Malay/Muslim families is discussed? The following excerpts give us some clues:

\begin{abstract}
Some of the perpetrators think that Islam allows them right to discipline their wives. They think that as the husbands, they are the head of the family or the leader or the Khalifa. Then they will cite a Hadith, which says that, yeah we can discipline our wives. I don't see this among the Christians, or the Hindus, or the Buddhists, but I see this in Muslim families: this idea, this concept-and I see this a lot in divorce cases—-that my wife is "nushuz $z^{11 "}$ " disobedient]. (Farah, legal professional)
\end{abstract}

Actually, this is not only about Muslim [men]... it's also about the man's position. This patriarchal system...power and control issues [exist] across all cultures, even Chinese men that I've met think that they have rights over their wives. It just makes it a little bit worse with all this misconception of understanding of the religion. (Yati, counsellor)

Although Farah's own experiences did not lead to her seeing a similar pattern among non-Muslims of claiming women's 'disobedience', many studies (Carlson et al., 2003; Davis, 2018) have pointed to similar beliefs among other cultural groups' forms of patriarchal authoritarianism. Yati diverged slightly from Farah's problematisation by discussing how patriarchal beliefs drive DV experiences within other cultural groups too, although the way she phrased her statement ("even Chinese men") indicates that this might be a surprising fact. This could be seen as a correction or reflection of how Muslim men tend to be stereotyped by society as particularly patriarchal.

11 Sometimes spelt 'nusyuz' 
Participants and first-hand accounts discuss how men perpetrating DV exploit women's fear of a punitive God, the consequences of which are reported as immediately impacting women's lives, or as feared to happen in an afterlife. For instance, Alia problematised the reasons which abused women thought, or were told, DV was happening to them. These ranged from "the idea that God is punishing them", or being told by friends or family that their non-conforming choices, such as not wearing the tudung, not doing "ibadah" (worship rituals) properly, being "too Westernised or too sexualised", caused violence, and that it was "ujian (a test) from Allah".

The following excerpts - from a first-person account shared on Beyond The Hijab (subsequently referred to as BTH, an online platform for Muslim women in Singapore to share their stories) and Irfan's interview-contain problem representations show that the violence women face comes in the form of men controlling their movement and limiting their liberty and agency.

When I was young, she shared an experience that I would identify as spiritual abuse. "Aku haramkan kau keluar dari rumah!" [I forbid you from leaving the house]...Later, she felt her knees gave way. She truly believed his curse worked. (Suraya, 2018)

Sometimes it's over the phone saying, "if you come back I will hammer you. You will regret your decision for leaving the house." It's aggressive messages...This is not my personal case but it was discussed in a group supervision setting... where the lady actually doesn't even dare to step out of the house. Like, you know, there's this ruling about you're not allowed to step out of the house unless you have the husband's permission. So she wasn't able to physically step out of the house but she was able to think of other methods like getting the children to go out and seek help. (Irfan, counsellor)

Discussions on obedience to the male head of household, in interviews and accounts, use the term 'nushuz'. This is the legal concept of 'disobedience', which exists in the language of the Administration of Muslim Law Act (AMLA) (AMLA, 2020). A legal website clarifies that "nusyuz means disobedience or failure to abide by the duties and or requirements" and that "many people use the term loosely on their wives", (Syariah Lawyer SG, 2020), implying that it is a term often culturally misused. At least two websites (Asia Law Network, 2017; IRB Law, 2020) state explicitly that nafkah iddah (maintenance support from the husband to the wife during the first three months after a divorce) may be affected in cases where "the Court is satisfied that the wife has been 
disobedient to the husband (nuysuz)" [sic], pointing to a patriarchal understanding of women's role in marriage.

Disobedience, therefore, has a legal backing, intermingled with cultural conceptions. The legal language in AMLA appears to be a gender neutral one, but how the Court determines whether someone has been 'nushuz' is unclear, as is the frequency of how often evidence of nushuz is brought to Court; not much public information can be found. Based on participants' responses, the tangible consequences of accusations of nushuz occur well before anything reaches legal institutions. 'Disobedience' is often wielded against wives, reinforcing patriarchal hierarchy within families.

Abused women's accounts speak to how such patriarchal psychological violence and coercive control leaves a traumatic imprint on their lives, sometimes more than physical violence. The following excerpts from BTH blogs show that there is significant attention placed on the coercive control and non-physical aspects of DV in women's problem representations:

....Many times, as fearful as I was, I really wanted him to hit me. It would be far easier to turn up at a police station or go to my parents with a bruise than to tell them he was a bully. Even though it got physical at the very end, for years, he never laid his hands on me. (Zubair, 2018)

There were no visible bruises that I could see on my mother's body. But I knew that the abuse my father had inflicted was not always physical, but constant emotional and mental abuse. My mother, who was once bubbly and happy, was crying her eyes out every night as my dad would lash out and shout at her. He would call her names and ironically, call her a useless wife. She became quiet and withdrew herself from people. ...Things became worse when she started falling ill and was hospitalised. I overheard her phone conversation with my aunt about my father being angry that she wasn't able to fulfil his 'sexual desires' due to her failing health. Being forced to have intercourse with my father was taking a toll on her body as well. (Leila, 2018)

Authoritarian and patriarchal coercive control also restricts women's freedom of choice, faith, agency and thought. It is reinforced not just through direct violence, but through the messages that bystanders and family members receive and reproduce, becoming values that are passed on intergenerationally.

[Someone I knew] was very upset...because she sent a [message] to a group WhatsApp chat, and the father sent back a text that says, obviously disapproving of her, "We will feel very sad if some of our family members do not reach Jannah [paradise]...so it is our duty to guide them". ...It informs the younger members of the family, who's in charge...who can guide and counsel and advise and that the wrongdoing...is only the women. 
...There's a very famous controversy in Singapore where Berita Harian ${ }^{12}$ carried teachings of an Ustaz...literally it's an article that says how to beat your wife. The religious authority had to step in and correct these kinds of beliefs. Even an entity like the media for the Muslim community thinks it is okay to run an article called how to beat your wife. Even though you correct this perception, it runs deep in the community, the beliefs are there and young girls and women are raised to believe that, that the men are entitled to inflict violence or to discipline their children under the rule of patriarchy.... But this is an interpretation, doesn't have to be the truth. (Maya, case worker)

Maya's problematisation suggests that patriarchal violence is not a simple matter of misinterpretations of religious texts, but is given a platform by even State-owned media (Sumartono, 2016), a testament to the prevalence of conviction in such values. Similarly, other participants negotiated with where patriarchal beliefs 'come from'. Representations of patriarchal beliefs ranged from unfortunate cultural misconceptions to manipulation tactics by those perpetrating DV. Yati problematised decontextualised readings of Quranic texts.

It's a very sad thing, I don't think religion really teaches that. Because they are not wrong, there are statements that clearly show that men have power over women. But there's also other things. So if you refer just reading the Quran, you have to really learn deeply, with scholars who have open discussions. If you just learn it on your own, that's where the misconception comes in. (Yati, counsellor)

This problematisation appears to reconcile the acceptance of gender roles with living free from patriarchal DV (perhaps suggesting the possibility of a benevolent form of patriarchy). Sofia shared how egalitarian interpretations are "alternative" readings of religious texts, sometimes running counterintuitively to societal acceptance of gender roles.

One of the biggest challenges is trying to convince people that this is not something new in religion. You look at figh, jurisprudence, and traditional Islamic law, and there are certain interpretations of how things should be, what kind of authority the husband has over the wife. And when you're trying to say that actually, it's about mutual respect, companionship, no one is superior to the other, maybe some people would say, "Are you departing from traditional Islam? Are you trying to sway to a certain agenda? Are you trying to put certain ideas into the community?" For them, [men] have these rights associated with what traditional Islam has come to define the role of a husband. So why are you challenging that? (Sofia, researcher)

As discussed in Chapter Three, international scholars and advocates have found that egalitarian ideas and concepts such as Islamic feminism exist within religious discourse and arenas, which is more in line with the ideas that Sofia puts forth of equal relationships. However, Singapore's restrictive laws and policies on religion and race,

\footnotetext{
12 Mainstream Malay newspaper
} 
a "coercive instrument" of the State which "castrated... alternatives in civil society" (K. Tan, 2017, p.68), and the presence of MUIS, a largely conservative statutory board, may have muzzled attempts for religious discourse to expand into more progressive arenas. The trickle effects of such State mechanisms of control can be seen in how less conservative ideas of "traditional" religion are not quite normalised within some segments of the Muslim population, as Sofia has seen.

Overall, participants problematised patriarchal structures in the household, in one form or another, as being the backbone of DV. The following sections explore how external factors prop up the status quo of the patriarchal structures that trap women in abusive relationships.

\title{
5.2. Housing and income in a patriarchal and capitalist economy
}

It is well established that economic security and housing are major barriers to safety for women facing DV. My participants discussed how women's fears of separation and divorce often centred around resources for their children's wellbeing. For example, Irfan explained:

\begin{abstract}
They may feel that the child needs the father...and the rest of the family members to be around in their growing up years. This is especially true for younger families. For older couples where the children have already grown up, I think they are more willing to explore other means. If let's say the husband no longer supports them and they will have more resources or more alternatives for them to stay with [someone else] and have support. When children are more grown up...I think they'll be bolder to take more steps to end violence, also to get out of the violent relationship." (Irfan, counsellor)
\end{abstract}

Here, it can be seen how women's access to safety hinges on the pressures of being a caregiver. Housing policies (discussed later) show that economic resources are deeply linked to two-parent, nuclear family set ups. Given this reality, the possibilityor threat-of divorce comes with material consequences. As supported by Tabrani (2018), divorce through the talaq (repudiation) system recognised under Muslim personal law, has been used as an abusive tactic, as it gives disproportionate power to men to enact divorce proceedings.

[l've seen] men using the threat of talaq to control the woman, and to make her do as he wishes. So when my clients come to me and say, my husband threatened to divorce me, and I'm very scared that if he divorces me, I will lose a lot of things, I will lose my children. I will lose the house, I will not get my alimony and all that. My advice to them is you don't have to worry 
because the court doesn't look at who starts the divorce or who is at fault. In terms of the financial relief, the children and all that, it has no impact. (Farah, legal professional)

Despite Farah's assurances of the Court systems' fairness, divorce still generally has serious consequences on women's economic security and access to housing ("Single Parents' Housing", 2016). Two participants shared how this tactic is particularly emotionally consequential and stressful for migrant women, whose right to stay in the country is tied to their marriages ("Migrant Wives in Distress", 2020). Participants spoke about economic insecurity as a barrier when considering seeking safety through leaving the relationship.

Particularly for foreign spouses, whose immigration status is tied to their husbands, [divorce] becomes one of one of the main ways in which they are threatened. For Singaporean Muslim women, what happens is that they will threaten [divorce] and they will utter [talaq] but then when you try and start the court process to actually begin the divorce proceedings...they either don't turn up, or they say no, I take back the talaq, it was said when I wasn't in my right mind. It actually works against the women in that it's used as a threat all the time. But when [the women] say okay, let's do it, then it's extremely difficult for them to [get divorced]. (Alia, case worker)

The migrant wife would be dependent on the husband, especially when they have these long term visit pass status. They don't have citizenship or PR status yet. They will be more afraid of seeking divorce or having the husband pronounce the talaq on them because they will be seen at the losing end. Especially if they do not have any more family in their country of origin and they're only dependent on the children and the husband here in Singapore. (Irfan, counsellor)

Divorce also comes with housing difficulties. With Malay/Muslim couples being overrepresented in divorce statistics in Singapore, the population may be disproportionately affected by economic and housing policies ("Marital Status, Marriages and Divorces", 2020). Although Singapore boasts a 90\% home ownership rate due to the government's public housing scheme under HDB (Statista, 2020), Singapore's housing policies are punitive for single parents, including migrant spouses ("Migrant Wives in Distress", 2020). Divorced parents with no full care and control of their children can only purchase under the Singles/Joint Singles Scheme, which requires one to be over the age of 35 years old. An unmarried mother and her children are not recognised as a 'family nucleus' and are directed to contact HDB for their housing circumstances to be dealt with on a "case to case" basis ("Eligibility conditions all schemes", n.d.; 99.co, 2020).

Often, divorced couples will be given a court order to sell their matrimonial home upon divorce. Upon sale of the matrimonial flat, divorced parents with shared care and control of their children are subject to a three-year debarment from buying (during 
which only one party may purchase a subsidised flat) and a thirty-month debarment from renting from HDB (“Single Parents' Housing”, 2016; Ong, 2018). In cases where single mothers can take over the flat, the children have to be under their care and control and they will have to continue with mortgage payments ('Single Parents' Housing", 2016; Isbintara, 2020).

However, more often than not, unemployed or underemployed mothers are unable to buy their ex-husband's share of the mortgage to stay in the matrimonial home, and therefore are left to the rental market - whether this is subsidised through HDB's Public Rental Scheme, or through the private "open market". My interviews, together with previous research, show how the open market is not an affordable route for those with little to no income. It also infamously comes with myriad barriers relating to landlords' discrimination against racial minorities and non-citizens (J. Tan, 2020). Public rental under HDB has its own set of barriers, including the unrealistically low monthly household income cap of $\$ 1500$ ("Eligibility - Public Rental Scheme", n.d.), forcing families into the difficult position of choosing between affordable housing, and a living wage. It is also framed as a temporary measure, a last resort for low-income families who have "no other housing options" (Hoe 2018; "Public Rental Scheme", n.d.). Singapore's "family as the first line of support" principle emerges in HDB's rental policy too: "if any of your children is able to house you in their home or financially able to provide other housing options for you." ("Eligibility - Public Rental Scheme", n.d). There are no known policies that specifically provide housing for those experiencing DV. On top of that, the Ethnic Integration Policy (EIP) imposes racial quotas for resale of HDB flats to be proportionate to Singapore's ethnic make-up ("Ethnic Integration Policy", n.d.). Ethnic minorities therefore have fewer opportunities than the Chinese population to have their application for housing in their preferred estate accepted ("Written Answer", 2021). As stated in an academic article on racism in Singapore by economist Linda Lim (2021), EIP has a ripple effect on the day-to-day lives of ethnic minorities.

[Minorities] face lower demand and thus lower prices for their property. Since housing constitutes the bulk of individual assets in any society, minorities' ability to build and realize wealth is forced lower. Minorities cannot practice or enjoy homophily, the utility of living among others of the same culture, as the majority do...there is also an intangible loss for both minorities and the majority in the lesser ability to experience, even occasionally, "immersion" in the minority's culture "without leaving home". (Lim, 2021) 
Participants reasonably shared in their discussions how housing is overwhelmingly at the forefront of Malay/Muslim women's fears when divorce is considered as an option to safety.

Housing is a big issue in Singapore. [Divorced couples] have to actually divide their matrimonial home. Then where are they going to stay while waiting for a rental flat? If you [purchased and sold] a matrimonial house you are barred for 30 months from [renting] another flat [from HDB]. All these policies make women really think twice. (Yati, counsellor)

One woman that I'm supporting (has) two children, she (left) the house after going through the safety plan...But three years later, she's in a state of flux, a state of uncertainty, especially in housing. Because walking out of the marital home (for her) meant that the man was still staying there. They are literally divorced, and they have a court order for him to release the marital home and divide the sale proceeds..but enforcement is just not there and that's the biggest frustration for her. (Maya, case worker)

Based on the example Maya gave, HDB policies do not guarantee protection of housing even with a court order. With so many barriers to accessing immediate shelter, indirectly, housing policies end up keeping the nuclear patriarchal family unit together. In this way, the State plays a large role in the continuation of DV.

Maya shared how the more expensive open rental market is out of reach for many lowincome women, which leads to them "bunking in with family" and dealing with the social and psychological repercussions of sharing domestic space.

When you don't have housing stability, you don't have job stability, schooling stability for the kids. It's a chain reaction of just being in a state of transition, but never settling. This could take years and years and children grow up in all those years, in this environment of either shelters or rental housing or uncertainty. (Maya, case worker)

Housing instability has been shown to result in interrupted or unstable employment and children's education (“Single Parents' Housing”, 2016). The instability also comes from having to stay with family and friends, a more viable option for women since longterm housing suitable for a divorced mother and her children is not easy to come by on a single or no income. Sofia and Irfan shared their perspectives below:

I vividly remember a conversation that I had with this lady. She was telling me, "at least by staying with my husband, "I have a roof over my head", and it's a big five room flat for her and the children. "I may not be able to get a shelter that is as big and as comfortable as this; I may have to rent a small one room flat, and that will be a shock to my children and myself." The emotional abuse was quite intense - he really made sure that she feels worthless and that she is nothing without him. I said, is that worth it, that you have to put up with all these things, so that you can stay in your current house? And she cried and said yes, that's how I feel about it.

(Sofia, researcher) 
When they have invested an equal amount of money into the house, they fear that they will be short-changed. The process of getting a house for themselves is a long and painful process. But in the last two years it has improved because of feedback that the Ministry gets from practitioners, counsellors and social workers. If you have children it's a bit quicker now to get alternative accommodation before you get more permanent housing [interim rental housing]. (Irfan, case worker)

The interim rental housing $(\mathrm{IRH})$ that Irfan is referring to is a rental scheme by HDB which provides temporary housing. While there has been more 'case-by-case' flexibility by the government in recent years ("Supporting Housing Needs of Unmarried Parents", n.d), it appears to be a band-aid solution to the more structural problem of how housing is conceptualised in Singapore. The problems of the current public rental system remain: research has shown single mothers have reported facing barriers including debarment policies, rejection on the basis of profits from the sale of matrimonial flats, and HDB officers' overreliance on the assumption that divorced mothers can seek shelter with their parents or siblings ("Annex: Single Parents' Housing", 2016), without taking into account overcrowded flats or poor family relationships. It also ignores the stretched resources and realities of many Malay/Muslim women who come from low-income families. Many single mothers also have found how IRH come with extremely poor social environments (including high rates of crime, substance abuse and violence) ("Annex: Single Parents' Housing", 2016).

These experiences are made worse for women going through DV. Participants shared how some women struggle to access economic security through employment because of their husband's controlling tactics. In one woman's account, published on BTH, she wrote about how the psychological abuse she experienced affected her decisionmaking on employment:

\footnotetext{
...He kept delaying me from taking another job, making excuses on the day of interviews so I would miss them. ...Wanting to be a good wife who's available to her husband, I tried to find jobs I could do from home. Notice how he never demanded I quit my job. He just kept repeating stuff and leading me to make decisions aligned with what he wanted, disguised as something "for my own good." (Zubair, 2018)
}

Alia also gave examples of how some women were not able to leave the house for job interviews, and "need to make sure the husband is not (around) or tracking them". But paid work is not always a solution - childcare responsibilities and high cost of 
professional childcare on a single or no income may affect their motivation to access employment. Other practical barriers include women's lower qualifications or career gaps.

They have not been working for a very long time because a lot of them are housewives, or their work has been disrupted by the violence from time to time, meaning that they couldn't advance in their particular jobs. So it's very difficult for them to progress or work in that sense. [...] All the barriers come together, like...insufficient to send their children to affordable childcare means that they are also discouraged from getting a job [to fulfil childcare responsibilities]. And then I guess that ties back to housing, like, well, where am I going to go now? [...] A lot of the women are very resourceful so they will try and do things on the side like sell kuih [Malay traditional cakes], and like one of my clients used to be like tukang jahit [seamstress] without her husband knowing so she would get money secretly lah, because filing for those court orders, there's like a million forms you need to fill out. You often need a lawyer for that. And you will have to do it repetitively. (Alia, case worker)

Alia shared how some women also feel that their ethnic minority status hinders their ability to access financial support. Women's economic insecurity exists within a policy landscape where there are no financial assistance schemes available specifically for those experiencing DV. Financial aid and childcare subsidies are tied to willingness to attain employment (Teo, 2017), which works less well for women whose DV experiences affect their ability to secure stable work. Financial support schemes like MSF's ComCare, are notoriously restrictive and have been criticised as "designed to be a last resort, subject to stringent conditions, and highly targeted" ("Why are you not working?", 2019), consistent with the neoliberal government's view of 'welfare'.

Alia reported how some women face challenges with defaulting maintenance payments from their husbands, which interferes with their economic security. Under AMLA, Muslim women can apply for a Court order against her husband for payment of nafkah (maintenance) (AMLA, 2020). However, this is far from straightforward.

It's a very long-winded process. Each time you will have to file a maintenance order and then let's say your husband pays you for three months, and then he doesn't pay you for month four or five and six, you then have to refile the order. Other than that, unfortunately, there isn't any legal recourse they can take. So that's also another reason why they stay in those marriages. (Alia, case worker)

The following excerpts by participants represent the problem of DV and economic insecurity slightly differently, as triggered or exacerbated by financial issues in the household. 
One major cause can be financial concerns and stressors within the couple. Sometimes it's the inability for the main breadwinner to bring home enough financial resources. The couple loses the ability to actually decide which is the one you need to prioritise, priorities get mixed up. There's also [sometimes] addiction issues mixed in. Whereby the financial resources are already thin and a spouse uses that financial resources to supplement their addiction needs, ignoring all the other aspects of the family like [buying their] children's books, or transport. (Irfan, counsellor)

But there are other kinds of domestic violence...like a teenage son can get violent on the mother as well, and in [one] particular household [I worked with] it's because the father accumulated a lot of debt and there's a lot of stress with moneylenders, [the son] didn't know what to take it out on, he took it on his mother, and really beat his mother up. (Maya, case worker)

These problem representations imply that financial concerns cause men to act out in violence. It is however important to recognise that financial insecurity is one of a complex web of socio-cultural factors that women are confronted with when making decisions about their safety. This complexity is important to articulate. For instance, the following quote by Maya, though intended to show that women have a high 'tolerance' of violence, demonstrates the personal complexities involved in women's decision to sever an abusive relationship:

\begin{abstract}
There is also a case where the wife has been abused for a long time and never thought of reporting or leaving the house. But one day she did report him...the impetus of it was because he was having an affair. ...Sometimes the reporting is not because of the abuse, but because she was disappointed by his behaviour. ...Victims have a very high tolerance for physical violence, including inflicted on the child, which, personally, I cannot come to grips with. But the minute that he cheated on her, and the minute he was shamed publicly because the police came and the neighbours saw, that ended the marriage. Violence is the least of the concerns of these two people. I don't know, maybe physical violence, you put up a barrier, or you can just get over it. And like I said even if it harms the child, they can get over it? As a practitioner I find this strange - that violence alone does not necessarily lead the woman the survivor to actually file for [report/divorce]. Other things come into play. Which usually does-the infidelity, the finances, or society's and public opinion of the family. (Maya, case worker)
\end{abstract}

While some representations like the above suggest irrationality in decision-making, others have chosen to view this as, in fact, "rationally motivated choices in their context of their lived experiences" (Ganapathy, 2008). This counters the assumption that women's decisions to stay in abusive relationships go against common sense. It represents the choices they make as very much rationally chosen as a result of the "social-structural circumstances in which they manifested" (Ganapathy, 2008). Therefore, the choice to stay becomes a reasonable and understandable strategy in a society where safety, housing, livelihood and overall welfare are not public goods, but relies on private capital from nuclear patriarchal families. 
In all, the economic and socio-structural marginality of Malay/Muslim families is as much part of participants' discussion of DV as patriarchal ideology in households and society. Together with patriarchal norms in families and society, as seen in 5.1, housing and economic realities in Singapore are structured in such a way so that women have fewer opportunities to live independently of a patriarchal head of household.

\subsection{Inadequacies with informal strategies of resistance}

\subsubsection{Personal strategies of resistance}

I asked participants how women have reported their negotiations with and resistance to abuse, including through defense and coping mechanisms such as prayer, as found in international studies (Hassouneh-Phillips; 2003; Thiara and Gill, 2009). Resistance has been categorised as: personal strategies (talking, hiding, avoidance, and passive or aggressive defense, contemplating and resisting suicide, challenging the fiscal control of those perpetrating DV); using informal sources of help (contacting family members, neighbours, friends, religious leaders); and using formal sources of help such as the police, social service agencies, and lawyers (Abraham, 2005). Modes of resistance are shaped by the sociocultural and political realities that women battle with, and the public and private resources they can draw upon (Paterson, 2009).

Participants and an online account on BTH point to the personal strategies women have reported using, to seek solace, resist violence, defend themselves or cope in their day-to-day.

For religious groups including Muslim women, they tap onto religion for coping. ...So we do remind them of the coping strategy, sometimes we've even prayed with our clients, because it has helped them to ground, to remind themselves that there could be a better future. (Bel, case worker)

Usually when they pray or do the dhikr [Islamic devotional acts] they are able to be more calm and to think of ways to cope better with the situation at home. If they feel that they need to escape, then they will plan it then. (Irfan, counsellor)

I cannot count the number of times warning bells set off in my head and instead of seeking for professional help, I turned to the praying mat instead. I'm not saying it didn't help. I'm very sure my prayers were answered in the way only God knows and provided great relief amidst the madness. (Zubair, 2018) 
Through their use of prayer, women of faith not only find ways to cope with their emotional responses to abuse, but may also overtly ask - from God_for the abuse to stop, not unlike other methods of resistance that also ask for support. Such methods of rejecting an abusive relationship by those who use immersion into religion or faith is not always recognised by people outside of the faith, but it has come up time and again as a legitimate form of resistance. At the same time, Yati mentioned how this method of using religion defensively is only something that women who are religiously empowered and informed are able to use.

It depends on how much knowledge [the women] have about religion. If they don't have much knowledge usually they will just succumb to [abuse], be quiet about it. If they know more about religion than they would counter... [if] they are brave enough to argue and say, let's check it out with Ustaz and see whether what you say is true. (Yati, counsellor)

It should be emphasised here that although the language of "succumbing" or "giving in" were used in the respondent's interpretations of religion as a tool of coping, it does not necessarily mean that resistance to abuse was completely missing. Women may also use other forms of personal resistance. In one account, a woman wrote about how she resisted abuse from her husband by yelling and asserting herself:

\begin{abstract}
The violence became such a daily occurrence that it was commonplace for me to cover my bruises and wounds before I went to work. ...The worst part of it all was that my children had to witness their mother being beaten up by their own father. Maybe it was seeing the look on their faces that something in me snapped, and I finally decided that enough was enough. When he beat me again, I said, "Stop! You cannot continue like this! If you rasa tak secure [if you feel insecure]...then pergi ROMM [go to the Registry of Muslim Marriages], do whatever you have to do! If you really don't like me right now, ambil pisau cucuk [take a knife and stab me]! I have to go out to work, kasi you makan [give you food], and you do this?!" (Ali, 2018)
\end{abstract}

Another theme that came up is the element of patience ('sabar') which is valued deeply by many women in accounts shared by participants. Yati and Alia described how patience is adopted by women to instil hope in them that "men would change" and that patience will result in good rewards in the afterlife. Sofia shares how the privileging of the religious value of patience can be misused when it comes to dealing with DV.

[A woman going through abuse] asked me, "Can you teach me how to be more patient? What are some of the things that I can do?" I feel that some people look for religious remedies to their problem to help them cope emotionally, to make them emotionally stronger, which has always been for me a painful thing to listen to. Because for me that's not what religion is supposed to help you with. It's to help you to be stronger emotionally in all circumstances but religion is also supposed to help you to get out of that situation that you're in. (Sofia, researcher) 
I fully understand how people, especially people of faith, might stay in abusive marriages. I, for one, kept telling myself "This world is temporary and even if I suffer for the next 70 years of my life, that is nothing compared to an ETERNITY with my Lord who loves me and will make it all worth it." (Zubair, 2018)

The pressure of patience also appears in representations of women's ability to cope with DV.

There's a very conservative view propagated by religion as well. That you should just bear with it, that you shouldn't be impulsive to want to leave the household. There's also the patriarchy that exists....[the idea that] just a few smacks or slaps [should be tolerated]. ... Their role is always tied to family, [if we say] "you deserve to have a fulfilling life"; these are ideas that are not so comfortable with them. (Maya, case worker)

[Recalling a case] She had three children and her husband was extremely abusive, emotionally, physically, sexually, economically. He wouldn't allow her to work...so he would isolate her quite a lot. For the longest time, there was a psychological set of barriers, where you don't want to leave your husband...and you would bear all the abuse, just to keep the peace in the family and to keep the family moving forward. When she realised that this abuse is also extended to children, then she starts to think, whether it's the right thing to move out or not because [she] couldn't accept this. (Bel, case worker)

Patience and forgiveness is taught in different contexts including through religious education and khutbahs (“Trials and Patience”, 2016; 2017; 2018). These messages are not specific to situations of DV, and are used more often in discussions about relationships with loved ones who have "caused hurt", arguments between couples, or patience as a virtue to hold amidst life's trials and tribulations. Such messages can be a huge force of positivity. However, I will explore later on how they are wielded by some members of the religious leadership, and how they have negatively impacted people experiencing DV. Overall, the value of patience is incredibly entrenched in the cultural values system that it has been internalised by women as they struggle with the abuse they face and, as we will later find, overused in responses to women's disclosure of DV.

\subsubsection{Friends and family}

Despite many formal policy documents directing women to seek support for DV from family service centres, participants shared that the social sector is not highly valued by women as sources of support that they can trust, and that friends and family are preferred as first-responders. They also discussed women's weak social support systems which are inadequately equipped to support them or offer advice and solidarity as they cope with the abuse. First-hand accounts published in BTH and 
Penawar, a zine by a support group for Muslim-raised cis-women, trans-women and non-binary individuals, also echo this:

When I wanted to run away from home, [my mother-in-law] said you can't go anywhere without your husband. "You can't step foot in heaven if you don't listen to your husband!" If you're a woman who doesn't listen to your husband and runs away from the house, the sins will be upon you. And l've always been told that what l've been doing, running from my marriage, is wrong. (Penawar, 2018)

When I tried to get my in-laws to speak to him, they said "You know he's always been difficult. We can't talk to him because it will make things worse. You guys are married now and need to find a way to work things out."

I then approached my sister-in-law. She was intelligent, mature and always seemed to have a cool head. "If there was someone who could help me, it would be her," I thought. There is no one way to talk about emotional abuse because it is a whole pattern of behaviours. Which one should I choose? I didn't know but told her of several incidents of him cutting me emotionally or using subtle threats to get his way and she said, "Look, I know he's difficult but those are nothing. Don't be so dramatic." (Zubair, 2018)

Similarly, in a study on experiences of violence among LGBTQ individuals in Singapore, a bisexual woman had a turbulent relationship with her family, who were concerned about "how her sexuality and life dishonoured them in the Malay Muslim community". A lesbian respondent who was abused by her parents was left out of Hari Raya (Eid) gatherings and treated "as if she did not exist" (Sayoni, 2019). These findings suggest that social networks within the ethnic community is an important lever into allowing victims to access support, and can be used as a weapon by abusers to isolate victims further.

Social networks can be both a possibility for support or isolation. Participants and an account on BTH spoke about this isolation through the exploration of the stigma in divorce, which affect the responses women receive when they seek help from family and friends and their reluctance in reaching out for support.

I heard of many clients who are afraid of this stigma of being janda [divorcee]. When you're a divorcee, they always tell me that you can't even speak to someone else's husband, people get very frightened that they're a threat. (Yati, counsellor)

With domestic violence also what is unique is that social isolation is used as a form of dominance over the other person. So, if you have been socially isolated already, your choices are very limited to find a safe place. Then you there's a sense of shame, to have to reach out for help, because of how the community expects you to stay within the relationship. So even if there are people you know — friends, family — you may not want to reach out. (Bel, case worker)

A lot of times they don't want to go and stay with family and friends, because they don't want to have to tell their stories. They don't even know if there'll be believed. And they don't want to be 
a burden to the other person. Because they don't know how long they will stay for. (Alia, case worker)

Because my mother was divorced, my father sees him marrying my mother as "selamatkan kau dari jadi janda" - saving her from the embarrassment of being [divorced]. Therefore, he feels entitled to her and to degrade her. (Suraya, 2018)

Among the examples of weak social support runs a common expectation for women to "keep the family together". The idea of a women's role to 'sacrifice' herself for her family (commonly, for children but also for elderly, more vulnerable adults in the household) was brought up in a variety of ways by interviewees.

For a lot of women too, they always quote their children as the reason why they stay on in the marriages. They feel that it's also their responsibility or like part of a maternal instinct to protect their children and and sacrificing what you think is for the children's interest, over sometimes their personal safety as well. (Sofia, researcher)

Sometimes parents tend to tell the child, their daughters to just stay put in the marriage. They are scared that, let's say if the marriage doesn't work out, who wants to support the wife or support the kids? (Irfan, counsellor)

Thus, poor social support does not simply happen because of stigma surrounding "broken marriages" or divorce, but also material constraints. When these responses are viewed within the context of housing and economic conditions, it can be assumed that under-resourced, weakened and materially poorer communities are more deeply and directly affected by divorce. It is not unreasonable to recognise family and friends' unhelpful advice for women to work through abusive relationships as a direct response to these material constraints. Much of the pressure to remain married and to support children and families cannot be separated from the way that women are unable to be economically independent without their spouse. Psychological pressure and advice from social networks also reproduce patriarchal norms by prioritising others' needs over women experiencing DV.

A few participants represented family interventions as another form of interference that would take away women's agency.

Something that I've also heard is that they would not want to reach out to other family members because the family members then think that they have the right to intervene in that situation. They take over, they take charge of intervention which may or may not be safe for the family. It can also retrigger the abuser to actually act even more violently if other people within the family know about this. (Bel, case worker) 
When they're lucky then they do confide in some family members but in our experience there have been very few family members and friends that have actually encouraged the survivors to get out. A lot of times the first responses of family and friends have also been about looking at what the survivor may have done wrong or [how they are] insufficient. (Alia, case worker)

Alia shared how, in one case, a man's reputation for being a good and religious man meant that the woman experiencing DV was not believed: "Her extended family told her that he's such an upstanding Muslim man, 'we don't believe your allegations and look at the way that you dress, you're way to modern, you're not pleasing your husband in the right way'." Based on these representations, the decision to avoid disclosing DV to family members can be seen as a form of resistance that women adopt, an equally rational decision that works as self-preservation and to regain autonomy.

Overall, Singapore's 'family as the first line of defence' principle stands in contrast to these problem representations. Responses that women receive from friends and family instead reflect the hegemonic patriarchal values that cause DV, many of which can be seen in the socio-cultural structures in society and the social isolation that many women experience or are threatened with. The ways in which Malay/Muslim women are able -or rather, not able - to gather private and public resources to resist their abuse ultimately decide for them whether they are kept within abusive relationships.

\subsubsection{Informal strategies of resistance}

\subsubsection{Asatizah and religious leadership}

Participants reveal some evidence of women's trust in religious institutions and leaders, although they also cast doubt on the legitimacy of the advice women receive. They claim that some religious authorities may contribute to the social pressure that privileges patience, sacrifice and obedience compelling many women to stay in abusive relationships. Yati explained that the support and advice given by asatizah "depends on where they learn the religion", though she also said that when some women "go to the mosque" to seek help, they would be directed to FSCs, PPIS or AMP "to see counsellors, social workers."

However, others revealed that it is not often as straightforward, and that advice provided by asatizah can be damaging to the psyche of those experiencing DV. Most 
of this results in advice to women to be patient or forgiving (repeating the more general messages put out by the Islamic religious council) ("The act of forgiving", 2018).

It's concerning when friends or religious leaders, and those who are not trained in family violence, tend to advise the wife to be patient, to seek refuge in God, and forget to actually help improve their situation. (Irfan, counsellor)

Not only in Muslim communities but within other religious communities as well, forgiveness is an option given to survivors. What I find problematic about this is that that's the only option given to them. It's not wrong to give that as an option because it could help people to cope as well. But you're limiting the options. I think religious spaces, being inherently institutions that are trying to keep families together, might provide options that means the family will stay together. (Bel, case worker)

In one online account from BTH, the author shares how her mother found religious practices comforting, but observed how many preachers would tout values of subservience, counter to what women need when struggling with a disempowering abusive relationship.

Religion became a solace for [my mother] turned to religion for comfort. ...As I grew older, I realised how turning to religion as a coping mechanism could also get problematic. Religious preachers would preach about how wives would end up in hell for not being 'good' wives. ...There was a lot of religious manipulation and guilt enforced on the woman, a lot of narration preached blamed women for failed marriages, yet very few gave support for those trying to escape abusive marriages. (Leila, 2018)

In situations where women reach out to faith-based organisations, Irfan shared how there is an expectation that the organisation be able to speak as a religious authority:

Sometimes they will assume that we are all trained asatizah. Which we are not. We need to explain to them that it's sometimes (the problem is) not really a religious method, [it is the] communication between husband and wife. I got this term from somewhere: you cannot fiqh ${ }^{13}$ your marriage. That means you just cannot use the rules of figh in Islam to actually solve your marital issues or stop violence in your family. (Irfan, counsellor)

The desire to use religion as a remedy is not contentious in and of itself. It is damaging when it is strengthened by how religious leaders, as respected figures, use their power to prioritise the needs of a "family" over the needs of individuals. A couple of participants of this study briefly spoke about how religious education and trained asatizah could support women experiencing DV.

It'd be very good if the mosque could start to look into it, providing psychoeducation, perhaps through Friday prayers khutbah...because we have so many mosques. And you're [speaking to mostly] men. The ustaz could give a message, how Islam really views family violence, how

13 The theory or philosophy of Islamic law. 
Islam actually say that men should protect woman instead of abusing them. Likewise, you should use it on your other platforms, sometimes they have weekly classes for women, so somebody can just come in like a counsellor... [educate] them on [forms of violence] besides just physical violence. I feel that the body that should start this is MUIS. (Yati, counsellor)

There has been improvement, to be fair. Sometimes the khutbah Jumaat [Friday prayer sermons], and I see this recently, they talk about non-violence, peace, love and affection towards your wife. There's a little bit of this, but more can be done. Because khutbah Jumaat, banyak lah orang dengar [many people listen to them], so it's a good platform. When [people] go for religious lectures, they must emphasise more of this instead of the rituals. There are a lot of avenues for public education. (Farah, legal professional)

Participants gave feedback that public education by MUIS has not been adequate or consistent (despite some attempts at addressing DV through issuance of khutbah), and that public education does not necessarily trickle to asatizah's teachings in classes, where asatizah may teach "different things". Previous studies show how premarriage courses have been known to perpetuate discursive violence and women's subservience to men (Suratman, 2011; Beyond The Hijab, Crit Talk, Penawar and WALI, 2021).

Based on these findings, participants found that religious leadership is used as a major avenue of outreach for women, but are inadequately sensitised to supporting women going through DV. Some participants also believe that MUIS can take on a more decisive role in leading the change to challenge patriarchal structures within the family. Taking on this task, however, would require a critical questioning of the ways that MUIS itself functions within and as a patriarchal and authoritative institution.

\subsection{Limitations of formal strategies of resistance}

\subsubsection{Police, PPOs and criminal justice system}

Recognising DV as a criminal matter is what many feminists have pushed for globally, in order to demystify a matter often conceived as a "private, family issue". As a result, where participants spoke of the role of the criminal justice system as a remedy, some discussed the lack of both powers and sensitivity that the police have in terms of intervening in situations of DV, and the limitations of the functional powers of a Personal Protection Order (PPO). 
The police still see this as a domestic issue. Even if you're talking about physical violence, police are very reluctant to go in and intervene and not well equipped, or trained. Even I would call the police also and see them flounder in having to tackle domestic issues, not even violence, just disputes or anything. (Maya, case worker)

I think there's a lot that needs to be done within the criminal justice system to make sure that police are sensitive to the understanding of family violence, and understanding the power dynamics within these relationships. It's not enough for police to look at family violence just from a criminal perspective but also from a perspective where social intervention is required within those cases. (Bel, case worker)

Participants also spoke about how women fear that PPO applications and involving the police would lead to "husbands divorcing them", showing that there might be a tendency to view criminal justice solutions as destructive to households, particularly under-resourced, minority households that have come to rely on nuclear family set ups. When asked about the experiences of Malay/Muslim women with the policing DV, Bel said:

I've never seen outright discrimination because somebody is from the Muslim community. I think experiences of Muslim women, in my experience, are as good or as bad as any other woman from any other community. There's a lot that needs to be done within the criminal justice system to make sure that police are sensitive to the understanding of violence family violence, first of all, then the understanding of the power dynamics within these relationships. (Bel, case worker)

However "discrimination" cannot be simplistically recognised as unfair or unequal treatment against any particular ethnic or minority group. To recognise systemic discrimination, one has to also be conscious of the existing social stratification of society. After all, policing practices reproduce "the social divisions of class, race, gender, and sexuality" in greater Singapore society (Ganapathy, 2008). Consider the fact that Malay and Indian minorities are incarcerated at disproportionate rates within the Singapore Prison System, and how Malay and Indian ethnic minorities are disproportionately represented in the re-offending population and "are significantly less likely to achieve reintegration than those who belong to the Chinese majority" (Ganapathy, 2015). Policing is therefore not free from the clutches of social stratification and the continued oppression of minority groups, though its manifestations are not often made visible to social sector practitioners.

Participants then shared about the effects of police intervention in cases of DV:

The role of the police is to maintain the peace; so their role is advisory. They will try and make sure that the struggle, the scuffle, the noise, all this stops, and they will advise the victim to seek medical help, and get a PPO.... If they come and there is stabbing, there's a knife wound 
and there's blood, that becomes a criminal issue, then they can arrest. (Farah, legal professional)

Even people with PPO...the police sometimes get a bit confused at what point that they could consider it a breach [of PPO]. So that disempowers women. If you have an experience that you call the police once and nothing is being done and your husband is still at home, the fear will escalate. So the next time we want to call the police they will think twice. Usually the perpetrator will be, "You think the police are going to do something?" I also have seen that the men get asked to leave the house and are sent away. But after two days, mostly they return home. (Yati, counsellor)

Usually the first few times, they will be more willing to [call the police] but after they maybe their experiences then they see that the police can't really do anything much about family disputes and if the violence isn't happening right in front of the eyes, they can't do anything to the husband...they tend to be more sceptical towards their help later on. (Irfan, counsellor)

The quotes above show that police intervention is not neutral, even if nothing comes out of it. Instead, they sometimes have an explicitly disempowering effect on women seeking help. It is therefore reasonable to believe that policing practices for Malay/Muslim women, who overall may have less resources, support systems and economic, cultural and social capital, would act in accordance with the current social system to reinforce their marginalised status. In fact, Alia mentioned one specific case where it a woman's perceived religious identity was brought into question by police:

[In the case of sexual violence by acquaintances, friends or intimate partners] There have been comments of police insensitivity as well, [like], "As a Muslim woman, you should be more careful. Why did you go clubbing? Why do you go drinking? This is against your culture, against your religion." (Alia, case worker)

Other instances of "discrimination" that occur may not be so obvious. For instance, participants shared how PPO applications require submission of evidence of abuse, for example in the form of medical reports to prove physical harm or incriminating text messages. This may make it more difficult for those whose experiences of religious coercive control are not as easily evidenced in an application. While PPO applications themselves do not cost much (a nominal fee of SGD\$1), the emotional, bureaucratic and labour costs can be high. PPOs are not a guarantee, demanding in terms of paperwork, and often have long processing times, may be tricky to navigate for the layperson, which discourages women and sometimes puts a strain on resources.

Structurally things like police reporting, the length and the laboriousness of the process deters clients and also applications for things like PPO. It's just a lot of paperwork, and very difficult for a client to actually do all of that on their own to understand what it means to write an affidavit to represent themselves. From the application date to you going for trial is about six months, and then you may not be granted the PPO. There's a lot of frustration about how processes that should be protecting them take a very long time. (Alia, case worker) 
They really do not know what goes through in a PPO. So they have that fear of going to the court. What do I need to do? What if I don't have documents like medical reports or I didn't make police report all that? (Yati, counsellor)

How do these structural barriers impact Malay/Muslim women who choose to report their experiences to the police? Alia's experience working with one woman illustrates the degree of challenges that Malay/Muslim women may face when attempting to seek justice through the State's legal systems:

\begin{abstract}
She had been married for 10 years, then, and it was extremely abusive throughout. Her husband is very well connected to Muslim organisations like MUIS and PPIS. She had to bear with dealing with this idea that she is not a good enough Muslim wife and her husband, who has carefully managed to pay Zakat [alms giving] and to go to the mosque every Friday has built up this image of being a very good Muslim man. And in comparison, she appears like the disobedient wife..... It's quite unfortunate because of the degree of trauma she does present as being overwhelmed, and has been very distraught in comparison to the perpetrator. This unfortunately also impacts how the systems interact with you. Like in the case of government agencies, if you present yourself in a certain way then you are taken more seriously. So because she always appears more frazzled, dishevelled and distraught than he does, he is taken more seriously and given more credence, even though he is the perpetrator. (Alia, case worker)
\end{abstract}

This social view of women experiencing DV and implicit pressure to be "perfect victims" also infiltrate into how women interact with the structures that claim to protect them. They face 'multiple perpetrators' from those abusing them, unsupportive firstresponders and the "systemic coercion" that women stand against when they interact with social policy structures (Milani et al., 2018). The structural violence that women face when reaching out to formal systems of help, like the police and Courts, can be seen in how women's experiences are minimised, how women are blamed for the assault or violence, and how accessing criminal justice remedies in and of itself may be traumatic and emotionally taxing.

\title{
5.4.2. Social services
}

\subsubsection{Shelters}

In many policy documents available online-including social service websites and MSF's website on family violence-shelters are included as one of the few options for support, as a physical safe space for those experiencing DV. MSF funds four DV crisis shelters in Singapore (Sajan, 2020). Participants brought up a range of challenges that 
women have to consider when attempting to seek refuge in a shelter. These include reluctance to live in a shelter or institutionalised community, insecurity about halal dining and cooking environments, shelter capacity issues, mismatch of women's working hours with the curfews imposed by shelter regulations, long waiting periods, lack of awareness of shelters available, distance from children's schools, age limits for male children in tow, and the lower likelihood of women experiencing non-physical violence to be admitted.

\begin{abstract}
When it comes to crisis shelters, it has been difficult for at least the clients I saw because the shelters were full. They needed to go and work, and their working hours were beyond whatever their shelter curfews were. It's very interesting that practical barriers exist, like timings that you can enter and exit, [and it] would impede your ability to go to work. A lot of times a referral to the crisis shelter will take at least a week or so. But you might need to get out [of your flat]...tomorrow. So there was no ability to expedite it. [The women] would say, then I mati [die] lah by next week, I [have to] find my own way. There's also [a policy where there should be] no risk [physical or mental issues that require monitoring] so obviously, if you've been through trauma, you might have risk issues, which then precludes you from shelters. (Alia, case worker)
\end{abstract}

Similarly, Yati said, "the easiest way for most of them to seek help is usually (if they have experienced) physical violence". That crisis shelters function only to support women who are not "at risk" of physical or mental illnesses excludes disabled people and shows a shocking lack of understanding of the impact that violence can have on women's bodies and lives. Restrictive curfews affect low-income workers who work odd shifts, a barrier to their financial stability. One US study aptly asks of the growing list of 'conditions' shelters have for women to abide by: who exactly are these DV programmes and systems for? (Koyama, 2006)

Participants relayed the challenges that a woman seeking safety might experience:

I've had families because they leave at night...they will have to wait until the next day, they then show up at the shelter. From the shelter they require a police report or a referral from some social worker. If they show up at a shelter, they will just send you back to a social worker. Some shelters are just for women only, some are for families, for mothers and children, some are for mixed families. So that's why that preparation is needed. I think better processes - there should be a halfway transition, while a family is waiting for a referral or paperwork to be done ....For the Muslims, the only shelter that I know of is Casa Raudha. There's of course SCWO's Star Shelter. Then there's some run by churches. But I think for Muslims we need to have more shelters. And you must know about them to go to them to seek help. There must be public education. At two o'clock in the morning, you have a fight, where are you going to go with your children in tow? (Farah, legal professional) 
We know the shelters are like they are doing their best in that with the resources they have. But it still means that for clients to get access to a crisis shelter, there needs to still be referral from an FSC. So that takes a lot of time and that deters clients as well. (Alia, case worker)

The lack of safe spaces outside of working hours references the policy for admission to a shelter-one has to go to the nearest FSC, hospital or police station for a formal referral. While hospitals and police stations operate 24 hours, FSCs abide by working hours. Women more often than not have to have been physically harmed recently and require physical distance from those perpetrating violence before shelters become an option. These policies do not account for coercive control in DV, which means that being physically apart from the person perpetrating DV does not mean that women are safe.

There may not be enough places and shelter homes. Shelter homes will require a certain threshold, only social workers can refer clients to shelter homes. And only if it's proven that it's unsafe for the woman to stay in those relationships. That's also another area of discomfort for me - that certain spaces are available only after something [physical harm] has happened, and is not based on the fact that there are certain warning signs. I don't think I've ever heard a case where somebody has been offered a shelter home because they've experienced emotional or psychological or financial abuse. (Bel, case worker)

Other participants shared how living in shelters results in mental and physical discomfort for women, since communal living is far from ideal when children are involved. Some shared that non-Halal food environments have been concerning for some Muslim women.

Fear of institutionalisation also came up as a barrier, based on one participant's experience working with a woman who was once institutionalised through a juvenile home. Thus, institutional settings are far from empowering for women experiencing DV, and counter-productive to their recovery.

I had one couple where the wife was in a juvenile system before, where she was placed in homes and in shelters. So she's not inclined to go back into that setting. It's also a way of wanting to protect the children from having to deal with these kinds of settings. If you want to offer them shelter, then it [has to be] unique to themselves where they won't interact with other people. Which is a bit difficult for us because we don't have the resources. For those with [male] kids above the age of 12 , they will be separated from the parents. The separation makes them not inclined to be placed in shelters. Sometimes we do explore [if] the older ones can stay with the aunts or uncles, and the wife with the small children in the shelter, but sometimes they are not inclined. (Irfan, counsellor)

Online information has represented shelters as 'last resort' options for those who are seeking refuge ("What to do", n.d.) or as an option when there are no alternative 
housing options from friends or family to turn to ("Family violence", n.d.). Generally, there is consensus among participants that crisis shelters are inadequate in providing even an immediate remedy to DV, whether this is because of the high compliance cost for accessing them, or the disempowering nature of such institutions.

More than that, however, shelter systems within many societies have been vehemently criticised by feminist theorists and practitioners as modelled after prison systems where women are monitored, policed and isolated, and critiqued as mimicking abusive patterns of control that further isolate women from their communities (Koyama, 2006). Shelters that are funded by the State-as Singapore's are-have received concern and criticism for patronising services instead of "empowerment, choice-based service philosophy" (Lehrner \& Allen, 2009). The term 'empowerment' should be understood critically here. Take for instance, Star Shelter, Singapore's only secular DV crisis shelter. Although it states that women's empowerment is at the forefront of its principles, the language used on its website (below) suggests a more authoritative, paternalistic approach, echoing State ideology.

\section{Condition of Stay.}

Each victim can stay a maximum of three months. During the stay, the victim must demonstrate willingness to work towards resolution of her issues-actively seeking alternative accommodation, job, etc. The shelter reserves the right to evict at any time when it is felt that the victim is not taking ownership of her own problems or there is undesirable behaviour on the part of the victim.

(Star Shelter, 2020)

Keeping women and families safe from patriarchal and violent relationships should not rely on social and organisational methods of monitoring and controlling women's lives, as it reproduces forces of subjugation in abusive relationships. Studies point to how shelters that adopt an intersectional feminist, choice-based framework in its operationalisation-for instance, organisations where there is emphasis on equal partnerships, that are anti-authoritarian, and a sense of closeness-tend to gain greater strength (Haj-Yahia \& Cohen, 2009). Transformative, structural work has to be done to consider all the needs that those experiencing violence have and to provide 
alternative, holistic safe houses that do not replicate abusive patterns to control women.

\subsubsection{Social service organisations}

Procedural barriers that women face occur not only during shelter referrals and PPO applications, but also in the process of looking for appropriate services for their needs. Women end up being referred from one organisation to another, which adds to the stress they face. Alia spoke directly about the struggles that Muslim women may face in the social service system as religious and racial minorities.

\footnotetext{
There's a general attitude of "how is it going to help me? Nothing will be done quickly, l'll just be passed from one case worker to the other case worker". There's also this perception that "they might just tell me to work on the marriage, or they might not fully understand where I'm coming from, because they are not Malay and they don't know the cultural nuances of what I have to go through. They don't know about my religion. I don't even have the means to economically support myself, I don't have time to go to another organisation. I don't have the energy to do all of that....if I was Chinese or of another race, then maybe it will be easier for me both to get financial assistance, to get employment assistance, to sort of mobilise". (Alia, case worker)
}

There is therefore a perception among some Malay/Muslim women who access services that they would face differential treatment. However, when it comes to working with Malay/Muslim women, participants described it as largely the same as working with non-Malay/Muslim women, with the exception that there may be religious values injected into counselling sessions. Bel revealed that the practice of "cultural competence" is ensured in the organisation she works for through the presence of at least one Malay/Muslim case worker or counsellor. She also explains how in her experience, culturally-specific knowledge tend to be usually "outsourced" - whether this is to other colleagues who happen to be Malay/Muslim or to faith-based organisations. Yati stated how she herself has been utilised for support as the counsellor attuned to Malay/Muslim cultural and religious issues within her own organisation:

Fortunately, in our team we've always had one or the other staff, who was culturally attuned to the Muslim community. If there were conversations with women who had a heavy emphasis on Sharia law or the teachings, then we would pull them in. ...For example we had [workers] who could speak Malay also were Muslim women. ...If we don't have that resource within the team, then we have some organisations that we can possibly reach out to for help. (Bel, case worker)

[Training] on Muslim issues, [we don't have] very much [of]. If you're lucky there's a Muslim worker in the FSC and then perhaps the other colleagues can somehow seek her advice. In my 
organisation, I have another senior staff who takes a lot of family violence cases and she doesn't fully understand our culture. So usually she refers to me. ...As I'm saying this, I recall a session with my supervisor. She's Chinese. She has a lot of work experience, but when I talk about this, she understands them, but she doesn't feel it fully. I don't know how to explain that. (Yati, counsellor)

In both cases, we can see how the effort of improving organisations' work with Malay/Muslim women relies substantively on the "luck" factor of having someone around who is able to "get" the cultural or religious elements. Ethnicity-based cultures and knowledge of laws are "othered" to minority staff members and understanding them is seen as an additional layer or barrier, rather than something inherently woven into the principles of working with women experiencing DV.

Although Yati shared how it is far easier for her, as a counsellor, to discuss cultural nuances with someone from the same culture, Alia revealed how her experiences have shaken this assumption that Malay/Muslim women would have a 'natural' affinity for workers from their own cultural group. She observed that the shame women feel in seeking help has led some women to start a session by saying "I hope you don't judge me", and sometimes to request for a counsellor who is "not Malay, because they feel like they will be judged or shamed if they see a counsellor of the same cultural background". She also said that the presence of Malay case workers in a secular agency does not mean that Malay/Muslim women are more likely to reach out, and that some might still prefer faith-based organisations.

Bel shared how Muslim women "may not always look for information that is culturally nuanced" and that sometimes, they are "facing the same set of abuse and violence that any other person...experiences". This idea of the "sameness" of violent experiences was found in the other interviews, and through the flattening or minimisation of the structural realities that Malay/Muslims in Singapore operate in, I noticed how participants spoke about DV mostly through its forms and resources for support available to all women, whether or not they were Malay/Muslim. For a few participants, where something is assumed to be "unique" to the Malay/Muslim population, it tends to be contextualised within spiritual abuse, Islamic law or conservative Quranic interpretations, less so within the context of the Malay/Muslim population's social, political and economic marginality, although at least one 
respondent (Maya) explicitly observed the disproportionate representation of ethnic minorities requiring welfare services.

One particular experience shared by Sofia made it clear that there are obvious gaps in offering knowledge specific to Malay/Muslim women's experiences and needs, beyond individual or ethnicity-based cultural experiences, particularly as Muslims in Singapore operate under a separate personal law. Sofia spoke about a call she received from a woman seeking help for what she was concerned was marital rape.

There's a recent one where a woman said that her husband kept forcing himself on her, even during Ramadan. He kept saying he wanted to divorce her, but on the other hand, he asked for sexual favors from her. I actually recommended [organisation name redacted to protect identity of informants] because she said she needed legal advice. And she said, "Oh yeah, I did call [aforementioned organisation] and they linked me up with a Sharia lawyer but the Sharia lawyer but I think [the lawyer] doesn't know much about Sharia law." [The client] was asking about divorce and the Sharia lawyer was saying that there's a three-year period of separation before she can finally get a divorce. But we all know that that is not under Sharia law, probably that's under WC [Women's Charter]. So the moment the lawyer said that she knew that the lawyer was not very well versed in Sharia law. (Sofia, researcher) ${ }^{14}$

While mistakes are inevitably made wherever people are involved, a thorough and institutionalised knowledge of Muslim personal law requires perhaps more care and resources than what social service systems currently have capacity for. Inadequate information given to women may not only have a damaging effect on the options women are given, but also in the trust that minorities have of social services and how these institutions are accountable to their communities-and whether these services were made with their particular, intersectional experiences in mind.

Sofia also shared her concerns about how social workers may take Muslim women's interpretations of religious beliefs at face value, and work with women without unpacking these interpretations:

During [a conference on family violence], some of the feedback that [we heard] from the social workers, even the non-Muslim social workers who deal with Muslim families, [was that] they never knew that [certain interpretations] are actually considered as a problematic narrative. Which kind of makes me feel like...then how have you been dealing with such issues? Maybe they are thinking, 'I shouldn't be seen as masuk campur [getting involved] in that sense, because this is how the religion has taught you to behave'. I feel that more communication and engagements across sectors could really be useful to really create a strong, more holistic approach to handling violence. (Sofia, researcher)

\footnotetext{
${ }^{14}$ With consent from Sofia and anonymity of all participants assured, this feedback has been relayed to the organisation. The organisation involved has agreed to look into the mistake made by the lawyer.
} 
Here, Sofia pointed out the need for stronger networks between organisations working on DV in order to tackle the nuances of cultural and religious experiences. Maya believed that social services are seen to be inherently at odds with the values-systems of those who prefer to reach out to asatizah, stating that social service workers who "introduce Western ideals to them of empowerment and self realisation" which are "foreign" concepts.

This hesitation to reach out to social workers is revealed not only in those seeking support for the abuse they are facing, but those who have been accused of DV. The latter group have shared with participants about perceived or actual gender biases that they face from social service workers.

\begin{abstract}
Because of our organisation's name [there is a perception] that we're more inclined to help the woman and the man will feel side-lined, which may drive them to isolation. And if it's not managed properly, they may turn to self harm or suicide. (Irfan, counsellor)

I remember there was an angry pakcik [older Malay man] saying that the counsellors are biased, like they come in with certain preconceptions of things, so they're not there to really help you but rather to kind of preach, and that sometimes they can be very distant and cold. (Sofia, researcher)
\end{abstract}

I get a lot of complaints on the man's side, that this is unfair, why should I get a PPO against me for this? (Yati, counsellor)

Irfan explains that the difficulty social service workers face in dealing with those who are "religiously-inclined' is that "they don't see counsellors or social workers to be in par with their own knowledge or what they perceive as what is their right: to educate their wife or their children". One suggested remedy to this is explained further by Irfan:

It needs to start at the asatizah level where they need to [create] a way for social service professionals to propagate the language or messages to the masses. They are, at this point of time, still more influential as compared to social workers and counsellors. Asatizah [should] also not discount the ability or the competency of social workers and counsellors to deal with marital issues and family violence. (Irfan, counsellor)

The tension between two streams of support here is clear. Professionalised social services are not as trusted by many women for a variety of reasons that go beyond cultural or religious reasonings. But they are given more legitimacy through social policies. On the other hand, informal support such as asatizah and family and friends function under patriarchal and paternalistic ideologies. Both systems are deeply flawed in the ways they have problematised DV: many religious leaders speak the language 
of remedies through cultural and religious values which are not helpful in DV situations, while social services sometimes flatten or diminish the structural, cultural and religious intersections that Malay/Muslim women live within.

Finally, participants were asked to expand on any training, programmes or models specific to the Malay/Muslim population. In a few interviews, much was discussed on 'cultural competence' and training. However, since the interviews were conducted, I have also expanded my understanding of cultural competency as organisations operating to understand and counter the effects of colonialism and structural oppression. Nevertheless, very few participants who work in service settings shared any relevant training they have received on the issue. Most did not receive training in what was defined in the interviews as 'cultural competency' nor practice/training related to working with the Malay/Muslim population, and largely had to rely on their own immersion into the culture or religion; otherwise, they relied on their minority colleagues or deferred to faith organisations.

In the social sector itself, there have been small moves towards addressing service needs of ethnic minorities. One social service organisation, AWARE, expanded its helpline services to include services beyond English and Mandarin, but also Malay, Tamil and Hindi, and included a Shariah Law legal clinic. However, this move was simply a language and service expansion; at this point, there is no information on any regular training on structural oppression and its effects on the Malay/Muslim population that the organisation runs.

In my interview with Bel, she shared how staff at her organisation who work in services receive a "maximum of two" training sessions that touched on 'culture', where counsellors and case workers are trained. She recalled one training that was run on unconscious biases, where the facilitator spoke "about the oppression that Muslim women...face" and "unpacks the myth that they are lazy". Although this indicates a small move to build a more "structural" understanding of how DV can impact families living in the intersection of marginalised identities, it begs further questions. How are these discussions and training on 'biases' run? Do they have deep understanding of the historical and structural forces that have shaped the prevailing racial and political hierarchy in Singapore and how they affect Malay/Muslim women? Is cultural 
competence of social services enough of a solution to address Malay/Muslim women's general sense of apprehension, fear or even distrust surrounding help-seeking through social services, considering their historical position in Singapore? Do we need more training for social services or do we need structural change to transform how it functions?

Many critics argue cultural competency is limited because "the lives and histories of women of color call on us to radically rethink all models currently developed for addressing domestic violence" (Smith, 2005). My findings imply that social services are still focused on competence on cultural and religious elements of DV, but remain largely disconnected from more holistic and transformative conversations on patriarchal, State and structural violence and oppression-conversations that need to go beyond gender oppression within specific ethnic/religious cultures.

\subsection{Conclusion}

Participants have expressed what, according to them, the problem of DV within the Malay/Muslim population appears to be, by identifying the patriarchal forms that DV takes, tracing its genealogy back to dominant (secular and religious) discourses that support patriarchal authoritarianism. Participants problematised the barriers women face when engaging in formal and informal strategies of resistance-namely material disadvantages such as lack of housing options and economic dependence on their husbands; inadequacies within social services to meet Malay/Muslim women's needs and desires; challenges with criminal justice solutions provided like PPOs; and lack of support from friends, family and religious leadership, which reinforce reliance on patriarchal households.

My analysis in this chapter touched on how the patriarchal and authoritarian State cocreates the cultural and structural barriers that women face. State support for the patriarchal household is evident through housing and welfare policies. Social service and criminal justice approaches show a paternalistic form of control and governance of women. Women are presented with two broad options: either work through abusive relationships through State mediation and counselling or leave violent relationships but face structural and material consequences. Considering these problematisations 
is a critical first step for us to be able to observe, through the WPR questioning approach, how the State views DV through the solutions it offers and how these solutions have affected discourses among those who work on DV. I will explore this further in the next chapter. 


\section{CHAPTER 6: WHAT'S THE PROBLEM REPRESENTED TO BE?}

Policy texts, State solutions and participants' problematisations

In the previous chapter, I reflected upon the problem representations of Malay/Muslim women's DV experiences based on participants' descriptions and first-person accounts. This was an opportunity to understand the way DV, as a social problem, has been framed within discourse. Through my analysis and discussion, I was able to understand the problematisations of DV, including some implicit solutions located within the data.

In this Chapter, I intend explore problematisations through the explicit solutions offered, using the conventional WPR mode of questioning. These commonly espoused DV 'solutions' act as levers to work backwards from to ultimately summarise how social policy has problematised DV within the Malay/Muslim population, using learnings from Chapter Five to build a more cohesive understanding of where the gaps may lie.

Based on the policy documents selected and interviews from participants, DV is identified as a social problem that can be 'solved' with family and individual counselling, empowerment of women, working with those who perpetrate DV, public education to change attitudes, religious and cultural counter-education and finally, legal remedies and criminal justice solutions. The next few subsections will dive into a WPR analysis of each of these policy solutions.

\subsection{Family and individual counselling}

Counselling is offered as a solution to addressing DV ("Family violence", n.d., SPF, 2020). These services are typically run within MSF-funded FSCs, and could be individual, couples or family counselling. MSF also runs mandatory counselling sessions for parties involved in a PPO application. Mandatory counselling was spoken of highly by participants in the interviews, though with caveats.

I think the mandatory counselling is good...but perhaps with the problem is like if the aim is to reconcile families...when actually it'd be safer for the woman to leave the relationship, then that's a bit shit. Which is often the case, like they will send the couple for mandated counselling 
with the aim of reintegrating for the benefit of the children. It sends the message to the client that if she wants to leave, there are a lot more structural barriers that she would have to cross and leaving is still secondary to trying to make it work. (Alia, case worker)

The purpose of counselling as a remedy to DV was discussed in interviews in several ways. Firstly, it was presented as a way of providing women with psychoeducation and emotional management, by helping women to "make sense" of their feelings of shame, loss and other emotional experiences they may have.

\begin{abstract}
A lot of the work was helping women to understand what they were going through. So using trauma education or the cycle of violence education for domestic violence or sexual violence survivors to make sense of why they were staying in such relationships, to make sense of why they were experiencing things like flashbacks or nightmares, why they were hyper vigilant at times. So during that, a lot of work was also helping them work through the self blame and the shame and the sense of loss that came with having experienced domestic violence and sexual violence. (Alia, case worker)
\end{abstract}

We provide trauma-informed services to these women...so that they are aware of their rights, they are able to cope with the distress and to be able to empower them[selves] to make informed decisions for their next steps. (Bel, case worker)

What this presupposes is that a restoration of women's self-esteem is a major component in ending DV. At its extreme, it assumes that women need to realise their self-worth, in order to not be abused. The offer of counselling as a safety or support option in policy documents themselves risks silencing the difficulties women face when dealing with professional social services, and may over-elevate the position of professional counsellors and State social services in the work to end DV, dangerously conflating intervention with systemic eradication.

Secondly, counselling sessions are also a way for advocates to support women in making safety plans to ensure least harm ("Keeping yourself safe", n.d.; "Help is here", 2020). Maya, who has supported women in making these safety plans, identifies herself that this approach as assuming that women have "all the important documents (they need)" and takes for granted "that nothing severe is going to happen while the woman is compiling her belongings and putting their safety plan in action right". She said, "Whereas we know that violence is not like that. Violence can erupt the very next minute, after contact is made with us or any social worker." Thus, according to this problematisation, ending DV requires women's emotional stability and ability to create safety plans and "work through" their trauma and emotions. 
Other participants spoke about counselling as a solution that works to emotionally regulate men who abuse, counselling as a form of remedy that can potentially stop abusive behaviours, and even the restorative effect of counselling for marriages. Participants spoke about how men's abusive tendencies could come from 'anger management' issues, underlying issues, lack of psychoeducation on men's roles as husbands, and men not knowing that DV is not good a solution to their problems:

\begin{abstract}
Sometimes with true counselling, marriage becomes better, and it's also protection. Generally with perpetrators there is always a trigger factor...It could be something that they learned from childhood, watching their parents, it could be anger management issues. So they also need to be counselled. (Yati, counsellor)

This counselling order is actually very, very good. The PPO stops the perpetrator from further action, and hopefully with the counselling, it helps him understand that domestic violence is not the solution to all your problems. Whatever disagreement you have with your spouse or your children, or whatever stress that you're going through, violence is not the solution. So the hope is that it helps him understand that and then deal with his anger management issue. (Farah, legal professional)
\end{abstract}

This presupposes that men who abuse do so because they hope to 'solve' something, which is not congruent with discourses that establish power and control as a central function of DV. Those who have perpetrated DV have also spoken about how nonissues cause their violent tendencies to erupt (John, 2017). Thus, this problematisation inadvertently places the blame on those experiencing DV by assuming that an issue that causes a violent or controlling response is something they can 'solve' one way or another.

Another aspect of the quotes above is the fact that counselling can address lack of anger management, which can cause DV. This framework has been repeated in other policy texts as well. For example, the Friday prayer Khutbah (sermon), disseminated by MUIS, recited on 29 November 2019 spoke about anger management as a form of avoiding DV, by using stories from Prophet Muhammad's (s.a.w.) life: 
This prophetic guideline, in my humble opinion, is indeed incredibly meaningful. It educates us about the true meaning of 'Sabr', or patience, during a state of anger. A truly patient person does not remain silent or avoid responding when triggered by something hurtful, but he/she is someone who strives to respond calmly and speak in the best manner possible to the person who is causing the anger.

Let us together appreciate and emulate Rasulullah s.a.w.'s character in educating his family with much patience and compassion. Not using force nor with anger. Just like many of us, Rasulullah s.a.w. also faced challenges in his household. However, how did Rasulullah s.a.w. Manage to overcome those challenges? Did he take immediate action and speak his mind in every single situation? Did he use violence against his wives? Or did he instead manage each conflict with patience, communication and love?

("Khutbah: Rasulullah's Way of Dealing With Anger", 2019)

In fact, MSF's Mandatory Counselling Programme for families who have a PPO lodged, describes its mission as aiming to:

...stop physical, emotional or verbal abuse in the family by helping the perpetrator find other ways of dealing with stress, anger or conflict without resorting to hurt or violence. It provides help and support victims of violence who need safety and protection from further hurt. ("Family Protection \& Welfare Services" (n.d.)

Similarly, ramped up outreach efforts by MSF to "detect signs" of DV and the taskforce organised by the Ministry discussed "importance of looking at family structures, living environments, financial stressors and also the ability of individuals to manage conflict" (Goh, 2020). Anger and conflict management as a solution to end or stop DV problematises individual psychopathological issues within DV. As a natural continuation of this problematisation, DV then becomes, through discourse, an issue of anger as a result of conflicting parenting styles, family conflicts and tension, and couples' quarrelling and disagreements, poor communication, financial insecurity and even retaliation from women experiencing DV:

I think it's completely a different set of values. A couple who have different parenting styles, so it just gives a lot of conflict and tension to the marriage.

...Usually what I do is, I say, "Maybe I also can teach you so that you don't quarrel with him. Even if you say that you have done this, [abuse] is not the way that he should react."'

...Perhaps yes, as a man, as the head of the household, you need to ensure [education] happens, but you do not need to use derogatory remarks, you don't need to use force, you don't need to use humiliating remarks. There are always other ways of motivating or encouraging you can use. (Yati, counsellor) 
Sometimes, they are also trying to take refuge in the faith. Once we listen to the issues over the phone, then we have a sense that it's not really about the religious ruling. It's how the communication pattern is with the spouse and how they understand the role of a man and a wife in the marital relationship in regards to Islam.

...Sometimes it's the victim that uses [some] kind of aggressive words which further inflame the perpetrator.

...They disagree with how their partner reprimands the child, and that leads to disagreements in the couple's system, sometimes other things are being brought in, then it becomes a mess in the marital system. (Irfan, counsellor)

What happens if they cannot resolve the issue after talking to the social worker and there is no resolution? The complainant can ask the perpetrator, the respondent to give an undertaking to the court not to commit family violence in the future. (Farah, legal professional)

I should note that the interviews did not allow for greater insight into the ways the family conflict theory stood in conflict with a more structural framing of DV centred around gendered power and control, and that these examples could also be excused as a matter of conversation style or simplicity in participants' choice of words. However, taken at face value, these problematisations of DV inadvertently flatten the power imbalance in abuse. It also ironically presupposes how DV is a problem of lack of control or power over one's emotions, rather than the deliberate use of power and control over others. On MSF's website, there is some effort to debunk this common conflation of family conflicts with DV:

Differences and conflicts happen amongst family members. However, in a healthy family relationship, members compromise and seek ways to overcome their differences. Violence is not a normal part of family life.

("Myths about family violence", n.d.)

However, this recognition in policy appears to be less about acknowledging power and control, and more about situating DV within families that are 'not normal', unhealthy or even dysfunctional. This echoes one of Yati's quotes ("I don't think a normal person would just resort to violence; it must be something underlying that you need to find out"). With DV perceived as something that 'normal' men would not do, there is an implication that society, as it is, functions 'normally' while abusive men veer from this standard.

The continuation of this framework of 'healthy' and 'unhealthy' family conflicts can be found in at least two videos by End Domestic Violence, a public education campaign 
by Casa Raudha (crisis shelter) and The Whitehatters, self-described on its website as a 'centrist' NGO. Spokespeople talked about the healthy ways of coping with family conflicts, then focused attention to families who are dealing with DV, and directed the audience to social service resources (Casa Raudha, 2020e). This way, DV is lumped in the same conversation with family conflicts, allowing the line to blur between DV and non-abusive conflict. This runs the risk of flattening the important distinguishing factor of unequal power and control in abusive relationships.

With flattened power structures, it makes sense then that counselling becomes a form of formal 'mediation' between two equal parties, or to keep families 'intact' (excerpts below).

Professionals will help mediate between the abused wife and her husband, in the hope that the woman and her children will leave the temporary shelter and return home.

"We want to help the women rebuild their lives. Their aggressors need to be approached carefully and counselled, too," Mr Hamzah Abdul Mutalib, president of the parent organisation called Casa Raudha Ltd, or CRL, said on Friday (March 9).

(Tee, 2018)

MSF released a study at the conference that found that people were not coming forward to report such cases because they feared breaking up families or saw it as a private matter. The study polled 2,000 people.

"Not every report (on family violence) will lead to the break-up of families. Some social workers tell me early reporting can actually help save marriages and keep families intact," said Mr Tan as he appealed to the audience of 800 professionals, from the judicial, law enforcement, healthcare, social services and academic sectors, to spread the word to get people in the community to flag out violence cases.

(Tai, 2016)

These sentiments presuppose, besides the acknowledgement of the need to keep families 'intact', that reports of DV can lead to the break-up of families, rather than DV itself. While it is reasonable that social services do not assume that every report of DV 
is underpinned by a desire for separation, these statements should be read in the wider ideological context of social policies. DV programmes function within a policy landscape where services and government institutions aim to "save marriages" ("Mission", n.d) and where professional interventions in DV work to solve "underlying issues" ("What to do if someone is experiencing violence", 2020). It is also reasonable to see the essence of this problematisation extend its reach to the unsupportive responses of family, friends and religious leaders to whom women have disclosed their experiences, when women are told to stay in abusive relationships.

The silences of this problematisation lie in how the pressure to keep families together has been unhelpful to many women, the lack of resources that women have when they leave their relationships, and the current patriarchal hegemonic structure, all of which are left "unproblematic". Policy documents do little to name and articulate patriarchal power and control as the major roots of DV. Social services' website materials ("What is violence", n.d.) do not extensively or visibly address the root causes of DV, the oppressions that emerge in cultural and structural arenas within and outside of the family unit, and the interactions between them.

This analysis is not to claim that counselling should not be among the effort to end DV, but the overwhelming approach to counselling still functions within a systemic strategy to support the patriarchal family unit. It therefore sits in tension with participants' articulations of women's experiences where decision-making is impaired by a myriad of factors that go far beyond problematisations of DV as a result of family conflicts, emotional mismanagement and disempowerment.

\subsection{Women's empowerment}

The significance of women's 'empowerment' in ending DV is found, both explicitly and implicitly, in numerous policy texts: from social service websites (e.g. Star Shelter and NCSS), to MSF's webpage on family violence. Crisis shelters aim to "empower residents to take control of their lives" and "build hope, self-reliance and minimize dependence" ("Vision \& Mission", 2020). The excerpts below demonstrate the language used in policy texts' conceptualisation of 'empowerment': 
Star Shelter aims to provide a safe temporary refuge for women and their children who are victims of family violence regardless of race, language, creed or religion. We also empower the victims to manage and take responsibility for their lives, and assist them in rebuilding their lives free from violence.

(Star Shelter, 2020)

If you believe there may be a problem in your relationship, do not ignore the warning signs and get help NOW. Taking the steps to stop the violence in your own home is the only way to break the cycle of violence.

(“Why seek help?”,n.d.)

The problem representations above are explicit and, in MSF's case, forceful: the responsibility of ending DV is in the victim's hands. It puts the burden of responsibility of survival and recovery on those experiencing DV, rather than the policy interventions meant to protect them from DV in the first place. I am also reminded of a response from an interview with Maya (below) which could be read as an echo of such a problematisation:

Some have stayed [in abusive relationships] for years, some have only just experienced it. As any human being you always feel strongly - this is my personal perspective-for the children involved because I hold the mother accountable for this, while at the same time, understanding that it is a very complex and multi layered issue, and not something that's black or white. I always look at the children from such households and wonder what it is that they're feeling or experiencing and assist their family to make changes. (Maya, case worker)

Children's safety is of course a reasonable concern, but the findings of this thesis have demonstrated how the responsibility of caring for children is already at the forefront of women's minds as they go through DV. Therefore, even the decision to stay in an abusive relationship could be seen as a rational one, made with children's wellbeing in mind and circumscribed by women's sociocultural realities (Ganapathy, 2008).

The problematisation of DV being the responsibility of women going through it seen also in messages in MSF's Break the Silence campaign to end family violence, where the concepts of "self-reliance" and "empowerment" are missing in the campaign's narratives of DV. In the short films of the campaign, those experiencing DV are rarely seen or heard. Greater airtime was given to bystanders whose interventions were 
independent of the decisions of people experiencing DV. Although some "victim" characters in the videos adopted what we have defined previously as personal strategies of resistance to violence (such as hiding or screaming), none of them were seen to actively seek outside help, whether informal or formal. I will discuss more about this campaign later on.

This problem representation drives the point further: that currently, those experiencing DV are overwhelmingly silent or passive, do not seek help, and thus need to be empowered enough to reach out. It mutes the ways that problem representations in Chapter Five have suggested women resist: using personal strategies such as prayer, seeking support from friends and religious leaders, going through laborious processes with social services and the criminal justice system, and attempting to be financially secure. It ignores the barriers that using formal and informal strategies come with. It demonstrates that because women are disempowered, they need to be individually empowered through counselling services, FSC support, and criminal justice interventions. This problematisation is consistent with international studies where it was found that much psychological research on DV focus on "an individual level of analysis" and view "violence against women as a problem that resides within individuals" (Salazar and Cook, 2002, p. 418). Ultimately the pattern of how DV operates as a social and structural problem, and the landscape that it happens in, is erased.

Based on policy documents and interviews, the definition of 'empowerment' is also limited. Personal empowerment is often talked about as building confidence, selfesteem, self-worth, changing mindsets and attitudes, and knowledge of rights, resources and services. All of this presupposes that women's lack of empowerment caused DV, and that "services" are there to eradicate DV (which the findings of this thesis have shown not to be always true). The excerpts below show how the empowerment framework undergird participants' perspectives on DV:

So a lot of my work when I see there's no more hope in the marriage....I will work with the woman to empower them. [It's] quite tough because it's a culture. It's a mindset. For the lowincome, we encourage them to take courses, start to believe in themselves....I think culturally, in terms of the Malay Muslim community, we need to really empower the women, the victims. (Yati, counsellor) 
They fear: what if he comes back, what if he kills me? There's also the other kind of fear where it's about poisoning the minds of children against [them]. For women...it's normalised for them to be weak and oppressed, they don't see their own power, [so they] go back to crying, and depression and walking around in a daze, [thinking] "they have taken away everything from me, including my right to housing". (Maya, case worker)

Simultaneously, some texts show how individual psychological empowerment sits within a greater context where other forms of empowerment can be imagined, for instance, in strengthening the community support that those experiencing DV are provided with, and improving material conditions:

We feel like if they are economically empowered, or they achieve some level of financial stability, they can handle the other issues that come up as a result of that. A woman securing a job is not good enough, there are so many barriers that prevent her from sustaining the job or having success in the job, revolving around childcare issues, not being prepared for juggling between work and home especially for single parents. (Maya, case worker)

Through the "Rebuild" Program, we also provide a one-time financial aid to assist victims to pay for transport expenses while looking for employment as well as a no interest home loan, which enables victims to set up a new home.

(Star Shelter, 2020)

As Maya stated, women's empowerment cannot simply be achieved with pushing for more women to be financially independent through full-time work. Efforts to provide financial support such as Star Shelter's home loan are laudable, though more strategic and systemic policies need to be imagined in order to ensure that it is a remedy that can apply more universally, rather than through individual shelters. However, many services focus on empowerment not through advocating for structural changes but through neoliberal remedies like marriage mediation, employment through back-towork programmes that focus on "confidence" ("Confidence Curriculum", 2020) and financial literacy programmes where poverty is described as something that can be remedied with "skills and knowledge" ("25 April 2019 Talk", 2019; "Program Bijak Belanja", 2018). In the conversation on empowerment, there is silence in how basic services like housing, healthcare, caregiving support, and economic security are, of course, empowering as well. 


\subsection{Working with men who use DV}

Although there are efforts to organise programmes with people who use violence (particularly through PAVE), several participants identified that more needed to be done to work with men who have perpetrated DV. The necessity of this work is also found in formal policy documents such as a White Paper speech by Law Minister K. Shanmugam (MHA, 2020). The interviews themselves did not provide sufficient data to allow for a thorough examination of the kind of intervention and rehabilitation programmes that participants knew or felt to be suitable. However, comments on the need for these services ranged from allowing men to find different ways to respond to life's stressors, to men learning to control themselves, to men learning violent behaviour from childhood experiences.

In my work, there're so many times male perpetrators would break down in the room because they have a lot of regrets. That's not what they want but it turned out that way and they lost control. (Yati, counsellor)

I'm fairly comfortable with the support being given to victims. But I still feel that not much has been done to reach out to perpetrators. ...Sometimes men who use violence tend to be sidelined, to be discounted of their feelings and thoughts of how they would want to improve the situation.....Sometimes I feel like they do not know of alternative ways of responding to life stressors. Maybe like in the early days of independence where life was more simple and the role of men is just to provide. ...But we have progressed and more is being expected of men. Maybe...men ourselves have not really evolved in our coping to the changes in the role of a woman and role of the family over time? ...The challenge is for us to engage the men if they don't come forward. Even if we dangle a carrot for them to come in, they come in for one time and then they will be off again. I'm not sure whether it's the way we engage them that needs to be improved. Or...they would rather want to speak to fellow men. Maybe they are not open to having women to facilitate these discussions for them. (Irfan, counsellor)

In participants' problematisations above, gender roles, patriarchal norms and capitalist pressures of fulfilling the role of a provider play a part in causing DV. At the same time however, they are referred to as individualised behaviours among 'some' men identifying patriarchal control as a toxic quality of the emotional needs of "angry" men who use violence.

This problematisation can be observed in wider media discourse on DV. In a media op-ed by Alan John, a management committee member of PAVE, the author wrote about working with men who have used violence against their wives and children (John, 2017). His piece identified that this group work programme allows men to recognise "danger signs" and "triggers" that cause them to erupt into violent 
behaviours. This problematisation establishes the problem of DV similar to Irfan's: a situation that happens when men are not aware of how to respond to stressful situations.

John's article states that "little will change if boys grow up and go through life with a Man Box that tells them violence is part of what it takes to Be A Man" (John, 2017). The Man Box-gender stereotypes and roles that are presupposed in this problematisation to cause men to be violent-is identified as a root cause of DV. The messages in this "Man Box" are stated in the piece as coming from "movies, advertisements, the Internet and even computer games", which was the closest the piece got to identifying the omnipresence of patriarchal forces in society without naming the problem itself. The piece went on to say that the group work allows PAVE to reinforce the following messages: "Violence is learnt behaviour that can be un-learnt; violence is a choice some men make to exert power and control over girlfriends, wives, children and others; a man who uses violence can choose to stop" (John, 2017). The silence then lies in the structural nature of patriarchy. The ways in which society functions and upholds patriarchy through its institutions and social organisations remain unproblematised.

Referring back to Irfan's musings, there is a suggestion that those who perpetrate DV choose not to participate in processes of engagement as they are unable to get past certain practices - such as women-led counselling sessions. However the consistency and amount of community accountability work to engage men who use violence is often underestimated (Smith, 2005). A lesson here can be seen in how social service organisations should not be viewed as the sole custodians of accountability programmes for those experiencing and using DV, especially as these organisations still function under the State's punitive approaches.

There is little to no acknowledgment of the concept of patriarchy in government policy documents on family violence. It is reasonable then to see how patriarchy is rarely named in discourse as a wider force in society that influences structural power relations, and instead is seen solely as learned behaviour that individual men pick up. This neutralises the power imbalances in gender roles which do not resort to violent and controlling behaviour. The subservience of women, girls and children that does not emerge directly from DV is made unproblematic, or inevitable, as a result of the 
silence; it represents DV as a problem that individual, 'angry' men use to exert power and control, and in the absence of acknowledging patriarchal power relations, assumes patriarchy as otherwise a benevolent force.

\subsection{Public education and attitudinal change}

In all interviews with participants, public education or religious education for Malay/Muslims was suggested as a solution to ending DV. Education is suggested as tool to counter the beliefs that people ('victims', 'perpetrators' and 'bystanders') have of violence being normal, that this is so because women are "not aware of their rights", that women need interventions to "realise their potential", that women have internalised patriarchal beliefs, that they need, as discussed, counselling and therapy to examine (or 'unpack') these beliefs, that bystanders are either unaware when DV is happening, unaware that DV is a moral wrong, or are disempowered from stepping in for a variety of reasons.

The following quotes showcase some of core beliefs on the importance of education for attitudinal change:

Overall, I'm for like education on general awareness on the rights of women, that they have political rights, human rights that they shouldn't be victims of any form of violence, whether in a university, whether it's at home, there are safe spaces, there are support services for them should they want to make a report. (Maya, case worker)

This idea that my wife is nushuz so I can go sebat-sebat [beat her]. If you start the marriage as: one is the leader, one is subservient-it's very problematic. Unless we have a lot of public education on marriage as an equal partnership, we are going to have a lot of problems. At the heart of it, violence is somebody wanting to exert control over the other party. (Farah, legal professional)

We acknowledge that some groups, certain genders, have been discriminated against for many years, because of the patriarchy that exists in society. Women may come with these expectations from themselves that women are supposed to take the beating, or they are supposed to behave a certain way within the society, and then being gender informed means that you are attuned to those nuances you are aware of those baggages [sic], you're aware of that discrimination, of how deeply rooted these myths and biases are even within survivors and how you slowly unpack them. (Bel, case worker)

Public education has been used by the State to raise awareness of DV. However these educational campaigns have tended to focus on "the identification of signs of family violence and the need to seek help early" (Goh, 2009). The resulting Ministerial efforts over the last decade or so which were derived from this strategy are tightly focused on 
types of abuse, resources available, and how to prevent family violence by teaching students how to identify DV and seek help (Teoh, 2020).

To understand the use of public education on DV in Singapore as a remedy, I studied two relatively recent campaigns, Break the Silence ("Break the Silence", n.d) and End Domestic Violence ("Help is here", 2020). I also looked to website materials and media reports on DV, mapping them against the analysis from the previous chapter.

Break the Silence (BTS) was a campaign by MSF and primarily uses campaign videos and a website themed around bystander intervention. The campaign was described by MSF below:

The key message is that family violence is not a private matter. Victims need help. They need to receive help early. ...The \#breakthesilenceSG effort was started to also gather stories on social media of how everyday Singaporeans stepped in to prevent, interrupt and report suspected family violence. ....We also have roving community roadshows, training sessions and collaterals being produced to help raise awareness and to equip bystanders with resources and also to update them on skills that are required to safely step in to help victims.

(“Break The Silence Intervention In Family Violence", 2017)

End Domestic Violence (End DV) was started in April 2020 and emerged in response to the increase in DV reports over the COVID-19 lockdown. The web-based community education campaign contains similar themes on remedies and tips for those experiencing DV, and tips for family, friends and neighbours. End DV is not an MSF campaign, but is funded by Our SG Fund, an initiative under the Ministry of Culture, Community and Youth.

Firstly, it should be noted that the overwhelming majority of actors in BTS are Chinese, pointing to how representation of ethnic minorities is limited even in mainstream discourse about DV. Unlike BTS, End Domestic Violence's campaign videos and educational material feature ethnic minorities heavily, and is organised by Casa Raudha, which is a shelter for Muslim women. Although these two campaigns alone offer a wealth of material to analyse, my focus will be on how public education on DV 
is focused on "raising awareness" of what is portrayed as largely physical and verbal violence, and the romanticisation of bystander interventions.

\section{"Raising awareness"}

The campaign videos in BTS have a similar soundscape: the din of neighbours' screams as violence erupts, the whoosh of the rotan (cane) through the air, the smack as it lands on flesh, the shrill screams seeping out of a colleague's phone. Designed to illustrate how signs of violence can be identified and interrupted, the videos show how DV stains all arenas of our lives beyond our homes: our hawker centres, HDB corridors, and offices. The campaign's message looms unseen throughout the video, rendered through the facial expressions of conflicted characters who face inner battles on how to step in, before punctuating their dilemma with a final question: What would you do?

In the video series, DV is clear enough. It can be seen-through marks and bruises on the body-or heard-through pained screaming, angry yelling, verbal harassment or otherwise vocal forms of resistance and expression. It occurs as "events" which can be easily identified as violence.

In End Domestic Violence, there are no film-like videos. Its webpage points to how non-physical and non-verbal forms of DV are equally crucial to address, stating that "we stand with the victims when they say that psychological and emotional abuse leave far deeper wounds and take longer to heal than physical ones." However, representations used in ads for the campaign still prioritise the physical aspects of DV, as seen in the examples below: 


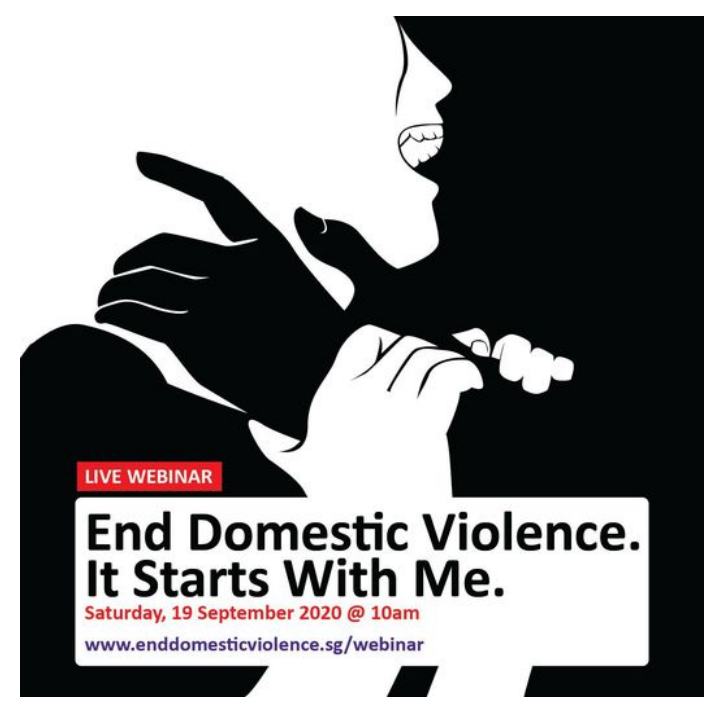

(Casa Raudha, 2020a)

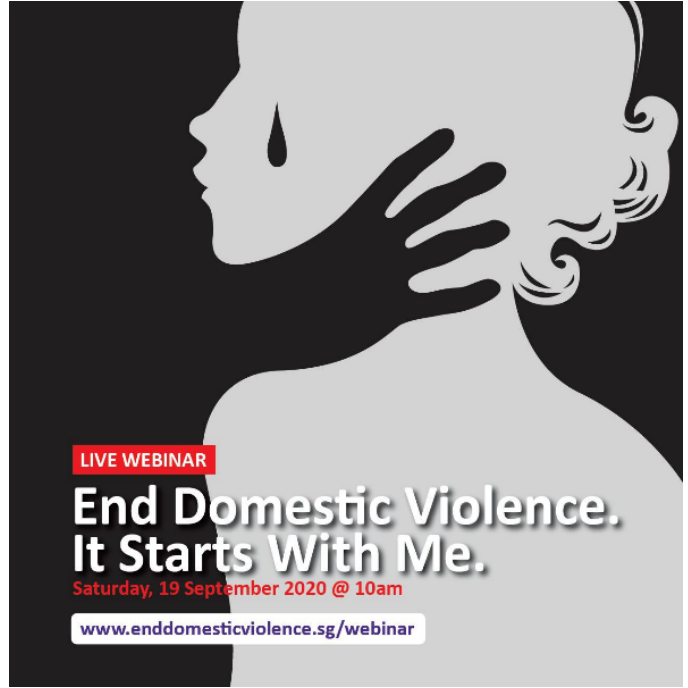

(Casa Raudha, 2020b)
End Dornesije Vlolenge. aturday, 19 sept mber $2020 @ 10 a m$

www.enddomesticuidence.sg/webinar
LIVE WEBINAR

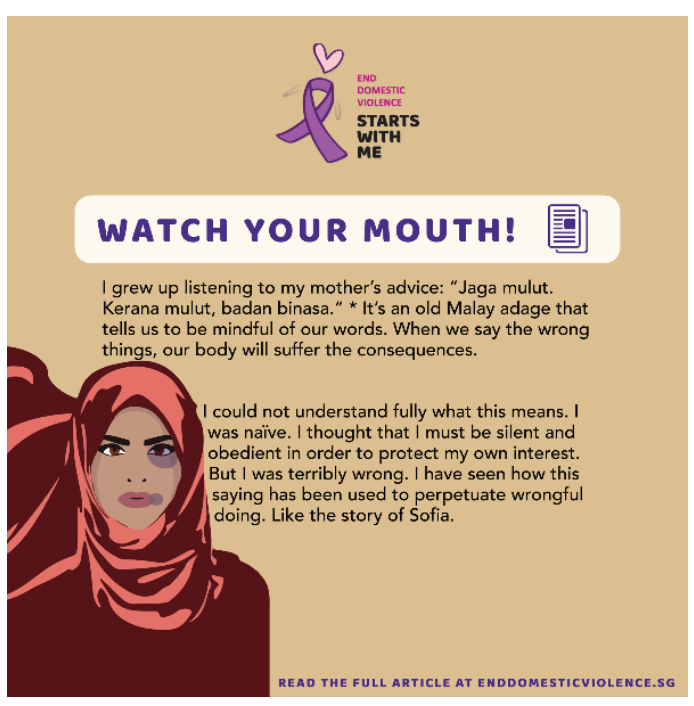

(Casa Raudha, 2020d)
(Casa Raudha, 2020c)

\section{End Domestic Violence.} It Starts With Me.

Saturday, 19 September 2020 @ 10am

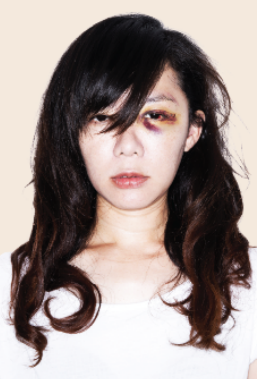

Beyond these campaigns the spotlight on physical violence is a message disseminated in the headlines, images and illustrations of mainstream media reports on $\mathrm{DV}$, as seen below: 
Coronavirus: More cases of family violence during circuit breaker; police

to proactively help victims

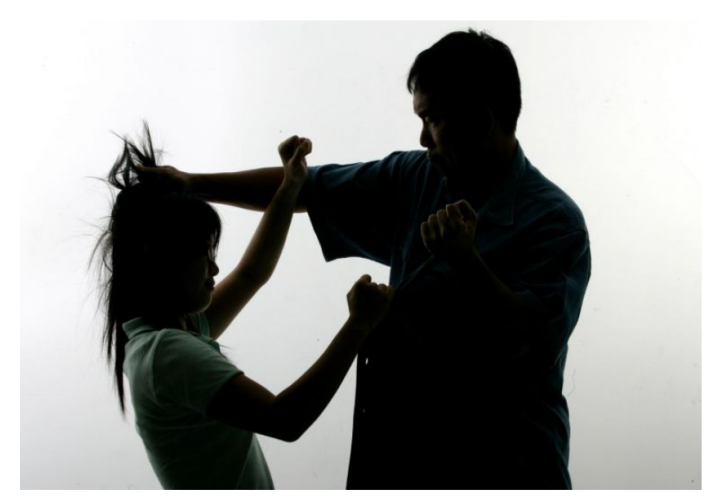

(lau, 2020)
Coronavirus: Rise in domestic abuse cases as families forced to stay home

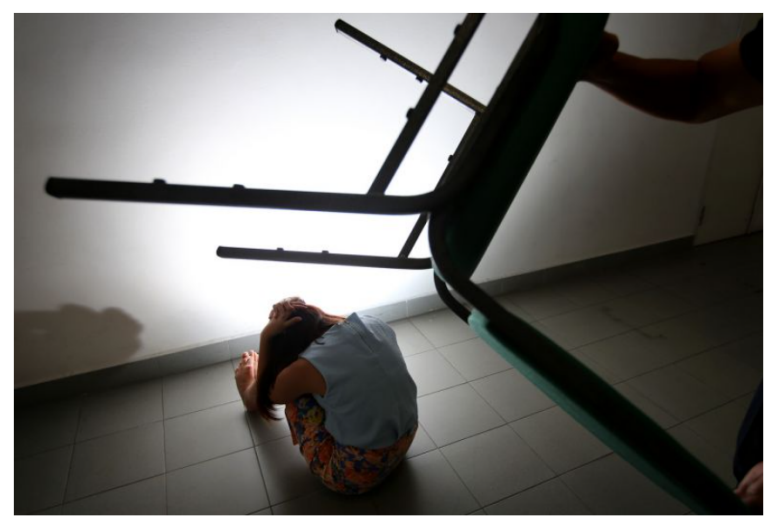

(Wong Yang, 2020)

MSF's educational resources and social service websites such as PAVE's briefly mention the non-physical and non-verbal aspects of DV, but much of the representation privileges support information for those whose experiences centre on physical violence: get a medical examination, apply for PPO and go to a crisis shelter, with "counselling" being the typical exception. This is consistent with how shelter policies admit mostly women who have gone through physical violence, and the difficulty of PPO applications for psychological or emotional abuse (J. Lim, 2019a).

The language of 'incidents' or 'events' is often used (Lim, 2020; Wong Shiying, 2020; lau, 2020). In a government article on DV over the COVID-19 lockdown, the tips offered to "stop" DV referred to violence as something that "erupts" from an argument; DV as events that happen through "violent explosion[s]" ("What to do if someone is experiencing violence", 2020): 
What can I do?

If you are a:

Victim

- Withdraw from an argument before it gets worse, if you know what triggers the person using violence

Person using violence

- Step away from an argument by using "time-outs" or a cooling off.

- During this cooling off, you should avoid activities that can aggravate violent behaviour like drinking or abusing drugs.

- Engage in positive activities that can help you to self-regulate your behaviour.

- If you know what your triggers are, learn how to watch for them and try to walk away from the situation. This is a temporary interruption technique that can curb a violent explosion.

However, the above tips may only work for a while. Said Ms Aw, "De-escalation is only a short-term strategy. Reaching out and seeking help from professionals to address safety concerns and underlying issues in the relationship is key to ending violence in the long run."

Although there is acknowledgment of the ongoing patterns of DV by Ms. Aw, overwhelmingly, the list represents DV as having a clear beginning and end: a trigger that can be identified, a build up in "arguments" caused by anger, eventually culminating in physical violence. These problematisations edge out the elements of power and control, the relational pattern of DV, and even the psychological or emotional aspects of DV. Coercive control, which does not necessarily have to "resort" to physical abuse or verbal denigration, is left unproblematic. This is incongruent with the discourses on DV experiences, particularly those articulated in first-hand accounts. There is also overwhelming silence about the ideological forces that uphold DV, particularly patriarchal violence. Rather, this problematisation takes patriarchy as an inevitable 'given' in our society and that intervention to stop physical or verbal violence is the best one can hope for.

\section{"Equipping bystanders"}

In all of BTS's videos, intervention is literally the final scene in narratives about DV. In one video ("First Steps", 2016), an old woman is seen getting increasingly frustrated and disturbed by the screams of a young boy emitting from her neighbour's flat, where his father canes him. The old woman eventually decides to walk to the neighbour's flat. The child's screams quieten as the abusive father answers the door. The old woman smiles and offers them some cake. She walks off, as he looks immediately remorseful. The video ends. In another ("Will you support?", 
2017), a woman's husband screams at her over the phone. As she looks anguished at the end of a work day, her colleagues get together to approach and console her. The video ends.

Both videos end with people interrupting violence, and we are left guessing what happens after an intervention-or, more likely, assuming that the intervention went successfully to end the violence once and for all. The process of the intervention, the considerations that women make, and the way State systems are able to support women are ultimately unquestioned. The videos do not show bystander intervention as one clear solution to ending DV; in fact it demonstrates a lack of tangible solution. They portray DV as something that will continue unless bystanders interrupt it (which implicitly reveals that it is bystanders responsibility to stop it), and will immediately halt or de-escalate when there is bystander involvement (which reveals the belief that all interventions are good interventions).

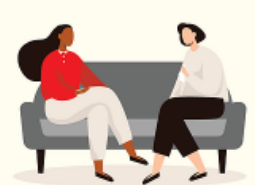

\section{TALK IT OUT}

Talk to the person in a non-judgmental tone and lend a listening ear. Allow the person to express her/his emotions and give time for the anger to subside.

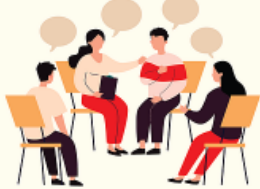

\section{MEDIATE}

When the situation stabilises, offer your help to mediate the couple's issues or offer your assistance in linking the couple to a Professional.

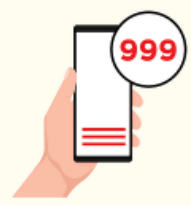

7. CALL the police

If the situation escalates and

gets out of hand, call the

Police if necessary.

(“Help is here", 2020)

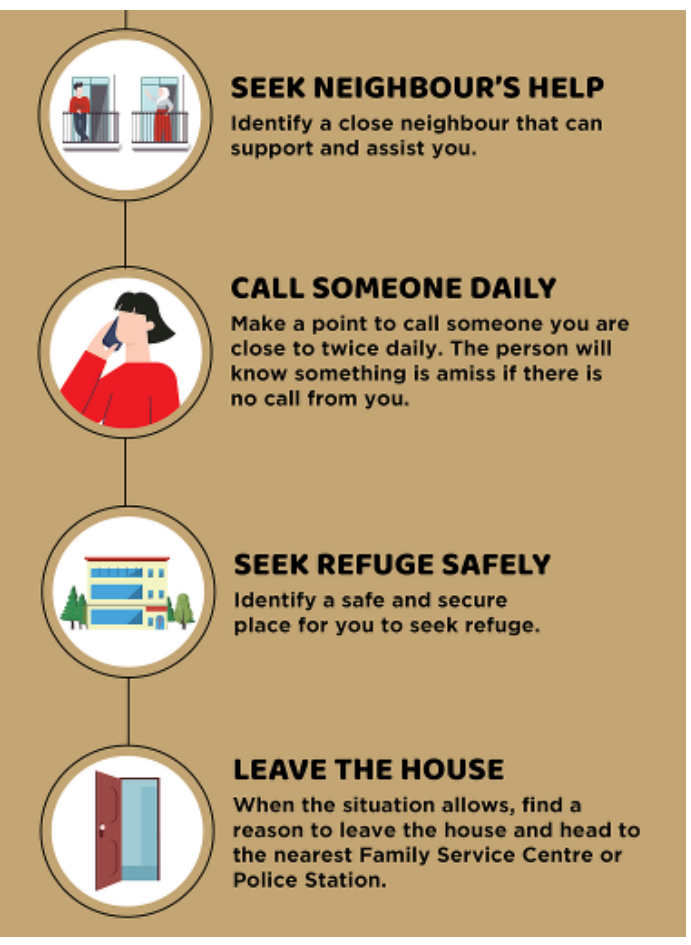

("Help is here", 2020) 
Similar to BTS, much of End Domestic Violence's focus is on the actions that those experiencing DV can do to minimise the impact of violence in their homes, and bystanders can do to support them (images above). It goes into a little more detail than BTS but still tends to emerge in simple lists of superficial dos and don'ts, revolving once again around noticing physical and verbal signs. The solutions are similarly limited to "calling the police", making contact with people experiencing DV to "listen and empathise" and accompanying them to the police/FSC. Notably, one infographic even gives brief details on mediation including "separating the couple" and "talking it out" until their "anger...subsides" ("Help is here", 2020).

What both these approaches do is assume that bystanders already have the information, skills, principles and ethical values required to end DV. But as established in the findings of this thesis, mediation efforts veer towards maintaining the status quo, typically for the purposes of restoration or reconciliation. Mediation runs the risk of flattening power dynamics. Given the dominant discourse and policies that support patriarchal, nuclear families, is it reasonable to expect communities to mediate a couple's 'issues' without reproducing ideologies that cause further harm to women? It is also dangerous to view physical intervention as a catch-all solution that will always lead to de-escalation, especially considering the findings of this thesis where women report family intervention causing abuse to, in fact, escalate.

Overall, there is silence in the way the State and services continue to enact indirect violence and oppression on families as they attempt to wean themselves out of abusive relationships. It is however consistent with the State's principle of family-and sometimes community-as the first line of social protection, rather than the State, and the privatisation of the problem and solutions of DV. This way, the State maintains its role as advisory, with a goal to keep the patriarchal family unit together.

Public education serves as a tool by the State to establish a specific role of bystanders as 'governable subjects': to manage DV (imagined only as physical and verbal violence), in one-off interventions (imagined only in the "FSC-hospital-policesometimes mediation" refrain), and for the purpose of restoring the peace (or keeping the family unit together). Public education is mainly aimed at "early intervention", rather 
than prevention and eradication. DV then becomes a problem of uninterrupted, visible violence, the responsibility of families and communities, instead of relational, invisibilised, structural violence, the responsibility of the State and the ideologies it upholds.

\subsection{Religious and cultural counter-education}

Over the years, substantive effort has been put into countering common misinterpretations of religious texts that seemingly justify DV (Sumartono, 2016). In a few campaign videos by End Domestic Violence, asatizah were brought in to debunk patriarchal interpretations of texts. MUIS and MSF also developed new training initiatives with asatizah on family violence (Baharudin, 2019).

Our asatizah play an essential role in widening outreach efforts and demystifying justifications of family violence that are perpetuated by sociocultural norms within the community. (MUIS, 2020)

Given that additional effort in policy has been placed to counter misrepresentations, DV is represented as a phenomenon that (at least prior to training) religious teachings and religion, by and large, have tolerated or misconstrued. How does this silence the ways in which DV and patriarchal beliefs are excused in wider society?

It is perhaps seen in the way patriarchy is represented as a foreign or Othered entity. In one 2019 article about family violence, a senior social worker stated, with regards to foreign women who experience DV in Singapore, that the women may "bring with them certain cultural beliefs rooted in patriarchy" where DV is "more tolerated and normalised" (J. Lim, 2019b). Although it was not stated which cultural group this was in reference to, patriarchy was specified as a problem of migrant wives' culture that was "brought in", implying that it is a foreign entity. In the problematisations above, the cultural realities and impact of Singapore's wider patriarchal ideologies therefore get erased, and patriarchal hierarchies and 'beliefs' become an entrenched part of a specific, minority cultural group.

In my interviews, some participants spoke of the importance of being more strategic with what could be seen as counter-education, to demystify religious interpretations 
within the 'right' context, and debunk misconceptions that arise, including from mistranslations of Arabic.

I think it'd be very good if the mosque could start to look into it, providing psychoeducation, perhaps maybe Friday prayers khutbah. Because we have so many mosques and [khutbahs] come from the MUIS text. So it could be something that the Imam could just say, you know, and you're looking at the men. The men are the ones that mostly go to Friday prayer, the ustaz could give a message [on] how Islam really views family violence, how Islam actually say that men should protect woman instead of abusing them. (Yati, counsellor)

[We need more] awareness building about domestic violence within the Muslim community. One area which is often overlooked is services for perpetrators of abuse. I don't know of space especially dedicated to that. A place where Muslim men can go, which is well informed. If you're saying that Muslim men often use religion as a way to control, then there needs to be a specialist organisation that can also speak that language with abusers. Like, okay, where in the Quran does it say that? How do we demystify some texts? (Bel, case worker)

In the above problematisations, misinterpretations of religious texts is identified as one source of patriarchal violence against women, presupposing that religious values (however distorted) in and of themselves may be what causes men to use violence. This problematisation can of course exist parallel with other ways that policy and practice have conceptualised DV. But given the policy texts analysed above, they, at the very least, run the risk of over-privileging value-systems within cultural or religious groups as the source of DV, and move towards remedies which we have already observed: 'solving' misinterpretations through religious education.

The first training that we have for [support workers] is all about unpacking their own biases and understanding structural problems that women face in our society today. [We] also talk about Muslim women and all the oppression that they have faced, try to unpack this myth that Muslims are lazy people, and there are many reasons why they could be more often than not in low paying jobs. One thing is key is for them to then unpack their biases and myths for particular communities, including domestic violence. I guess we'll talk about some level of cultural competence, not just in the Muslim community but other cultures as well. Because we do recognise our (support workers) as a mix of so many cultures. (Bel, case worker)

In a couple of other interview responses, there appears to be a desire to see the cultural understanding of marriage redefined to be more egalitarian, and, as quoted before, a call for religious authority to play a role in this cultural reshaping.

Muslim families, we really have to rethink what are our expectations are. If we don't get it right, this is where all sorts of all sorts of shit in the vicious cycle go on. Child abuse...the child grow up being abusive himself and all that. What is it you expect your wife to be, your husband to be, and how we perceive marriage. Because if we can sort of get that right. I'm not saying all our problems will be solved (but) a lot of things will improve. (Farah, legal professional) 
In this problem representation, marriage education on equality within gender relations is presupposed to be a preventative remedy to DV. At the same time, the ways in which gender roles and relations are reproduced in other arenas are rarely brought up. For instance, MUIS' own statements on 'roles and responsibilities' in a household reaffirms this ("Understanding our roles and responsibilities", 2017), although it appears to reconcile this with a violence-free household. As seen in the previous chapter, these ideologies have trickled down into the formation of families and the inconsistency in some participants' acceptance of patriarchal gender roles and their understanding of patriarchal DV.

Furthermore, the unflinching acceptance of families as authoritarian may contribute to the social isolation of those experiencing violence. Any attempt to reconcile a 'head of household' or leader in a family with a healthy relationship has to explicitly deny that abusive relationships centre around an imbalance of power in an abusive relationship. This is something that is precisely seen in some problematisations of DV, wherever participants and policy texts flatten the power dynamics between those perpetrating violence and those that experience it.

The privileging of the role of Malay/Muslim "culture" is also seen represented in trainings organised by government institutions such as the National Council of Social Services (NCSS). One training titled "Understanding and Working with the MalayMuslim Clients" [sic] works to focus on the "multi-faceted nature of Malay-Muslim culture, in allowing social work practitioners to attain in-depth awareness and understanding when working with Malay-Muslim clients". Based on the course outline alone, it focuses on cultural practices and religious beliefs which would allow social workers to:

By the end of the course, participants will be able to:

1. Identify the subtle differences in working with the Malay-Muslim clients

2. Identify and understand how participants' beliefs and values impact on the intervention plans for the Malay-

Muslim clients.

3. Understand the change process (Muslim Perspective of Change).

4. Integrate western-based counselling theories to the socio/religious perspective of the Malay-Muslim clients.

("Understanding and working with the Malay-Muslim clients", 2017) 
This text demonstrates a few things: that differences with working with Malay/Muslim clients are largely cultural and religious (rather than in relation to other intersections such as socioeconomic oppression); that a Muslim framework is necessary for "change" to arise; and that the "Western" theories of counselling stand in opposition to Malay/Muslims' belief systems. It has the effect of essentialising culture and religion, and risks over-privileging cultural reasonings to social and political problems that emerge as a result of historical and oppressive forces that are far greater than the individual Malay/Muslim 'client'. Thus, culture and religion appear to be reduced to a set of attitudes, beliefs, misconceptions and dispositions that individual 'perpetrators', 'victims' and the 'society' hold, unlinked to the State structural conditions. This works to imply how wayward religious and cultural values within an ethnic minority population are a major cause of DV.

\subsection{Legal and criminal justice remedies}

Finally, legal and criminal justice remedies are offered as a major solution to DV, with information on websites offering information on making police reports or applying for a PPO or Magistrate's complaint ("Help available", n.d.; "Family violence", n.d.). I also witnessed this solution offered in participants' ideas of what should be done by those experiencing DV.

I usually get cases that's referred by the family court. They are the mandated counselling cases, where actually this client already approached Family Court to seek PPO. So that's when the client is more ready, and that's when work can be easily done, because [they've done] the first step of getting PPO. (Yati, counsellor)

The idea of women's readiness is therefore prioritised in their access to safety, and it could be assumed that this readiness is tied to women's use of criminal justice tools, presupposing that the criminal justice system is necessary for DV to truly 'end'.

Participants' interviews revealed another discursive effect of criminal justice or legal solutions: DV is presented as a violation of women's or human rights. Bel spoke about the way direct services are used "to allow somebody to realise their full potential and the rights that they have". This is seconded by Maya's beliefs where she stated that education on 'women's ... and human rights' would remedy DV. More broadly to the 
point on legal and criminal justice remedies, Farah described ignorance of the law as one reason why people perpetrate DV, while Yati spoke about how PPOs can have a tangible effect on ending abusive actions:

\begin{abstract}
I think a lot of it is because the perpetrator didn't know the law doesn't condone what he's doing that....just because this is my child I can go and whack until blue and black. Or just because it's my wife right, I can push her around, lock her out of the house, physically injure her. So the minute an application was made for PPO suddenly they realised, oh shit actually I cannot do this. So a lot of this ignorance. They don't know that the law doesn't allow it and that there's this thing called the Women's Charter. (Farah, legal professional)
\end{abstract}

PPO is not just protection for the victim, but it's also protection for the perpetrator because it stops them from acting out their violent behaviour. (Yati, counsellor)

In these problematisations, there are assumptions that if it were not for ignorance of the criminality of their actions, men might not use violence; or that PPOs have more than a symbolic legal power and act as a force or 'protection' which can stop abuse. This gives a huge amount of power to PPOs as a legal remedy, propping up the current law against DV, and centres conversations on solutions to DV around the PPO system. The power of the law is also reiterated by Yati, who said:

Sometimes, I will still check in with (the women), see how they are doing. You need to journey with them, because if you let go, then their hope becomes even less. Because this culture, this mindset is so strong that you need to really show them that women can get help, that there's laws in Singapore [to protect them]. ...In Singapore, because we have the Women's Charter, and we are under the secular system, we have MSF and the Family Court, that could be [helpful]. It is just how women personally want to seek out help. (Yati, counsellor)

Above, we see how some of the State's problematisation have resulted in professionals viewing women's role in ending the DV they experience, the perception of laws as rational forms of remedies, and the view that the law's "protections" is assumed to be strong enough to go against cultural norms_-seen as "outside" the law.

Participants also spoke about their hopes for changes to family violence law. Bel spoke about working towards "some advocacy areas to inform changes in the law, policies, and procedures that have an impact downstream to individual lives." Sofia said:

I think a lot of people think it is just something pragmatic to have a head of household. Singapore at the end of the day is a very pragmatic state, and they do have a certain idea of how a very structuralist, functionalist kind of family as the ideal family. So while the discourse and narrative is slowly changing, the policy is still sticking to what it thinks is pragmatic and what works, but I think it's a good thing to at least get the discourses going because policies tend to change a lot more slowly. I know that there's this issue of, shouldn't you change your policy first and then you know, community will follow. But it's always a chicken and egg question 
- what do you change first, because on one hand you want to the changes to be more organic, so that people will not challenge the policy, rather than you impose a very controversial policy and people make a hoo-hah and you end up maybe losing a few people before you even start.

For me the, one of the main problems, that kind of contributed to DV within the Muslim community is this idea of submission to the husband, [husbands having] an authority over the wives and all that. Which is why I think more can be done in terms of family law to address that. ...I think policies and even premarital courses are very important touch points, even the F2F sessions with the naib kadis [solemnisers]. (Sofia, researcher)

Here, changes to policy and law is presupposed to trickle down into the way individuals behave. But the removal of an already existing patriarchal policy was also described, by Sofia, as a controversial move by the State that would cause society to challenge it.

Based on all of the above, the problematisation of DV lies in the shape and borders of the legal system: DV is presupposed as something that will be remedied or reduced according to whether laws change, and whether individuals are aware of their rights. Rights-based discourse are therefore more likely to limit its remedies to criminal justice or legal remedies, representing the solution to DV as State mechanisms like police reports, PPOs and court orders.

To understand the over-privileging of legal and policy remedies to DV, I studied a speech made in September 2020 by Minister for Law K. Shanmugam (MHA, 2020), where he announced the process of a White Paper on gender equality. The speech goes into policy and legal actions taken to address violence against women. Yet even its title ("Conversations of Women Development") frames gender inequality as an issue of the lack of development and the responsibility of women. The speech uses the language of "mindset change" and education, but there was also a description of violence being a violation of "fundamental values". While this appears to be a promising expansion of the State's problematisation of DV, there is little self-reflexivity involved: 'fundamental values' is described as something that must be instilled, with State leadership, instead of an act of learning and unlearning that State systems need to do, too. The Minister spoke about what transgressing these values will result in: 
10. Gender equality is going to take a lot of effort, but I believe we can do it. It is going to require a change in our cultural value system.

11. How would this work? Take penalties for sexual violence for example. It should not be approached simply as penalising an offence.

12. It must also be seen as penalising a gross violation of fundamental values. That means the usual mitigating factors will have less force when they are viewed in the light of an act that is a breach of fundamental values.

15. The approach should not be that it is just another offence. And our laws, penalties, mitigating factors, and whether some factors are mitigating factors, should all reflect our values and mores as a society.

21. Let me say, in terms of the penalties, we have made them stiffer for a series of offences. We created new offences on grooming, but those are the relatively easier parts.

22. As I said, the discussions set me thinking: Is there a more philosophical, fundamental way of approaching this to deal with the problem, beyond just increasing the penalties? To try and make sure that in the first place, people are aware that they shouldn't do it, and how society views these offences.

In his problematisation, expanding the role of the criminal justice system - through stiffer laws and harsher penalties -is a given. Criminal justice penalties are inevitable in the way DV is dealt with, for society to be more progressive and safe for women. It represents the State's punishments as proportionate to the amount of harm caused by DV, imagining that penalties can actually end DV.

Unfortunately, the silence in this problematisation is in the role of the State in enacting further structural violence on vulnerable families (e.g. through economic consequences on weakened families and communities) and the emotional costs of seeking support from a legal system. It also silences the possibilities of other solutions and measures that are not punitive - that are, in fact, transformative in dismantling existing structures of patriarchal oppression. Criminal justice remedies sit uncomfortably given the reality of ethnic minority oppression within its system. For instance, we know that punitive drug laws disproportionately impact the Malay population. Even in one of my interviews with Irfan, he mentioned how DV is complicated by "addiction issues", wherein those perpetrating DV might justify their control of finances with reasons such as "I need (this drug) to work, I need to be able 
to function." There is no denying the intersection of class and race, and the quote by Irfan shows how it operates within abusive households too.

In DV cases, State violence and re-victimisation occur also through victim-blaming first-responders, inadequate support from social services, lack of holistic, long-term support for those experiencing DV, the economic oppression that ethnic minority families struggle against, and the material effects on their wellbeing, health and livelihoods as a result of multiple systems of oppression (Ganapathy, 2008). Reliance on these remedies bolsters the racism, patriarchy and homophobia coursing through criminal justice systems, and promotes an individualistic approach to ending DV (Davis, 2000). As a result, we are left grasping at straws when trying to imagine community accountability strategies that transform social and community support systems-beyond restorative efforts to keep families together despite the needs of those experiencing DV.

\subsection{Conclusion}

In this chapter, I observed how solutions offered by social policies represent DV as: events or incidents culminating in physical violence, resulting from the individual criminal conduct of controlling or violent men, particularly within a racial and religious minority (which in turn rationalises increased policing and regulation of the population through religious education and governance); individual lack of 'empowerment' of women who are unable to leave abusive relationships largely by adapting to a neoliberal capitalist economy; disempowered communities who tolerate or ignore violence; and those experiencing and perpetrating DV both lacking an understanding of human rights. Through the solutions offered, the State acts to intervene (even if it is a last option) and change its governable subjects-'victims', 'perpetrators' and 'bystanders'-positioning itself as the solution to patriarchal violence.

Bacchi encourages researchers to apply the same mode of questioning to their own problematisations as a step to encourage self-reflexivity. It was difficult confronting my own presuppositions about DV that I came into this study holding on to - and undoubtedly, inadvertently brought into the research journey. The approach has revealed to me how, having had to professionally work within the confines of the 
State's limitations for so long, I had restricted my own imagining of policy solutions to ways that do not stray too far from the State's own problematisations and remedies. Over the last few years, several presuppositions I had were repeated by others around me rather than interrogated. I assumed that cultural competency of social services is a rational solution, thereby imagining the parameters of 'culture' as divorced from historical, ideological and structural conditions. Like many of my participants, I shared visions of greater community education efforts organised by MUIS, presupposing the disproportionate power of individual religious values in the cause of $D V$, and not deeply interrogating the ways in which MUIS functions to support a patriarchal, authoritarian State. I found rationality in expanding the legal definition of family violence to include coercive control, inadvertently relying once again on a punitive and racist criminal justice system to come up with effective solutions. I also witnessed my problematisation beyond the theoretical, and in my personal responses: how, in wanting to be a "fixer" in situations of violence, I had learnt to be adamant about fitting my circumstances into a pre-constructed mould of what DV looks like, according to the solutions that are already available.

None of the above is to say that these remedies are entirely invalid; rather, they cannot be held to a standard where they become the solutions to DV in an otherwise unchanging structural landscape. Structural transformation-in a form of governance that is intersectional, feminist and anti-capitalist-is the solution to DV that is needed and it could be reasonably assumed that from there, what ripples out (whether it is an expansion of services or greater public education) will reflect these ideologies. 


\section{CHAPTER 7. CONCLUSION}

Despite State campaigns and statements that articulate the belief that family violence is not a private matter, Singapore's social policy solutions are still privatised and cultural. In the fight against DV, the State is positioned as a solution, with rational, advisory powers to fix DV, and distinctly separate from the problem itself. The problem of DV is seen as cultural, and understood to be a problem that may be fixed through treating and 'educating' individuals about problems with their culture/religion. This has resulted in solutions "for" the Malay/Muslim population, carving the old line between mainstream, Anglo-Chinese culture and what the State sees as a backwards and violent "Malay/Muslim culture" resistant to social progress and integration (J. Tan, 2014). Cultural solutions are expected to work against the largely unchanging, seemingly inevitable status quo of societal and structural realities.

The State's ideologies-authoritarianism, patriarchy and neoliberal capitalism-are hence made rational and legitimised in policy and practice. Within this problematisation, women's safety and freedom from violence hinges almost entirely on their own behaviour. So for DV to end, abused women absorb the responsibility. To be safe, they must be empowered, know their rights, recognise abuse, make police reports, call social services, work out their "conflicts", and have their responsibility monitored in disempowering policing and shelter systems. If they must leave their relationships to be safe, they have to get a divorce, find housing, get a job, absorb the cost of care, and rely on the wealth and support of extended family.

To tie these findings back to my overarching research question, I conclude that Singapore's social policies represent DV within the Malay/Muslim population as a result of collective or cultural deficiency, divorced from historical and structural realities, and the ideological stance of the State. This is despite how representations of DV by participants and in first-hand accounts, instead, show that the problem is an echo of wider structural violence, the tragic poetry of which can be observed in the details. Malay/Muslim women's freedom of religion and faith practices are limited by men who coercively control them, and wield conservative interpretations of religious texts - an echo of how the State relies on patriarchal leadership and a paternalistic 
approach (including through laws that gag racial and religious discourse) to govern the 'othered' Muslim population. Malay/Muslim women's freedom of movement is curbed by those abusing them, while the government's social policies, social sector and criminal justice system supervise and police their only options for safety. Women face violations in their autonomy in private and public spheres for instance, through clothing regulations: by men who determine what they wear, and a government that similarly imposes justifications of prohibitions of the tudung in many job sectors. Women articulate DV as violence that results from "disobeying" their husbands, justified by religious leaders, while the State similarly justifies "nushuz" in law, sanctions violence through messages within pre-marriage courses, doles out carceral punishments and regularly uses corporal violence against its own transgressors. Women are told by family, friends and religious leaders to uphold the patriarchal household, and State policies punish those who leave patriarchal households.

By ignoring how structural violence ripples out into individual experiences, social policies and practices eliminate the role of main characters of domestic violencepatriarchal authoritarianism, neoliberal capitalism and racial and class oppression. It allows the State to conceive of an idea of patriarchal DV decontextualised from historical and political forces, and to shape public discourse to be limited to solutions that produce governable subjects, from 'victims', to 'bystanders', to 'perpetrators'ensuring that individuals work largely within the purview of the State's agenda.

Devastatingly, our current system leaves in its wake an Indigenous population that bears the weight of a turbulent relationship with the nation State and its colonial history. Malay/Muslim women experiencing DV continue to seek trust and connection and resistance within their own community - which are politically weakened, disrupted and represented by its most conservative leadership through colonialism and neoliberalism.

To truly end DV, instead of simply creating DV policies and programmes, we must radically re-imagine and change the structures in our society, including how the "domestic violence industry" (Koyama, 2006) has co-created current problematisations of DV. How can organisations commit to an intersectional, antineoliberal capitalist framework in their work with women and families? Self-reflexivity 
is necessary to change advocates' social constructions of those affected by DV (not as "clients" but as advocates or potential organisers), of culture (not as simply centred around ethnicity and religion, but as variable, and co-led by ideologies within State norms), of community (not as a static, romanticised 'bystanders' and mediators, but as overlapping groups that social service organisations need to be held to account to); and of criminal justice or legal remedies (not as neutral, rational solutions, but as current sites of patriarchal authoritarianism that have the effect of traumatising and disempowering minority communities) (Smith, 2005).

More radically, the process of 'decolonisation'-increasingly popular in academic literature, and public and political discourse-is seen as a structural way to eradicate DV. Lisa Kahaleole Hall (2009) identifies Indigenous feminism as the solution to patriarchal colonialism when she wrote:

Feminist theory remains integral to the process of decolonization for Hawaiian and other indigenous women because colonialism takes place through gendered and sexualized forms that reconstitute both individual and communal indigenous identities in stigmatized and disempowering ways. (Hall, 2009, p.15)

The solution to DV then lies in the decolonisation efforts that can dismantle the violence of colonial structures. As seen in my literature review, Malays have, as a direct result of colonial racial hierarchies, gradually been left concentrated in the lower rungs of economic progress since the British colonial era (Rahim, 1998; Ng, 2019). Yet in Singapore, 'decolonisation' as a process, arguably, more often refers to the move of the nation as a former British colony to the independent Republic that it now is. Some scholars have attempted to draw attention to the continued struggle of decolonisation within the post-colonial State (Curless, 2016) and examining particular laws such as ones that restrict free speech as a colonial inheritance (Thanapal, 2020). But British colonisation of Singapore has largely been praised in education and politics, and British rule has been described by Singapore's influential leaders as a "positive legacy" (Dziedzic, 2020). Efforts to catch up to the wider, global conversation on decolonisation has been limited, and arguably attempts for decolonial social movements would be restricted by the government's laws that muzzle free speech and assembly. But to end DV, the Singapore State has to see itself as part of the problem, to critically confront its colonial past and present, by recognising how it inherits 
mechanisms of control and stratification that the British colonial government employed which marginalise the Indigenous Malays and minoritised populations.

Such ideological reframing is one small part of the work required to prevent DV. While much ink has been spilled on ending DV and gender-based violence through the implementation of DV and health-relationships education in schools and universities, structural transformation challenges us to consider intersections. Prevention of DV should also include mandatory education in schools on gender, race, sexuality and socioeconomic class inequality. A critical look at how the inherited forces of colonialism have affected racial and gender minorities must also be included in this education. This has to mean that public discourse on systems of oppression and privilege should not be censored or regulated by the State, in order to allow progressive, decolonial work to grow.

Structural transformation also includes infrastructural guarantees, where basic material needs such as stable, comfortable housing, legal resources, Internet, healthcare, financial resources and more-all of which are ultimately crucial for women in vulnerable circumstances-are provided by the government. This is crucial to mend or mitigate the social consequences that women (and their weakened communities) are now burdened with when leaving or remedying violent relationships. Such support services have the potential to tend to the outcomes of trauma from DV in the shortterm (by eliminating structural and discursive violence that women now experience), and when DV has ended for them (through robust mental and physical healthcare and recovery).

Ending DV is an enormous undertaking requiring more than quick-fix, culture-specific solutions. In imagining healing, I imagine transformation. Transformation carries the potential of repairing the harms caused by generations of colonial and State oppression. Instead of allowing the internalisation of problematisations that point to self-reliance and individualised empowerment to continue, transformation of our systems can create flourishing, supportive, well-resourced and empowered communities. Such an approach benefits not only the Malay/Muslim population, but will uplift and strengthen many vulnerable groups who are oppressed by current neoliberal and authoritarian conditions. 
We need vigorous interrogation of taken-for-granted solutions to domestic violence, and to reimagine what long-term eradication and recovery can look like. In the work for justice-driven, structural change, policy workers, politicians and advocates alike need to always reflexively ask themselves "what is the problem represented to be?" in any policy proposal, so that abused women are never taught to absorb the effects of their current lack of inquiry by, instead, asking themselves, "Apa salahku?" - what's the problem with me? 


\section{REFERENCES}

Ab Razak, M. (2019). "World-class Muslims": Examining the Discursive Construction of a Singapore Muslim Identity. The Muslim World (Hartford), 109(3), 417-430.

Abdul Rahman, N. A. (2012). Muslim Personal Law and Citizens' Rights: The Case of Singapore. Asian Journal of Comparative Law, 7(1).

Abraham, M. (2005). Abused South Asian women's resistance. In N.J. Sokoloff (Ed.) Domestic Violence at the Margins: Readings on Race, Class, Gender and Culture. New Brunswick, N.J: Rutgers University Press. Print.

Alatas, H. (1977). The myth of the lazy native: A study of the image of the Malays, Filipinos and Javanese from the 16th to the 20th century and its function in the ideology of colonial capitalism. F. Cass.

Ali, Z. (2018) A Mother's Love: In Conversation with Shiqah. In F. Sumartono \& M. Thomas (Eds.) Growing Up Perempuan. Singapore: Ethos books.

Aljaru, M. (2020). GE2020: "Hello, I am not your model minority." In Wethecitizens newsletter. https://wethecitizens.substack.com/p/ge2020-hello-i-am-not-your-model Allowing hijab problematic for some jobs: Yaacob. (2013) TODAY.

https://www.todayonline.com/singapore/allowing-hijab-problematic-some-jobs-yaacob Almeida, R., \& Lockard, J. (2005). The cultural context model. In N. J. Sokoloff (with C. Pratt; Eds.), Domestic violence at the margins: Readings in race, class, gender, and culture. New Brunswick, N.J: Rutgers University Press. Print.

Almeida, R., R. Woods, R. Font, and T. Messineo. (1992). Power and Control wheels. Institute for Family Services.

Al-Yaman, F., Van Doeland, M., \& Wallis, M. (2006). Family violence among Aboriginal and Torres Strait Islander peoples. Australian Institute of Health and Welfare. 
Amirthalingam, K. (2003). A feminist critique of domestic violence laws in Singapore and Malaysia. Asia Research Institute. Working Paper Series, No. 6. https://ari.nus.edu.sg/wp-content/uploads/2018/10/wps03_006.pdf

Administration of Muslim Law Act (AMLA). (2020). Singapore Statutes Online. https://sso.agc.gov.sg/Bills-Supp/611965/Published/19651218?DocDate=19651218\&Provlds=legis\#legis

Annex: Single Parents' Access to Public Housing. Findings from AWARE's Research Project (2016). AWARE. https://www.aware.org.sg/wp-content/uploads/Single-ParentsAccess-to-Public-Housing-Annexes.pdf

Asia Law Network (2017). Muslim Divorce in Singapore.

https://learn.asialawnetwork.com/2017/09/07/muslim-divorce-in-singapore/

Bacchi, C. (2012a). Introducing the 'What's the Problem Represented to be?' approach (Vol. Engaging with Carol Bacchi: Strategic Interventions and Exchanges). Adelaide: University of Adelaide Press.

Bacchi, C. (2012b). Why study problematizations? Making politics visible. Open Journal of Political Science, 2(01), 1.

Bacchi, C., \& Goodwin, S. (2016). Introduction. Poststructural Policy Analysis: A Guide to Practice (pp. 3-12). New York: Palgrave Macmillan US.

Baharudin, H. (2017). New Cabinet line-up: Six office-holders each from Malay, Indian communities. The Straits Times. https://www.straitstimes.com/politics/cabinet-to-havetwo-malay-full-ministers-as-masagos-takes-charge-of-msf-and-maliki-moves-up Baharudin, H. (2019). Training to identify signs of family violence for Islamic teachers. The Straits Times. https://www.straitstimes.com/singapore/islamic-religious-teachers-to-gothrough-training-to-identify-signs-of-family-violence

Barwick, K., McGorrery, P., \& McMahon, M. (2020). Ahead of Their Time? The Offences of Economic and Emotional Abuse in Tasmania, Australia. In Criminalising Coercive Control (pp. 135-158). Springer Singapore. https://doi.org/10.1007/978-981-15-0653$6 \_7$ 
Beng-Huat, C. (1985). Pragmatism of the People's Action Party Government in Singapore: A Critical Assessment. Southeast Asian Journal of Social Science, 13(2), 29-46.

Beyond The Hijab, Crit Talk, Penawar and WALI (2021). Let's Not Talk About The Bad Stuff. A Study of Violence in Muslim Pre-Marriage Courses in Singapore. Unpublished study. Bograd, M. (1999). Strengthening Domestic Violence Theories: Intersections of Race, Class, Sexual Orientation, and Gender. Journal of Marital and Family Therapy, 25, 275-289. Bohall, G., Bautista, M.-J., \& Musson, S. (2016). Intimate Partner Violence and the Duluth Model: An Examination of the Model and Recommendations for Future Research and Practice. Journal of Family Violence.

Break the silence. (n.d.) MSF. https://www.msf.gov.sg/breakthesilence/Pages/Home.aspx Break the silence campaign to encourage intervention in family violence situations. (2017). MSF. https://www.msf.gov.sg/media-room/Pages/Break-the-Silence-campaign-toencourage-intervention-in-family-violence-situations.aspx

Briggs, F., Ang, B.L., Yeo, G. \& Lushington, K. (2001). Social Worker and Counsellor Perceptions of Singapore's Domestic Violence Prevention System. Asia Pacific Journal of Social Work and Development: Social Work in the 21st Century, 11(2), 85-108.

Bryers-Brown, T. (2015). "He reached across the river and healed the generations of hara": Structural violence, historical trauma, and healing among contemporary Whanganui Māori. Thesis (M.A.) - Victoria University of Wellington, 2015.

Carlson, B.E.; Worden, A.P.; Ryn, M.V. \& Bachman, R (2003) Violence Against Women: Synthesis of Research for Practitioners. https://www.ncjrs.gov/pdffiles1/nij/grants/199577.pdf

Casa Raudha [@Enddomesticviolence.sg] (2020c). End Domestic Violence webinar. [Image attached] [Status update] Facebook. https://www.facebook.com/enddomesticviolence.sg/photos/202594564559668/

Casa Raudha [@Enddomesticviolence.sg].(2020a). End Domestic Violence webinar. [Image attached] [Status update] Facebook. https://www.facebook.com/enddomesticviolence.sg/photos/200701488082309/ 
Casa Raudha [@Enddomesticviolence.sg]. (2020b). End Domestic Violence webinar. [Image attached] [Status update] Facebook. https://www.facebook.com/enddomesticviolence.sg/photos/202906397861818/

Casa Raudha [Enddomesticviolence.sg]. (2020d). First-person account. [Image attached] [Status update] Facebook.

https://www.facebook.com/enddomesticviolence.sg/photos/201228554696269/

Casa Raudha [Enddomesticviolence.sg]. (2020e). Video featuring Rishi Budhrani \& Sharul Channa. [Video attached] [Status update]. Facebook. https://facebook.com/watch/?v=961550377615216\&_rdr

Cavino, H. (2016). Intergenerational sexual violence and Whānau in Aotearoa/New Zealand - pedagogies of contextualisation and transformation. Sexual Abuse in Australia and New Zealand, 7(1), 4-17.

Census of Population (2010a). Statistical Release 1: Demographic Characteristics, Education, Language and Religion: Key Findings. Statistics Singapore. https://www.singstat.gov.sg//media/files/publications/cop2010/census_2010_release1/findings.pdf

Census of Population (2010b). Resident Working Persons Aged 15 Years and Over by Gross Monthly Income from Work, Ethnic Group and Sex. Statistics Singapore. https://www.singstat.gov.sg//media/files/publications/cop2010/census_2010_release3/cop2010sr3.pdf Chan, W. (2012). Violence Against Women in Singapore: Initial Data from the International Violence Against Women Survey. Handbook of Asian Criminology (pp. 329-342). Springer New York.

Chandan, T. (2020). Risk of Cardiometabolic Disease and All-Cause Mortality in Female Survivors of Domestic Abuse. Journal of the American Heart Association, 9(4), e014580-e014580. 
Charlton, E. (2019). Singapore crowned world's most open and competitive economy. https://www.weforum.org/agenda/2019/10/competitiveness-economy-best-top-firstsingapore-secret-consistency/

Chew, P. (2004). Sons and Daughters: Benevolent Patriarchy in Singapore. NIAS Nytt, 1

Chua, A. M. (2017). Campaign to help Malay/Muslims fight diabetes extended. TODAY. https://www.todayonline.com/singapore/campaign-help-malaymuslims-fight-diabetesextended

Clammer, John. (1997). Reinscribing patriarchy: the sexual politics of neo-confucianism in contemporary Singapore. Journal of the Anthropological Society of Oxford, 28(3), 249273.

Confidence Curriculum. (2020). Daughters of Tomorrow. https://daughtersoftomorrow.org/get-support/confidence-curriculum/

Conversations on Women Development. (2020). Speech by Mr K Shanmugam, Minister for Home Affairs and Minister for Law. MHA.

https://www.mha.gov.sg/newsroom/speeches/news/conversations-on-womendevelopment-speech-by-mr-k-shanmugam-minister-for-home-affairs-and-minister-forlaw

Connell, R. (1987). Gender and power: Society, the person and sexual politics. Allen \& Unwin.

Crenshaw, K. (1991). Mapping the Margins: Intersectionality, Identity Politics, and Violence against Women of Color. Stanford Law Review, 43(6), 1241-1299. https://doi.org/10.2307/1229039

Curless, G. (2016). "The people need civil liberties": Trade unions and contested decolonisation in Singapore. Labor History, 57(1), 53-70. https://doi.org/10.1080/0023656X.2016.1140623

Dasgupta, S. D. (1998). Women's realities: Defining violence against women by immigration, race and class. In R. K. Bergen (Ed.). Issues in Intimate Violence (pp. 209-219). Thousand Oaks, CA: Sage. 
Davis, A. (2000). The Color of Violence against Women. ColorLines, vol. 3, no. 3

Davis, R.A. (2018). Domestic Violence in Oceania: The Sin of Disobedience and the Violence of Obedience. In C. Blyth, E. Colgan \& K.B. Edwards (Eds.), Rape Culture, Gender Violence, and Religion (pp. 143-158). Springer International Publishing.

Declaration on the Elimination of Violence against Women. (1993) OHCHR.

https://www.ohchr.org/en/professionalinterest/pages/violenceagainstwomen.aspx

Dhunna, S., Lawton, B., \& Cram, F. (2018). An Affront to Her Mana: Young Māori Mothers' Experiences of Intimate Partner Violence. Journal of Interpersonal Violence, 886260518815712.

Doran, C., \& Jose, J. (2002). Globalization, the Patriarchal State and Women's Resistance in Singapore. Gender, Technology and Development, 6(2), 215-232.

Dziedzic, S. (2020, February 11). Singapore's quarrel over colonialism. The Interpreter. https://www.lowyinstitute.org/the-interpreter/singapore-s-quarrel-over-colonialism Eligibility - Public Rental Scheme. (n.d.). HDB. https://www.hdb.gov.sg/cs/infoweb/residential/renting-a-flat/renting-from-hdb/publicrental-scheme/eligibility

Eligibility conditions that apply to all schemes (n.d.). HDB. https://www.hdb.gov.sg/cs/infoweb/residential/buying-a-flat/resale/eligibility\#: :text=Buy\%20an\%20HDB\%20resale\%20flat\%20as\%20a\%20single.,are\%20widow ed\%20or\%20an\%20orphan.

Ethnic Integration Policy. (n.d.) HDB. https://www.hdb.gov.sg/cs/infoweb/residential/buyinga-flat/resale/eligibility/ethnic-integration-policy-and-spr-quota

Family Protection \& Welfare Services. (n.d.). MSF. https://www.msf.gov.sg/policies/Strongand-Stable-Families/Supporting-Families/Family-Protection-andWelfare/Pages/Family-Protection-and-Welfare-Services.aspx

Family violence. (n.d.) MSF. https://www.msf.gov.sg/policies/Strong-and-StableFamilies/Supporting-Families/Family-Violence/Pages/default.aspx 
First Steps. (2016, November 16). MSFCares. [Youtube video].

https://www.youtube.com/watch?v=ISP0Ful9US0\&t=3s

Foo, C. L., \& Seow, E. (2005). Domestic violence in Singapore: A ten-year comparison of victim profile. Singapore Medical Journal, 46, 69-73.

Fortune, R. D. M. M., Abugideiri, S. E., \& Dratch, R. M. (2010). A Commentary on Religion and Domestic Violence. In L. L. Lockhart \& F. S. Danis (Eds.), Domestic Violence: Intersectionality and Culturally Competent Practice (2016-06-22 ed., pp. 318-342): Columbia University Press.

Ganapathy, N \& Lian, K.F. (2016) Race, reintegration, and social capital in Singapore, International Journal of Comparative and Applied Criminal Justice, 40:1, 1-23

Ganapathy, N. (2008). Policing marital violence in Singapore. ProQuest Ebook Central https://ebookcentral-proquest-com.helicon.vuw.ac.nz

Gauthier, G. R., Francisco, Sara C., Khan, B., \& Dombrowski, K. (2018). Social Integration and Domestic Violence Support in an Indigenous Community: Women's Recommendations of Formal Versus Informal Sources of Support. Journal of Interpersonal Violence.

Ghafournia, N. (2017). Muslim women and domestic violence: Developing a framework for social work practice. Journal of Religion \& Spirituality in Social Work: Social Thought: Islam in the 21st century: Challenges and opportunities for social work with Muslims, 36(1-2), 146-163.

Goh, L. (2009). The Singapore Strategy in Managing Family Violence. College of Family Physicians Singapore. http://cfps.org.sg/publications/the-singapore-familyphysician/article/121_pdf

Goh, Y.H. (2020). Outreach efforts stepped up amid more reports of family violence. The Straits Times. https://www.straitstimes.com/singapore/outreach-efforts-stepped-upamid-more-reports-of-family-violence 
Guest, G., MacQueen, K. M. \& Namey, E. E. (2012). Introduction to applied thematic analysis. In Applied Thematic Analysis (pp. 3-20). SAGE Publications, Inc., https://www.doi.org/10.4135/9781483384436

Haj-Yahia, Cohen. (2009) On the Lived Experience of Battered Women Residing in Shelters. Journal of Family Violence.

Hall, L. K. (2009). Navigating our own "sea of islands": remapping a theoretical space for Hawaiian women and indigenous feminism. Wicazo Sa Review, 24(2), 15+. https://link.gale.com/apps/doc/A208588714/ITOF?u=vuw\&sid=bookmarkITOF \&xid=1373fb0c

Han, F. K, Fernandez, W. \& Tan, S. (1998). Lee Kuan Yew: The Man and His Ideas, Singapore Press Holdings: Singapore.

Han, K. (2020). On Black Lives Matter, racism, and what we should be doing in Singapore. https://wethecitizens.substack.com/p/on-black-lives-matter-racism-and

Hassouneh-Phillips, D. (2001a). American Muslim women's experiences of leaving abusing relationships. Health Care for Women International, 22(4), 415-432.

Hassouneh-Phillips, D. (2001b). Marriage is half of faith and the rest is fear Allah - Marriage and spousal abuse among American Muslims. Violence against Women, 7(8), 927946.

Hassouneh-Phillips, D. (2003). Strength and vulnerability: Spirituality in abused American Muslim women's lives. Issues in Mental Health Nursing, 24(6-7), 681-694.

Help Available (n.d.). PAVE. https://www.pave.org.sg/resources-help-available.php Help is here. (2020) End Domestic Violence. https://www.enddomesticviolence.sg/help-ishere

Hilsdon, A. \& Rozario, S. (2006). Special issue on Islam, gender and human rights. Women's Studies International Forum, 29(4), 331-338.

Hingorani, S. (2018). Commentary: The unequal, unnoticed life of a female worker. Channel NewsAsia. https://www.channelnewsasia.com/news/commentary/gender-equalityequal-pay-singapore-work-cpf-life-savings-10877958. 
Ho, T. (2020). [2020 Edition] How Much Does It Cost To Hire A Maid In Singapore?.

DollarsAndSense.sg. https://dollarsandsense.sg/2019-edition-much-cost-hire-maidsingapore/\#: :text=Find\%20out\%20more\%20about\%20their,maid\%20in\%20Singapore $\% 20$ is $\% 20 \% 24597$.

Hochschild, A., \& Machung, A. (2012). The second shift: Working families and the revolution at home. Penguin.

Hoe, N.K. (2018). To tackle inequality, policy mindsets must change. The Straits Times. https://www.straitstimes.com/opinion/tackling-inequality-vigorously

Holtzworth-Munroe, R. (2000). General and spouse-specific anger and hostility in subtypes of maritally violent men and nonviolent men. Behavior Therapy, 31(4), 603-630.

Hunnicutt, G. (2009). Varieties of Patriarchy and Violence Against Women: Resurrecting "Patriarchy" as a Theoretical Tool. Violence Against Women, 15(5), 553-573. https://doi.org/10.1177/1077801208331246

lau, J. (2020). Coronavirus: More cases of family violence during circuit breaker; police to proactively help victims. The Straits Times.

https://www.straitstimes.com/singapore/courts-crime/coronavirus-more-cases-offamily-violence-during-circuit-breaker-police-to

IRB Law (2020). Nafkah Iddah \& Mutaah. https://irblaw.com.sg/learning-centre/nafkahiddah-mutaah/

Isbintara, R. (2020) From Matrimony to Acrimony - What Happens to the Home upon Divorce? Karyawan.. https://karyawan.sg/from-matrimony-to-acrimony-what-happensto-the-home-upon-divorce/

Ishkanian, A. (2014). Neoliberalism and violence: The Big Society and the changing politics of domestic violence in England. Critical Social Policy, 34(3), 333-353.

Jagdish, B. (2018a). Universal welfare and saying 'no' to tuition: Teo You Yenn goes On the Record about inequality. Channel NewsAsia.

https://www.channelnewsasia.com/news/singapore/teo-you-yenn-this-is-whatinequality-looks-like-on-the-record-10246872 
Jagdish, B. (2018b). Commentary: Government transfers and social assistance - Who deserves them? Who doesn't? Channel NewsAsia.

https://www.channelnewsasia.com/news/commentary/who-deserve-governmenttransfers-and-social-assistance-10502180

Jaipragas, B. (2019). Singapore's 'brownface' saga sparks debate on race as Preetipls rap video condemned. South China Morning Post. https://www.scmp.com/weekasia/society/article/3020844/singapores-brownface-saga-sparks-debate-race Jalote, S. (2014). Discontinue the use of polygraph on assault victims. AWARE. https://www.aware.org.sg/2014/01/discontinue-the-use-of-polygraph-on-victims-ofassault/

Jamil, N. (2016). "You Are My Garment”: Muslim Women, Religious Education and SelfTransformation in Contemporary Singapore. Asian Studies Review, 40(4), 545-563. John, A. (2017). Family abuse: Men need to know violence is unmanly. The Straits Times. https://www.straitstimes.com/opinion/family-abuse-men-need-to-know-violence-isunmanly

Joraimi, F. (2019). Singapore's Malay Privileged: Affluence, Alienation and Anxieties, New Naratif. https://newnaratif.com/journalism/singapores-malay-privileged-affluencealienation-and-anxieties/share/xuna/bb4ea12f999f3e1c0df45ab2983be5df/ Josephson, J. (2002). The Intersectionality of Domestic Violence and Welfare in the Lives of Poor Women. Journal of Poverty, 6(1), 1-20. https://doi.org/10.1300/J134v06n01_01 Jumblatt, W.A. (2017). Conflating Muslim "Conservatism" with "Extremism": Examining the “Merry Christmas" Saga in Singapore. Journal of Muslim Minority Affairs, 37(3), 344356.

Keller, S. N., Wilkinson, T., \& Otjen, A. J. (2010). Unintended effects of a domestic violence campaign. Journal of Advertising, 39(4), 53-68.

Keeping Yourself Safe. (n.d.) PAVE. https://www.pave.org.sg/resources-keeping-yourselfsafe.php 
Khalik, S. (2014). Malay population the most unhealthy group in Singapore. The Straits Times. https://www.straitstimes.com/singapore/health/malay-population-the-mostunhealthy-group-in-singapore

Khng, J. N. W., \& Ow, R. (2009). Getting Out: Factors that Influenced Abused Wives'

Decisions to Leave Their Abusive Spousal Relationships in Singapore. Families in Society, 90(2), 153-161.

Khutbah: Rasulullah s.a.w.'s Way of Dealing With Anger. (2019). MUIS. https://www.muis.gov.sg/-/media/Files/OOM/Khutbah/English/PDF/2019/E19Nov29-Rasulullah-saws-Way-of-Dealing-With-Anger.pdf

Kim, M. (2019). Anti-Carceral Feminism: The Contradictions of Progress and the Possibilities of Counter-Hegemonic Struggle. Affilia, 35(3), 088610991987827-326.

Kim, S.T. \& Bhaskaran, M. (2015). The Role of the State in Singapore: Pragmatism in Pursuit of Growth. Singapore Economic Review, 60(3), 1550030-

Kong, L, \& Chan, J.S (2000). Patriarchy and pragmatism: Ideological contradictions in state policies. Asian Studies Review, 24(4), 501-531. https://ink.library.smu.edu.sg/soss_research/2272

Koyama, E. (2006). Disloyal to Feminism: Abuse of Survivors within the Domestic Violence Shelter System. http://eminism.org/readings/pdf-rdg/disloyal.pdf

Kwa, B. (2018). Studying Singapore Before 1800. NUS Press Pte Ltd.

Larsen, A.C. \& Peterson, A (2001). Rethinking responses to "domestic violence" in Australian indigenous communities. The Journal of Social Welfare \& Family Law, 23(2), 121-134.

Legal and policy distinction between legitimate and illegitimate children. (2016, September 13). MSF. https://www.msf.gov.sg/media-room/Pages/Legal-and-policy-distinctionbetween-legitimate-and-illegitimate-children.aspx

Lehrner, A. \& Allen, N.E. (2009). Still a Movement After All These Years?: Current Tensions in the Domestic Violence Movement. Violence Against Women, 15(6), 656-677. 
Leila. (2018, July 13). Life as a Child of Intimate Partner Violence. Beyond the Hijab. https://beyondhijab.sg/2018/07/13/life-as-a-child-of-intimate-partner-violence/

Levitsky, S. and Way, L. (2009). Competitive Authoritarianism, Cambridge: Cambridge University Press.

Lim, A. [Adrian] (2018). New programme launched to help Malay-Muslim drug offenders get back on their feet. The Straits Times. https://www.straitstimes.com/singapore/newprogramme-launched-to-help-malay-muslim-drug-offenders-get-back-on-their-feet

Lim, C. [Corinna] (2019). How to attract and retain local workers in Singapore's long-term care sector: Lessons from a two-year programme. AWARE. https://www.aware.org.sg/2019/07/how-to-attract-and-retain-local-workers-insingapores-long-term-care-sector-lessons-from-a-two-year-programme/

Lim, J. [Jessie] (2020). App for reporting domestic violence on trial. The Straits Times. https://www.straitstimes.com/singapore/app-for-reporting-domestic-violence-on-trial Lim, J. [Janice] (2019a). The Big Read in short: Abuse against women comes in many forms, and can happen to anyone. TODAY. https://www.todayonline.com/big-read/bigread-short-victims-domestic-violence-and-abuse-words-can-hurt-more-actions

Lim, J. [Janice] (2019b). The Big Read: Some men just don't get it - more awareness but abuse of women in S'pore still a problem. Channel NewsAsia. https://www.channelnewsasia.com/news/singapore/abuse-women-psychologicalphysical-singapore-harm-men-gender-11399120

Lim, L. (2021, June 21). Racial preference: Bad for the economy, bad for business. AcademiaSG. https://www.academia.sg/academic-views/racial-preference-bad-for-theeconomy-bad-for-business/

Lincoln, Y. S., \& Guba, E. G. (2013). Part 1: The Presumptions. In The Constructivist Credo. Walnut Creek, UNITED STATES: Taylor \& Francis Group.

Lingle, C. (1996). Singapore's Authoritarian Capitalism, Asian Values, Free Market Illusions and Political Dependency. Mass Market Paperback. 
Lum, S. (2020). Jail and caning for two youths who sexually assaulted and raped intoxicated teenage girl. The Straits Times. https://www.straitstimes.com/singapore/courtscrime/jail-and-caning-for-two-youths-who-sexually-assaulted-and-raped-intoxicated

Manap, B. M. (2010). The Interplay of Structure and Culture in Intergenerational Underdevelopment. Master of Social Science (Sociology). National University of Singapore, Singapore.

Marital Status, Marriages and Divorces - Latest Data (2020). SingStat. https://www.singstat.gov.sg/find-data/search-by-theme/population/marital-statusmarriages-and-divorces/latest-data

McHugh, M. C. (2014). Feminist qualitative research: Toward transformation of science and society (Vol. Oxford Library of Psychology). New York, New York: Oxford University Press.

Mehta, K. (2006). A Critical Review of Singapore's Policies Aimed at Supporting Families Caring for Older Members. Journal of Aging \& Social Policy, 18(3-4), 43-57.

Migrant Wives in Distress. (2020, June 1). AWARE. https://d2t1lspzrjtif2.cloudfront.net/wpcontent/uploads/AWARE-Report-1-June-2020-Migrant-Wives-in-Distress.pdf

Milani, A., Leschied, A., \& Rodger, S. (2018). Beyond cultural sensitivity: Service providers' perspectives on Muslim women experiences of intimate partner violence. Journal of Muslim Mental Health, 12(1), 49-75.

Minorities and special position of Malays. (2020) Singapore Statutes Online. https://sso.agc.gov.sg/Act/CONS1963?Provlds=pr152$\&$ ViewType $=$ Within $\&$ Phrase $=$ Malay $\&$ WiAl $=1$

Ministry of Women's Affairs, New Zealand. (2013). Current thinking on primary prevention of violence against women. Wellington: Ministry of Women's Affairs.

Mission. (n.d.) Syariah Court. https://www.syariahcourt.gov.sg/Syariah/frontend/Default.aspx?pid=M02.03

MUIS (2020). "Family violence is a complex issue". [Status update] Facebook. https://www.facebook.com/MUIS.SG/posts/10157871776921329 
Murray, S., \& Powell, A. (2009). "What's the Problem?": Australian Public Policy Constructions of Domestic and Family Violence. Violence against Women, 15(5), 532552.

Mutalib, H. (2004). Parties and Politics: A Study of Opposition Parties and the PAP in Singapore. Second edition. Singapore: Marshall Cavendish Academic

Myths about family violence. (n.d.) MSF. https://www.msf.gov.sg/policies/Strong-and-StableFamilies/Supporting-Families/Family-Violence/Pages/Myths-about-familyviolence.aspx

Nason-Clark, N. (2004). When terror strikes at home: The interface between religion and domestic violence. Journal for the Scientific Study of Religion, 43(3), 303-310.

Ng, G. H. Y. (2019) If You Talk Like a Coloniser and Eat Like a Coloniser... New Naratif. https://newnaratif.com/research/if-you-talk-like-a-coloniser-and-eat-like-acoloniser/share/nmzvy.gnlro/b3966abaf83991f27f70c909d1f19979/?fbclid=IwAR0B7vY hzP6_Xro18blORjQtXwr0s6kUaR5tSbYXq4cYWxUN2b3dEebVxM4\#_ednref143

99.co (2020). Buying a HDB flat as a single parent in 2020: How to do it. In 99.co https://www.99.co/blog/singapore/purchasing-hdb-singleparent/\#: :text=Divorced\%20or\%20widowed\%20parents,to\%20purchase\%20a\%20HD B\%20flat.

Niu, X., \& Laidler, K. A. J. (2015). Understanding domestic violence against Muslim women in China. Feminist Criminology, 10(1), 92-112.

Ong, R (2018). How HDB punishes divorcees in Singapore. 99.co. https://www.99.co/blog/singapore/divorcees-hdb-singapore/

Ortmann, S. (2011). Singapore: Authoritarian but Newly Competitive. Journal of Democracy, 22(4), 153-164.

Ow, R., \& Saparin, N. H. B. (2014). Malay Muslim worldviews: Some thoughts for social work practice in Singapore. Journal of Religion \& Spirituality in Social Work: Social Thought: Indigenous Spirituality and Social Work Practice, 33(1), 73-94. 
Paterson, S. "(Re)Constructing Women's Resistance to Woman Abuse: Resources, Strategy Choice and Implications of and for Public Policy in Canada." Critical social policy 29.1 (2009): 121-145. Web.

Penawar (2018). Zine \#1. Penawar Support Group. Self-published.

Pence, E. (1993). Education groups for men who batter: the Duluth model. New York: Springer Pub. Co.

Point Research Ltd (2010) An innovative approach to changing social attitudes around family violence in New Zealand: Key ideas, insights and lessons learnt. The Campaign for Action on Family Violence. https://www.msd.govt.nz/documents/about-msd-andour-work/publications-resources/research/campaign-action-violence-research/aninnovative-approach-to-changing-social-attitudes.pdf

Police investigating WP candidate Raeesah Khan over alleged online comments on race, religion. (2020, July 5) Channel NewsAsia. https://bit.ly/2SyWtOq

Program Bijak Belanja. (2018). MSENSE. https://msense.sg/programmes/program-bijakbelanja-pbb/

Public Rental Scheme. (n.d.) HDB. https://www.hdb.gov.sg/cs/infoweb/residential/renting-aflat/renting-from-hdb/public-rental-scheme

Purnell, R. D., Teng, S., \& Warrier, S. (2011). Cultural competency in California's domestic violence field: Ensuring access to DV services for all Californians. Oakland, California: Blue Shield of California Foundation.

Rahim, L.Z. (1998). The Singapore dilemma: the political and educational marginality of the Malay community . Oxford University Press.

Rahim, L.Z. (2012). Governing Muslims in Singapore's secular authoritarian state. Australian Journal of International Affairs, 66(2), 169-185.

Rasool, S. \& Suleman, M. (2016). Muslim women overcoming marital violence: breaking through "structural and cultural prisons" created by religious leaders. Agenda (Durban), 30(3), 39-49. 
Report on CEDAW and The Republic of Singapore. (2017). SG CEDAW Coalition. https://sgcedawcoalition.files.wordpress.com/2017/10/many-voices-one-movementcoalition-report-of-national-ngos-on-singapore.pdf

Reproductive Rights. (2015) Women's Action. AWARE. https://www.womensaction.sg/article/reproductive

Richards, L., \& Morse, J. M. (2007). Readme first for a user's guide to qualitative methods (2nd ed.). Sage Publications.

Ruane, J. M. (2016). Introducing social research methods: Essentials for getting the edge. ProQuest Ebook Central https://ebookcentral-proquest-com.helicon.vuw.ac.nz

Sahgal, G. \& Yuval-Davis, N. (1992) Refusing Holy Orders: Women and Fundamentalism in Britain. London: Virago

Sajan, C. (2020). Crisis shelters a safe haven for battered women, especially during the Covid-19 outbreak. https://www.straitstimes.com/lifestyle/crisis-shelters-a-safe-havenfor-battered-women-especially-during-the-covid-19-outbreak

Salazar, L., \& Cook, S. (2002). Violence against women: Is psychology part of the problem or the solution? A content analysis of psychological research from 1990 through 1999. Journal of Community \& Applied Social Psychology. P. 418

Sayoni (2019). Violence and Discrimination Against LBTQ Persons in Singapore.

Sharp, S. (2014). Resisting religious coercive control. Violence against Women, 20(12), $1407-1427$.

Singapore's Demographic: Heads of Household. (n.d.) MSF.

https://www.msf.gov.sg/research-and-data/Research-and-Statistics/Pages/SingaporeDemographic-Heads-of-Households.aspx

Singapore's response of family violence: 1997-2007 — What comes next? (2008). Society Against Family Violence. Singapore.

Single Parents' Access to Public Housing. Findings from AWARE's Research Project. (2016). AWARE. https://aware.org.sg/wp-content/uploads/Single-Parents-Access-toPublic-Housing.-Final-version..pdf 
Smith, A. (2005). Looking to the Future. From Domestic violence at the intersections of race, class, and gender: Challenges and contributions to understanding violence against marginalized women in diverse communities

Smith, L. T. (1999). Decolonizing Methodologies. London, New York and Dunedin: Zed Books Ltd, London; Room 400, New York, USA; University of Otago Press, Dunedin, New Zealand.

Sokoloff, N. J., \& Dupont, I. (2005). Domestic violence at the intersections of race, class, and gender: Challenges and contributions to understanding violence against marginalized women in diverse communities. Violence against Women, 11(1), 38-64.

Sokoloff, N. J., and Pratt, C. (2005) Domestic Violence at the Margins: Readings on Race, Class, Gender, and Culture. New Brunswick, N.J: Rutgers University Press. Print.

SPF (2020). Enhancing police's response to combat family violence.

ttps://www.police.gov.sg/Media-

Room/News/20200514_OTHERS_Enhancing_Police_Response_To_Combat_Family_ Violence

Star Shelter (2020) What we do. https://www.scwo.org.sg/what-we-do/services/star-shelter/

Stark, E. (2008). Coercive control: The entrapment of women in personal life. Oxford University Press.

Stasiulis, D., \& Yuval-Davis, N. (1995). Unsettling settler societies: articulations of gender, race, ethnicity and class. Sage.

Statista (2020). Rate of home ownership in Singapore from 2009 to 2018.

https://www.statista.com/statistics/664518/home-ownership-ratesingapore/\#: :text=In\%202018\%2C\%20the\%20rate\%20of,owned\%20a\%20HDB\%20r esidential\%20unit.

Straka, S. M., \& Montminy, L. (2008). Family violence: through the lens of power and control. Journal of Emotional Abuse, 8(3), 255-279. 
Straughan, P. T. (2009). Marriage dissolution in Singapore: Revisiting family values and ideology in marriage. ProQuest Ebook Central https://ebookcentral-proquestcom.helicon.vuw.ac.nz

Sumartono, F. (2016). An open letter: Domestic violence should not be condoned or excused. https://www.aware.org.sg/2016/11/domestic-violence-should-not-becondoned-or-excused/

Supporting Housing Needs of Unmarried Parents. (n.d.) HDB. https://www.hdb.gov.sg/cs/infoweb/about-us/news-andpublications/publications/hdbspeaks/helping-singleparent-households

Suratman, S. (2011). Gender Relations in Singapore Malay Dual-Income Households: (Un)Changing Perceptions and Practices. Islam and Civilisational Renewal. ICR Journal, 3(1). https://icrjournal.org/index.php/icr/article/view/58

Suraya, A. (2018, August 2). My Mother was Abused by my Father, but Everyone Around Allowed it to Happen. Beyond the Hijab. https://beyondhijab.sg/2018/08/02/my-motherwas-abused-by-my-father-but-everyone-around-allowed-it-to-happen/

Sweet, E. (2016). Carceral feminism: Linking the state, intersectional bodies, and the dichotomy of place. Dialogues in Human Geography, 6(2), 202-205.

Syariah Lawyer SG (2020). Commonly Asked Questions. https://syariahlawyersg.com/commonly-asked-questions-in-syariah-divorce/

Tabrani, N. B. (2018). Constraints, confrontations, choices: Malay female survivors' agency in intimate partner violence. Thesis (Honours). National University of Singapore.

Tai, J. (2016) Public urged to 'break the silence' on family violence with launch of new campaign. The Straits Times. https://www.straitstimes.com/singapore/public-urged-tobreak-the-silence-on-family-violence-with-launch-of-new-campaign

Tamney, J. B. (1996) The Struggle Over Singapore's Soul: Western Modernization and Asian Culture, Berlin: Walter de Gruyter. 
Tan, E. K. B. [Eugene K.B.] (2008) A union of gender equality and pragmatic patriarchy: International marriages and citizenship laws in Singapore, Citizenship Studies, 12:1, 73-89,

Tan, J. [Jeanette] (2014). PM Lee on tudung issue: Government will continue to evolve position gradually, carefully. https://sg.news.yahoo.com/pm-lee-on-tudung-issue-government-will-continue-to-evolve-position-gradually--carefully-023321430.html

Tan, J. [Jolene] (2020). Explainer: Discrimination in Singapore https://newnaratif.com/research/explainer-discrimination-in-singapore/\#_edn44

Tan, K. [Kenneth P]. (2017) Governing Global-City Singapore: Legacies and Futures after Lee Kuan Yew. Taylor \& Francis Group. ProQuest Ebook Central, http://ebookcentral.proquest.com/lib/vuw/detail.action?doclD=4771784.

Tan, W.M. [Wu Meng]. (2020). Mr Pritam Singh supports Alfian Sa'at - People's Action Party. People's Action Party. https://www.pap.org.sg/news/opinion-news/mr-pritamsingh-supports-alfian-saat/.

Tee, C. (2018). Women's shelter expands services to include mediation. The Straits Times. https://www.straitstimes.com/singapore/womens-shelter-expands-services-to-includemediation

Teo, Y.Y. (2015). Interrogating the Limits of Welfare Reforms in Singapore. Development and Change, 46(1), 95-120.

Teo, Y.Y. (2017). Poor people don't like oats either. New Naratif. https://newnaratif.com/research/poor-people-dont-like-oats-either/

Teoh, T. (2020). Comic book on family violence launched, to be given to all primary school pupils. The Straits Times. https://www.straitstimes.com/singapore/comic-book-onfamily-violence-launched-to-be-given-to-all-primary-school-pupils

Terwiel, A. (2019). What Is Carceral Feminism? Political Theory, 48(4), 009059171988994442.

Tham, Yuen-C (2020). Death penalty is a deterrent: Shanmugam. The Straits Times. https://www.straitstimes.com/politics/death-penalty-is-a-deterrent-shanmugam. 
Thanapal, S. (2020). The neo-colonized entity: Examining the ongoing significance of colonialism on free speech in Singapore. First Amendment Studies, 54(2), 225-235. https://doi.org/10.1080/21689725.2020.1837650

The act of forgiving and pardoning others. (2018). MUIS. https://www.muis.gov.sg/officeofthemufti/Khutbah/English/22-June-2018

Thiara, R., K., \& Gill, A. K. (2009). Understanding violence against South Asian women: What it means for practice. In Violence against women in South Asian communities: Issues for policy and practice: Jessica Kingsley Publishers.

Those with agenda have entered political arena. (1995) The Straits Times, 24 January. Tremewan, Christopher (1994) The Political Economy of Social Control in Singapore, MacMillan Press: London.

Toh, Y. (2017). Malay-Muslim groups urged to tackle challenges. The Straits Times. https://www.straitstimes.com/singapore/malay-muslim-groups-urged-to-tacklechallenges

Tonsing, J. (2016). Domestic Violence: Intersection of Culture, Gender and Context. Journal of Immigrant and Minority Health, 18(2), 442-446.

Tonsing, K. N., \& Tonsing, J. C. (2019). Exploring South Asian Women's Experiences of Domestic Violence and Help-Seeking Within the Sociocultural Context in Hong Kong. Violence against Women, 25(12), 1417-1432.

Trials and patience. (2016). MUIS. https://www.muis.gov.sg/officeofthemufti/Khutbah/English/2016-Sep-16

25 April 2019 Talk: Financial Literacy and Low-Income Women, by AIDHA and Daughters of Tomorrow. (2019) AWARE. https://www.aware.org.sg/2019/04/25-april-2019-talkfinancial-literacy-and-low-income-women-by-aidha-and-daughters-of-tomorrow/ Understanding and Working with the Malay-Muslim Clients. (2017). NCSS. https://eservices.ncss.gov.sg/Training/Course/Detail/dfa87087-9625-e611-8112000c296ee03a 
Understanding our roles and responsibilities. (2017). MUIS.

https://www.muis.gov.sg/officeofthemufti/Khutbah/English/2017-Feb-17

Valencia-Weber, G. and Zuni, C.P. (1995) Domestic Violence and Tribal Protection of Indigenous Women in the United States. St. John's Law Review, 69: 61: 69-170.

Vision \& Mission. (2020). Casa Raudha. https://www.casaraudha.org/about/vision-mission-2/ What are the racial proportions among Singapore citizens? (2019). Gov.sg. https://www.gov.sg/article/what-are-the-racial-proportions-among-singapore-citizens What is violence. (n.d.) PAVE. https://www.pave.org.sg/resources-what-is-violence.php What to do if you are facing family violence? (n.d.) AWARE.

https://www.aware.org.sg/information/dealing-with-family-violence/what-can-i-do-if-iam-facing-family-violence/

What to do if you know someone is experiencing family violence. (2020, Jul 24) Gov.sg. https://www.gov.sg/article/what-to-do-if-you-know-someone-is-experiencing-familyviolence

Why are you not working?: Low-income mothers explain challenges with work and care. (2019). AWARE. https://d2t1lspzrjtif2.cloudfront.net/wp-content/uploads/Advocacyreport-why-are-you-not-working-updated-2-April-2019.pdf

Why seek help? (n.d.) MSF.

https://www.msf.gov.sg/breakthesilence/SitePages/Seek\%20help.aspx?seek=1

Will you support? (2017, July 28). MSFCares [Youtube video].

https://www.youtube.com/watch?v=ZiH5zXPvdPk

Windsor, N. (2009). Substance Abuse and Dependence Among Low Income African Americans: Using Data from the National Survey on Drug Use \& Health to Demystify Assumptions. Journal of Addictive Diseases, 28(3), 258-268.

Wolfe, D., \& Jaffe, P. (1999). Emerging strategies in the prevention of domestic violence. The Future of Children, 9(3), 133.

Women's Charter (2020). (Chapter 353) Singapore Statutes Online. https://sso.agc.gov.sg/Act/WC1961 
Wong, C [Cara] (2020). Inter-agency task force formed to tackle the problem of family violence. The Straits Times. https://www.straitstimes.com/singapore/inter-agencytaskforce-formed-to-tackle-the-problem-of-family-violence

Wong, C. (2019). Faster, better access to legal aid for poor. The Straits Times. from https://www.straitstimes.com/singapore/faster-better-access-to-legal-aid-for-poor

Wong, P. and Toh, E. (2017). War On Diabetes: Changing Eating Habits Of Malay, Indian Communities An Uphill Task. TODAY. https://www.todayonline.com/singapore/war-ondiabetes-changing-eating-habits-of-malay-indian-communities-an-uphill-task

Wong, S [Shiying] (2020). 30\% rise in inquiries to MSF on family conflicts. The Straits Times. https://www.straitstimes.com/singapore/30-rise-in-inquiries-to-msf-on-familyconflicts

Wong, Y. [Yang] (2020). Coronavirus: Rise in domestic abuse cases as families forced to stay home. The Straits Times. https://www.straitstimes.com/singapore/coronavirusrise-in-domestic-abuse-cases-as-families-forced-to-stay-home

Wrage, S. D. (1995). Singapore, a Model of Intimidation. Nieman Reports, 49(4), 43-45. https://www.proquest.com/scholarly-journals/singapore-modelintimidation/docview/1514897336/se-2?accountid=14782

Written Answer by Ministry of National Development on number of appeals received from HDB flat owners for waiver of Ethnic Integration Policy (2021). MND. https://www.mnd.gov.sg/newsroom/parliament-matters/q-as/view/written-answer-byministry-of-national-development-on-number-of-appeals-received-from-hdb-flatowners-for-waiver-of-ethnic-integration-policy

Zhang, J. (2012). From Hong Kong's Capitalist Fundamentals to Singapore's Authoritarian Governance: The Policy Mobility of Neo-liberalising Shenzhen, China. Urban Studies, 49(13), 2853-2871. http://www.jstor.org/stable/26144117

Zubair, A. (2018). Domestic Abuse for People of Faith. Beyond the Hijab. https://beyondhijab.sg/2018/07/20/domestic-abuse-for-people-of-faith/ 


\section{APPENDIX}

\section{Human Ethics Application Approved with Conditions (as a Category B) 0000028464 Vs N/A Automated Email}

researchmaster-help@vuw.ac.nz

to carol.harrington, me -

Kia ora Nabilah Husna,
Tue, May 5, 2020, 12:05 PM 色 $九$ :

Application ID: 0000028464 Vs N/A

Title: Cultural competency in social policy approaches to address domestic violence within Singaporean Muslim households Primary investigator: Nabilah Husna Binte Abdul Rahman

Your project, as described in the application, is approved with conditions as of today. Your approval applies for three years from the date of this email.

If you would like to receive a formal letter, please contact the Research Office. If you need to make changes to your project, you will need to apply for an amendment to this application.

For your approval to be valid, you must meet the conditions outlined in the feedback section of your application. These conditions are:

There is one thing we would like changed: the information sheet has a different name to the project title, and we wonder if this could therefore be misleading. We would like the info sheet title to be changed to 'Social policy approaches to address domestic violence within Singaporean Muslim households'.

You must meet these conditions prior to data collection. If you do not, your approval is invalid.

Best wishes with the research.

Ngā mihi,

the Research Office 


\section{Social policy approaches to address domestic abuse within Singapore's Muslim households \\ INFORMATION SHEET FOR INTERVIEW PARTICIPANTS}

You are invited to take part in this research. Please read this information before deciding whether or not to take part. If you decide to participate, thank you! If you decide not to participate, thank you for considering this request and for your time!

\section{Who am I?}

My name is Nabilah Husna and I am a Masters student in Social Policy at Victoria University of Wellington (Wellington, New Zealand). This research project is working towards my thesis.

From 2013 to 2019, I worked at a Singapore NGO that focuses on women's issues and rights, where I strengthened my knowledge on the safety and health of Muslim women and girls, who face unique challenges in their experiences of domestic abuse. As a Muslim-raised woman, I am invested in this religious and cultural community and in improving the social policy landscape for victims of domestic abuse as a whole.

\section{What is the aim of the project?}

The overarching aim of this research study is to understand social policy interventions aimed at combating domestic abuse, and recommend culturally-sensitive approaches so Muslim victims are better able to seek support or access justice.

Your participation will contribute to valuable efforts in strengthening the instruments currently used to combat domestic abuse within the Muslim cultural and religious context. It will offer social service practitioners like yourself sharper evidence-based approaches to work with this community.

This research has been approved by the Victoria University of Wellington Human Ethics Committee (0000028464).

\section{How can you help?}

You have been invited to participate because of your experience directly working to support victims of domestic abuse in Singapore. Your expertise will help to build robust data on the unique challenges Muslim victims, in particular, face. The population has been selected as a focus for my study because of their unique positioning in Singapore, as individuals operating under Muslim personal law (Syariah). 
If you agree to take part I will interview you remotely (via Zoom) and follow-ups will be done via email. I will ask questions about your knowledge on working with domestic abuse victims, Muslim domestic abuse victims, the support systems available to your clients, and your thoughts and recommendations on the ways to strengthen support for and policies aimed at them.

The interview will take approximately an hour. You will need to have a strong internet connection, and access to a private room for the duration of the interview, to maintain privacy and confidentiality. I will audio record the interview with your permission and write it up later. You can choose to not answer any question or stop the interview at any time, without giving a reason. You can withdraw from the study by contacting me at any time before $\mathbf{1}$ August 2020. If you withdraw, the information you provided will be destroyed or returned to you.

\section{What will happen to the information you give?}

This research is confidential. This means that the researchers named below will be aware of your identity but the research data will be combined and your identity will not be revealed in any reports, presentations, or public documentation.

Organisational consent may be required, depending on the nature of your role. The organisations you work or have worked for will not be revealed. However, you should be aware that in small projects or unique designations/roles your identity might be obvious to others in your community.

You will be asked to provide broad, general descriptions of client experiences to aid in the research findings. You will not be required to provide information or details that will reveal or identify any of your former or current clients. Utmost care will be taken to ensure that details provided will not cause harm to or disrupt the community or its members.

Only my supervisor and I will read the notes or transcript of the interview. The interview transcripts, summaries and any recordings will be kept securely and destroyed on $\mathbf{3 1}$ December 2021.

\section{What will the project produce?}

The information from my research will be used in my Masters thesis, in research articles, and in academic publications and conferences.

\section{If you accept this invitation, what are your rights as a research participant?}

You do not have to accept this invitation if you don't want to. If you do decide to participate, you have the right to:

- $\quad$ choose not to answer any question;

- $\quad$ ask for the recorder to be turned off at any time during the interview;

- $\quad$ withdraw from the study before 1 August 2020;

- $\quad$ ask any questions about the study at any time;

- $\quad$ receive a copy of your interview recording;

- $\quad$ receive a copy of your interview transcript; 
- be able to read any reports of this research by emailing the researcher to request a copy.

If you have any questions or problems, who can you contact?

If you have any questions, either now or in the future, please feel free to contact either:

Student:

Name: Nabilah Husna Binte Abdul Rahman

University email address:

nabilahhusna.binteabdulrahman@vuw.ac.nz

School: School of Social and Cultural Studies

Phone: +64-04-463 7451

\section{Supervisor:}

Name: Dr. Carol Harrington

Role: Senior Lecturer, Sociology and Social Policy

Phone: +64-04-463 7451

\section{Human Ethics Committee information}

If you have any concerns about the ethical conduct of the research you may contact the Victoria University of Wellington HEC Convenor: Associate Professor Judith Loveridge. Email hec@vuw.ac.nz or telephone +64-4-463 6028. 


\section{Social policy approaches to address domestic abuse within Singapore's Muslim households}

\section{CONSENT TO INTERVIEW}

This consent form will be held for five years.

Researcher: Nabilah Husna Binte Abdul Rahman, School of Social and Cultural Studies, Victoria University of Wellington.

- I have read the Information Sheet and the project has been explained to me. My questions have been answered to my satisfaction. I understand that I can ask further questions at any time.

- I agree to take part in an audio-recorded interview.

I understand that:

- I may withdraw from this study at any point before 1 August 2020, and any information that I have provided will be returned to me or destroyed.

- The identifiable information I have provided will be destroyed on 31 December 2021.

- Any information I provide will be kept confidential to the researcher and the supervisor

- I understand that the findings may be used for a Masters thesis, research articles, academic publications or presented to conferences.

- I understand that the recordings will be kept confidential to the researcher and the supervisor.

- My name will not be used in reports and utmost care will be taken not to disclose any information that would identify me.

- I understand that organisational consent might be required and the organisation will not be named in any of the reports. If organisational consent is required, please indicate below.

The relevant organisation has given permission for participation in this Yes $\square$ No $\square$ study. 
- I would like a copy of the recording of my interview

- I would like to receive a copy of the final report and have added my Yes $\square$ No $\square$ email address below.

Signature of participant:

Name of participant:

Date:

Contact details: 


\section{Interview questions}

Tell me about the roles you've had working on domestic abuse + Muslim women's rights/issues

How do you work with other social service organisations?

What definition of domestic abuse do you rely on in your work?

What are the remedies for domestic abuse?

What are the misconceptions of domestic abuse that you come across often?

What are Muslim women's experiences of DV?

How do they resist DV?

What challenges do they encounter?

What are their belief systems, values etc about marriage, family or culture?

What are their experiences with Muslim personal law?

What are their experiences with criminal justice processes?

What are Muslim women's experiences with accessing economic security (e.g. housing, jobs)?

Who do they reach out to for support?

Tell me about the training in your organisations on Malay/Muslim issues?

Any experiences of Muslim women relating to LGBTQ identity?

Any experiences of Muslim women relating to their migrant status you can share?

Any experiences with religious leaders you know of that you can share?

What are their experiences or concerns (if any) of institutional settings (crisis shelters,

experiences with juvenile homes)?

What are the recommendations you have on how policy, practices and education can be improved to support Muslim (or generally) domestic abuse victims? 